\title{
Detecting and quantifying palaeoseasonality in stalagmites using geochemical and modelling approaches
}

Article

Accepted Version

Creative Commons: Attribution-Noncommercial-No Derivative Works 4.0

Baldini, J. U.L., Lechleitner, F. A., Breitenbach, S. F.M., van Hunen, J., Baldini, L. M., Wynn, P. M., Jamieson, R. A., Ridley, H. E., Baker, A. H. ORCID: https://orcid.org/0000-0003-26971350, Walczak, I. W. and Fohlmeister, J. (2021) Detecting and quantifying palaeoseasonality in stalagmites using geochemical and modelling approaches. Quaternary Science Reviews, 254. 106784. ISSN 0277-3791 doi:

https://doi.org/10.1016/j.quascirev.2020.106784 Available at https://centaur.reading.ac.uk/97596/

It is advisable to refer to the publisher's version if you intend to cite from the work. See Guidance on citing.

Published version at: https://www.sciencedirect.com/science/article/pii/S0277379120307460

To link to this article DOI: http://dx.doi.org/10.1016/j.quascirev.2020.106784

Publisher: Elsevier

All outputs in CentAUR are protected by Intellectual Property Rights law, including copyright law. Copyright and IPR is retained by the creators or other copyright holders. Terms and conditions for use of this material are defined in the End User Agreement. 


\section{www.reading.ac.uk/centaur}

\section{CentAUR}

Central Archive at the University of Reading

Reading's research outputs online 
1 Detecting and quantifying palaeoseasonality in stalagmites using geochemical and modelling approaches

3

4

5

6

James U.L. Baldini ${ }^{1}$, Franziska A. Lechleitner ${ }^{2,3,4}$, Sebastian F.M. Breitenbach ${ }^{4}$,

Jeroen van Hunen ${ }^{1}$, Lisa M. Baldini ${ }^{5}$, Peter M. Wynn ${ }^{6}$, Robert A. Jamieson ${ }^{7}$, Harriet E. Ridley ${ }^{1}$,

Alexander J. Baker ${ }^{8}$, Izabela W. Walczak ${ }^{9}$, and Jens Fohlmeister ${ }^{10,11}$

${ }^{1}$ Department of Earth Sciences, Durham University, DH1 3LE, United Kingdom.

${ }^{2}$ Department of Earth Sciences, University of Oxford, South Parks Road, Oxford OX1 3AN, United Kingdom.

${ }^{3}$ Laboratory for the Analysis of Radiocarbon with AMS (LARA), Department of Chemistry and

Biochemistry, and Oeschger Centre for Climate Change Research, University of Bern,

1 Freiestrasse 3, 3012 Bern, Switzerland.

${ }^{4}$ Department of Geography and Environmental Sciences, Northumbria University,

3 Newcastle upon Tyne, NE1 8ST, United Kingdom.

${ }^{5}$ School of Health \& Life Sciences, Teesside University, Middlesbrough, TS1 3BX, United Kingdom

6 'Lancaster Environment Centre, Lancaster University, Lancaster, LA1 4YQ, United Kingdom.

${ }^{7}$ School of Earth and Environment, University of Leeds, Leeds, LS2 9JT, United Kingdom

$8{ }^{8}$ National Centre for Atmospheric Science and Department of Meteorology, University of 9 Reading, RG6 6BB, United Kingdom.

$20{ }^{9}$ Durham Centre for Academic Development, Durham University, Durham, DH1 1TA, United 1 Kingdom.

$22{ }^{10}$ Potsdam Institute for Climate Impact Research, Telegrafenberg, 14473 Potsdam, Germany.

${ }^{11}$ GFZ German Research Centre for Geosciences, Section 'Climate Dynamics and Landscape Development', Telegrafenberg, 14473 Potsdam, Germany. 
Stalagmites are an extraordinarily powerful resource for the reconstruction of climatological palaeoseasonality. Here, we provide a comprehensive review of different types of seasonality preserved by stalagmites and methods for extracting this information. A new drip classification scheme is introduced, which facilitates the identification of stalagmites fed by seasonally responsive drips and which highlights the wide variability in drip types feeding stalagmites. This hydrological variability, combined with seasonality in Earth atmospheric processes, meteoric precipitation, biological processes within the soil, and cave atmosphere composition means that every stalagmite retains a different and distinct (but correct) record of environmental conditions. Replication of a record is extremely useful but should not be expected unless comparing stalagmites affected by the same processes in the same proportion. A short overview of common microanalytical techniques is presented, and suggested best practice discussed. In addition to geochemical methods, a new modelling technique for extracting meteoric precipitation and temperature palaeoseasonality from stalagmite $\delta^{18} \mathrm{O}$ data is discussed and tested with both synthetic and real-world datasets. Finally, world maps of temperature, meteoric precipitation amount, and meteoric precipitation oxygen isotope ratio seasonality are presented and discussed, with an aim of helping to identify regions most sensitive to shifts in seasonality.

\section{Introduction}

Over the past few decades stalagmites have become one of the most important terrestrial archives of climate and environmental change. Their widespread distribution, amenability to 
radiometric dating, and capacity for retaining seasonal to decadal-scale environmental

51 information have made them indispensable archives for a wide variety of climate information, most commonly rainfall or temperature variability. The field has developed rapidly, and it is now clear that stalagmites generally do not record a single climate parameter (e.g., cave temperature, rainfall amount) exclusively, but instead record a combination of processes. It is increasingly acknowledged that every stalagmite contains a robust history of some aspect of environmental change. The issue is one of complexity; generally speaking, the stalagmite with the least complex signal is considered the ideal. Records generated from stalagmites with more complex stratigraphies, whose drip flow route changes through time, or that are influenced by numerous environmental processes, often prove more difficult to interpret. Some stalagmite records may miss short-lived climate excursions because they are fed by drips that do not respond to the transient climate forcing in question. Others might lose sensitivity or respond non-linearly to a climate forcing; for example, a stalagmite might record droughts faithfully, but miss exceptionally wet intervals when the epikarst (the highly fractured transition zone between soil and bedrock) is saturated with water. To exacerbate the issue further, most stalagmite records lack the requisite resolution to detect palaeoseasonality, an aspect of the climate signal that is increasingly recognised as critical to the interpretation of geochemical records from stalagmites (Baldini et al., 2019; Morellón et al., 2009; Moreno et al., 2017). In other words, the desired climate signal is often compromised by: i) inherent complexities associated with the hydrological transfer of the climate signal to the stalagmite, ii) overprinting of the desired climate-driven signal by other environmental variables, and iii) bias introduced via the necessarily selective sampling of the stalagmite for analysis. The challenge for palaeoclimatologists is to extract and correctly interpret the desired climate signal from a stalagmite, bearing these complexities in mind. 
The detection of a seasonality signal within a stalagmite can greatly help interpret all datasets from a stalagmite sample, of any temporal resolution. For example, the detection of a seasonal geochemical cycle can contribute to chronological models (Baldini et al., 2002; Carlson et al., 2018; Ridley et al., 2015b), in some cases permitting the development of highprecision chronologies over extended time intervals (Ban et al., 2018; Carlson et al., 2018; Duan et al., 2015; Nagra et al., 2017; Ridley et al., 2015b; Smith et al., 2009). Unlike most other laminated records (e.g., tree rings, ice cores), high-precision radiometric dates can anchor stalagmite layer count chronologies, reducing accumulated counting errors. Proxy information from laminated stalagmites can be linked to environmental variability at seasonal resolution (Mattey et al., 2010; Orland et al., 2019; Ridley et al., 2015b), allowing much needed insights into past climatic dynamics that are difficult to obtain otherwise.

The fact that stalagmites can reveal palaeoseasonality, a notoriously difficult climate parameter to reconstruct, is critical for identifying wholesale shifts in climate belts. For example, monthly-scale geochemical data from a stalagmite has detected variability in the Intertropical Convergence Zone influence on rainfall seasonality in Central America over the last two millennia (Asmerom et al., 2020) and the shift from a maritime to a more continental climate in western Ireland in the early Holocene (Baldini et al., 2002), transitions which must otherwise be inferred using annual- to centennial-resolution data (e.g., Breitenbach et al., 2019). High spatial resolution approaches yielding palaeoseasonality can distinguish rainfall occurring at different times of the year, for example, monsoonal rainfall versus dry season rainfall (Ban et al., 2018; Ronay et al., 2019), providing a wealth of information not attainable by other means. 
Seasonality is one of climate's most important aspects, and this is reflected in the basic subdivisions of the Köppen system, the most commonly used climate classification scheme (Köppen, 1918; Peel et al., 2007). Reconstructing past seasonality is not only relevant for pure palaeoclimatological studies, but also for palaeobotany and archaeology, and for establishing a benchmark by which to compare recent changes in seasonality during the Anthropocene; recent research suggests seasonality in rainfall (e.g., Feng et al., 2013) and temperature (e.g., Santer et al., 2018) are shifting under modern climate change. This is particularly concerning because changing seasonality has had broad ecological and social implications in the past. For example, human dispersal through Asia was limited more by water availability rather than temperature, and likely followed habitable corridors with favourable rainfall seasonality (Li et crops are linked to rainfall seasonality, because optimal growth conditions depend on Kennett et al., 2012).

Despite the clear importance of reconstructing palaeoseasonality, it is rarely directly observable in climate proxy records. The obfuscation of seasonality by undersampling or nor realistically (given that the karst system transmutes the signal) possible. 
Here we review both the advantages of obtaining palaeoseasonality information and methods

120 for its reconstruction using stalagmite geochemistry and modelling, as well as common issues

121 in extracting this information. A short review of the history of speleothem science and techniques frames the discussion and highlights how speleothems have become the premier archives for annual- to sub-annual scale terrestrial climate reconstructions, particularly during the Quaternary. We also suggest a methodology to maximise the likelihood of successfully the climate at (and in regions near) the site.

\section{Background and technique development}

Very early studies demonstrated the potential of stalagmites to record climate information (Allison, 1923, 1926; Broecker, 1960; Orr, 1952). However, the real growth in the application of stalagmites as climate archives occurred after the convergence of Thermal Ionisation Mass extracting palaeoseasonality information from a stalagmite, including evaluating the hydrological characteristics of the drip feeding a stalagmite sample prior to collection, modelling palaeoseasonality from lower resolution data, and determining the seasonality of

Spectrometry (TIMS) uranium-thorium dating of stalagmites in the 1990s (e.g., Edwards et al., 1987; Edwards and Gallup, 1993) (which allowed accurate dating) and high resolution sampling techniques in the 2000s (permitting the reconstruction of climate on sub-decadal timescales). The subsequent development and proliferation of multi-collector inductively coupled plasma mass spectrometry (MC-ICP-MS) permitted extraordinarily robust (precise and accurate) chronological control (e.g., Cheng et al., 2013; Hellstrom, 2003; Hoffmann et al., 2007), while the development of a variety of microanalytical techniques provided climate proxy information of an unparalleled temporal resolution. The realisation in the late 1990s 
(Roberts et al., 1998) and early 2000s that stalagmite carbonate trace element compositions and isotope ratios often vary seasonally (Baldini et al., 2002; Fairchild et al., 2000; McMillan et al., 2005; Treble et al., 2003; Treble et al., 2005b) opened the door to the investigation of palaeoseasonality on an unprecedented level.

\subsection{Increasing resolution of analysis}

Immense technical progress has facilitated the transition from the first speleothem studies, which broadly placed periods of speleothem growth into the global climatic context (Harmon, 1979; Hendy and Wilson, 1968; Thompson et al., 1975), to increasingly detailed sub-annual resolution hydroclimate reconstructions (Fairchild et al., 2001; Johnson et al., 2006; Liu et al., 2013; Mattey et al., 2008; Maupin et al., 2014; Myers et al., 2015; Ridley et al., 2015b; Ronay et al., 2019; Treble et al., 2005a). Methodological developments, particularly after the mid2000s and particularly with respect to trace element analysis, greatly reduced the required sample size and increased measurement precision. This included the widespread adoption of micromilling techniques (Spötl and Mattey, 2006), laser ablation (Müller et al., 2009; Treble et al., 2003), secondary ionisation mass spectrometry (Baldini et al., 2002; Fairchild et al., 2001; Finch et al., 2001; Orland et al., 2008, 2009), and the development of protocols for stable carbon and oxygen isotope measurements with reduced sample sizes (Breitenbach and Bernasconi, 2011).

Here, we apply the recently compiled Speleothem Isotope Synthesis and Analysis (SISAL) database v1b (Atsawawaranunt et al., 2018; Comas-Bru et al., 2019) to document the evolution of speleothem stable isotope record resolution. SISAL was created with the primary 
objective of providing access to a comprehensive repository of published stalagmite $\delta^{18} \mathrm{O}$ records to the palaeoclimate community and for climate model evaluation (Comas-Bru and Harrison, 2019; Comas-Bru et al., 2019). SISALv1b contains 455 speleothem records (i.e., SISAL 'entities') from 211 globally distributed caves published since 1992 (Comas-Bru et al., 2019). More than half the records (264) included in the database cover at least portions of the last 10,000 years.

To investigate how stable isotope record resolution has evolved over the last three decades, we extracted all records from the database and calculated their temporal resolution as the absolute difference between two consecutive samples. Hiatuses and gaps in the individual records were excluded from the analysis, as these would have erroneously suggested much lower resolution than that actually present. In a second step, we performed the same calculation, considering only Holocene records.

The analysis reveals how the number of speleothem stable isotope records steadily increased with publication year (Figure 1), highlighting the increased popularity of speleothem science over the past three decades. A trend of increasing temporal resolution with time becomes apparent after binning all records published in the same year and calculating their mean resolution (Figure 1). This trend becomes even clearer when only Holocene records are considered, with a particularly striking increase in resolution over recent years (post-2010) (records pre-2010: mean resolution $=50.1$ years, STDEV $=38.9$ years; records between 2010 and 2018: mean resolution $=16.5$ years, STDEV $=7.4$ years), and is likely related to the widespread adoption of microanalytical advances. Additionally, a record's resolution will typically depend on the time period covered by the record; in general, resolution is higher in Holocene records compared to the full dataset, which includes older records as well. This 
partly arises because of greater availability of independent data and information on climate conditions during more recent time intervals, thus requiring higher resolution records to tackle relevant research questions. It may also be partially due to typically lower growth rates during the last glaciation compared to the Holocene. However, overall only nine of the records in SISALv1b have resolution $<0.5$ years, allowing for investigations of paleoseasonality. This highlights the difficulties often encountered with conventional sampling techniques, as this compilation only includes stable isotope records, and does not consider other methods (e.g., laser ablation trace element analysis), which can generate higher resolution time-series. The increasing resolution possible via technological developments has largely involved the analysis of trace elements, whereas stable isotope analysis still predominantly relies on micromilling or drilling techniques.

\subsection{Transition from temperature to rainfall amount to seasonality}

Early speleothem palaeoclimate studies focused on using $\delta^{18} \mathrm{O}$ to generate quantitative cave temperature records (Gascoyne et al., 1980; Hendy and Wilson, 1968; Lauritzen, 1995; Lauritzen and Lundberg, 1999), based on the insight that oxygen isotope fractionation during carbonate deposition is temperature dependent (Epstein et al., 1951; O'Neil et al., 1969), and building on similar work on marine carbonates (Emiliani, 1955). It was quickly recognised however that speleothem $\delta^{18} \mathrm{O}$ is a complex mixed signal reflecting variations in cave temperature, changes in dripwater isotope composition, and various kinetic effects, which severely hamper the use of this proxy for quantitative temperature reconstructions (McDermott, 2004). The subsequent shift in how speleothem $\delta^{18} \mathrm{O}$ is interpreted led to its establishment as a proxy for past hydroclimate changes, including atmospheric circulation, 
regional temperature, moisture source dynamics, and amount of precipitation (Lachniet,

211 2009).

212 At the same time, the toolkit of geochemical proxies available to speleothem researchers continued to expand. In particular, trace element concentrations in speleothem carbonate emerged as tracers for numerous processes, from surface productivity to karst hydrology and transport (Borsato et al., 2007; Fairchild et al., 2001; Huang and Fairchild, 2001; Treble et al., 2005a). The combination of multiple proxies measured on the same speleothem provided a means to disentangle complexities regarding mixed signals in individual proxies and allowed a progressively deeper understanding of the archive and the associated processes in soil, karst, atmosphere, and cave. In tandem with these developments regarding the climate proxy development, monitoring of cave and local atmospheric conditions became increasingly important, as it was recognised that understanding sometimes highly localised controls on geochemical signatures is crucial for their interpretation (Genty, 2008; Mattey et al., 2008; Mattey et al., 2010; Spötl et al., 2005; Verheyden et al., 2008).

The presence of annual petrographic cyclicity within stalagmites was recognised very early on (Allison, 1926). The later identification of visible and luminescent annual banding (Baker et al., 1993; Broecker, 1960; Shopov et al., 1994) underscored that the deposition, mineralogy, and chemical composition of speleothems varied seasonally. However, the concept of seasonal shifts in climate variables (e.g., temperature, precipitation) as contributing to the net multi-annual climate signal did not gain traction until the early to mid-2000s (Wang et al., 2001). Cave monitoring revealed drip rate seasonality in Pere Noel Cave, Belgium (Genty and 
element study at Grotta di Ernesto, Italy (Huang et al., 2001). Meteorological data were

234 compared to seasonal trace element data for an Australian stalagmite (Treble et al., 2003), and the potential to use seasonal-scale geochemical data to reconstruct the East Asian Summer Monsoon (EASM) was investigated using a stalagmite from Heshang Cave, China (Johnson et al., 2006). Studies coupling cave environmental monitoring and 'farmed' carbonate precipitates were critical for clarifying the links between hydrological and cave atmosphere conditions on the chemistry of stalagmites, including at a seasonal scale (Czuppon et al., 2018; Moerman et al., 2014; Sherwin and Baldini, 2011; Tremaine et al., 2011). Drip monitoring was also key for establishing how cave hydrology attenuates seasonal and interannual rainfall variability, and was used to predict ENSO variability preservation within stalagmites (Chen and Li, 2018; Moerman et al., 2014). These studies all illustrate that a thorough understanding of annual geochemical cycles requires the development of extensive cave monitoring records, which highlight the complexities inherent in signal transfer from surface environment to the stalagmite.

\subsection{Importance of monitoring for understanding the seasonal signal}

249 Monitoring environmental conditions in and above a cave at a high temporal resolution greatly improves the accuracy of palaeoclimate interpretations derived from stalagmites.

251 Linking proxy characteristics at a given site with current environmental conditions via monitoring is relevant for reconstructing past conditions. Although modern conditions may differ from ancient conditions, monitoring the cave environment elucidates processes operating at a site, including the timing and extent of ventilation and the general nature of a 
hydrological signal, acknowledging that some hydrological re-routing may have occurred

256 through time for certain drip types.

257 Understanding a stalagmite geochemical proxy record is difficult without first understanding how that signal is transferred and altered from the external environment to the sample. Environmental changes affecting the seasonal signal fall under four main categories: i) Earth atmospheric, ii) Meteoric precipitation, iii) biological (e.g., soil processes), and iv) cave atmospheric.

Earth atmospheric processes affect the seasonality signal retained within stalagmites by influencing meteoric precipitation isotope ratios at the cave site. Possibly the most common atmospheric process is the seasonal variation in precipitation $\delta^{18} \mathrm{O}$ induced by shifts in the temperature-dependent water vapour-meteoric precipitation fractionation factor. Other related changes in atmospheric processing include seasonal shifts in moisture source and pathway of the moisture package to the cave site, as, for example, in monsoonal settings.

Meteoric precipitation: Meteoric precipitation variability regards the nature of the primary rainfall amount-derived seasonality signal. Here we include meteoric precipitation amount and seasonal distribution as separate from 'Earth atmospheric' processes (such as changes in source moisture source), although clearly the latter affect the former. Meteoric precipitation is a fundamental control on stalagmite seasonality that is worth considering independently of other atmospheric processes. Stalagmites deposited in monsoonal climates (e.g., the East Asian Summer Monsoon, Indian Summer Monsoon, South American Monsoon, and Australian Summer Monsoon) with distinct wet and dry seasons are excellent examples of samples whose geochemistry generally (but not always) responds to hydrologic seasonality. In

277 temperate mid-latitude settings with more evenly distributed rainfall, hydrological shifts 
might record less seasonal than inter-annual (e.g., ENSO) dynamics or possess a seasonal bias

279 (see section 3.1) derived from effective infiltration dynamics.

280 Biological (soil-derived) seasonality is the least clearly defined control, and predominantly affects the trace element composition and carbon isotope ratio of cave percolation waters. However, evidence also exists that increased soil bioproductivity can affect oxygen isotope ratios by preferential uptake of water during the growing season during intervals with substantial surface vegetation (Baldini et al., 2005). Trace element transport critically depends on the biological activity and water supply, both factors that are inherently variable and not necessarily in-phase. Hydrology can affect biological seasonality, as leaching of organic matter and trace elements from freshly decomposed litter depends on excess infiltration. Soils may thus produce a wet season pulse of colloidal material (organics as well as weathering products) which contributes to an annual peak in trace element concentrations in some samples; such dynamics are highly site-specific. The evidence for this pulse is derived both from synchrotron-based stalagmite studies (e.g., Borsato et al., 2007) and daily-scale automated dripwater collection schemes (Baldini et al., 2012). Treble et al. (2003) suggest phosphorous enrichment in stalagmite carbonate stemming from seasonal infiltration pulses, and monitoring at Shihua Cave (China) revealed that organic carbon was transported during the wet season (Ban et al., 2018; Tan et al., 2006). Whether this pulse is truly independent from hydrological variability is unclear, but some evidence from dripwater monitoring in temperate Irish caves suggests that the seasonal trace element pulse is not associated with increased autumnal water throughput, but rather with seasonal vegetation die-back (Baldini et al., 2012). In monsoonal north-eastern India biologically-induced litter decomposition reaches a maximum in early summer (Ramakrishnan and Subhash, 1988), which increases 
element availability in the soil that can be leached during the entire wet season (Khiewtam and Ramakrishnan, 1993). The transport of trace elements may also hinge directly on the presence of natural organic matter in dripwater, which may link the dripwater directly to surface bioproductivity (Hartland et al., 2012; Hartland et al., 2011). Thus, biological seasonality is highly site-specific and likely variable through time; this and the complexities outlined above underscore the importance of dripwater monitoring campaigns.

Cave atmospheric variability can also impart a seasonal signal to a stalagmite geochemical record. Seasonal changes in cave air mixing with outside air lead to conditions within the cave that lower cave air carbon dioxide partial pressure $\left(p \mathrm{CO}_{2}\right)$ and potentially even contribute to dripwater evaporation, promoting calcite deposition. Cave atmosphere variability, induced by ventilation (through thermal gradients or changing wind patterns) therefore affects the calcite deposition seasonality, as well as kinetic fractionation amount. Excellent examples of caves whose stalagmites are affected by this variability include New St. Michael's (Gibraltar) (Mattey et al., 2016; Mattey et al., 2010) and numerous caves in Central Texas (Banner et al., 2007; Breecker et al., 2012; Cowan et al., 2013; Wong et al., 2011). These effects are discussed in detail below (Section 3).

\section{Issues inherent to speleothem-based high-resolution climate reconstructions}

Detecting any seasonal component in a stalagmite climate signal includes quantifying growth rate and input signal seasonality. It is worth noting that the input signal is sometimes unexpected, and a thorough site monitoring scheme can help identify the main contributing factors. For example, although many trace elements (and particularly $\mathrm{Mg}$ ) are affected by recharge (often via prior carbonate precipitation (PCP) mechanisms (Fairchild and Treble, 2009)), other factors can also influence (seasonal) stalagmite geochemistry. This is the case 
at ATM Cave, Belize, where various trace elements (including magnesium) increase in concentration at the beginning of the annual rainy season, and are probably linked to dry deposition during the preceding dry season followed by transport to the stalagmite with the onset of the rainy season (Jamieson et al., 2015). In other cases, the advection of atmospheric aerosols directly into the cave can affect the stalagmite trace element signal (Dredge et al., 2013). Seasonal non-deposition caused by either drying of the feeder drip or by seasonally high cave air $\mathrm{pCO}_{2}$ can bias any record where every data point integrates more than a few months of deposition. From this perspective, most stalagmite records integrate palaeoseasonality information to some extent, but, without appropriate monitoring strategies in place, deconvolving the extent to which the shifting seasonal signal dominates the overall record is difficult.

\subsection{Mixing within the aquifer}

The degree of recharge mixing within the aquifer and epikarst is a fundamental control on the preservation of a seasonality signal within stalagmites. A long residence time and/or thorough mixing within the overlying aquifer can greatly attenuate any hydrological seasonal signal, and understanding the hydrology feeding a cave drip is therefore critical (Atkinson, 1977; Ayalon et al., 1998; Baker et al., 1997; Baker and Brunsdon, 2003; Baker et al., 2019; Kaufman et al., 2003). For conservation and logistical reasons, monitoring and classification of the drip should ideally occur prior to sampling a stalagmite.

Smart and Friedrich (1987) undertook one of the earliest efforts to comprehensively categorise cave drips. Their scheme involved measuring drip rates at G.B. Cave, in the Mendip 
Hills, UK, and parameterising them by plotting maximum drip rate versus the coefficient of

347 variation (C.V.; the standard deviation divided by the mean multiplied by 100). Baker et al. 348 (1997) later modified the scheme, dividing drips into six categories (seepage flow, seasonal drip, percolation stream, shaft flow, vadose flow, subcutaneous flow). Other classification schemes (e.g., Arbel et al., 2010; Arbel et al., 2008) focussed on analysing drip hydrographs, and suggested terminology such as 'post-storm', 'seasonal', 'perennial', and 'overflow', which are broadly consistent with the categories introduced by Smart and Friedrich (1987). The introduction of automated drip loggers revolutionised the field (Mattey and Collister, 2008), partly by ensuring that transient hydrological events were not missed. This ensured a substantially more robust characterisation of drips than that possible via manually measuring drip rates only during on-site visits.

Understanding the hydrology feeding a stalagmite is fundamental for determining if a stalagmite retains a seasonal signal. Drip rate is controlled by surface processes (e.g., meteoric precipitation, evaporation, soil moisture capacity, and susceptibility to runoff) and aquifer characteristics including reservoir capacity and bedrock permeability (Markowska et al., 2015; Treble et al., 2013). Bedrock pathways recharging a drip are broadly divisible into matrix (or 'diffuse') and conduit (or 'fracture') flows (Ayalon et al., 1998; Baker et al., 1997; Perrin et al., 2003; Smart and Friedrich, 1987), and recent models suggest that many drips are a combination of the two. Matrix permeability typically refers to either the primary intragranular bedrock permeability or to secondary permeability along fine fractures, and is characterised by a slow response to precipitation events and a large reservoir capacity (Atkinson, 1977; Smart and Friedrich, 1987). Fracture permeability relates to potentially solution-enlarged bedding plane partings and joints and is characterised by a rapid to intermediate response to precipitation events, and a low to moderate storage capacity. 
Conduit permeability refers to often solutionally-enlarged pipe-like openings $>1 \mathrm{~cm}$ in diameter (Atkinson, 1977; Smart and Friedrich, 1987). Such conduit flow is characterised by a rapid response to storm events followed by a rapid return to baseline flow (Baldini et al., 2006), and often carries chemically aggressive waters that do not allow secondary carbonate deposition. Large conduits or bedding planes may intersect a network of more diffuse hydrological pathways, leading to dual-component flow where the fracture is itself fed by some diffuse recharge in addition to the fracture flow. The hydrologic permeability of the fracture flow component compared to the diffuse flow component essentially defines the drip type; $100 \%$ diffuse flow would exhibit no response to storm events, whereas $100 \%$ fracture flow would usually have no drip except for immediately following storm events large enough to activate the pathway (Figure 2). Most drips would fall along the spectrum between these two endmembers; a constant base drip (the diffuse flow component) combined with a variably rapid response to storm events (the fracture flow component).

From a seasonality perspective, pure fracture-flow drips vary considerably seasonally but may experience occasional dripwater undersaturation and/or drying, and consequently the resultant stalagmite could have abundant microhiatuses (hiatuses in growth too brief to leave a clear petrographic expression, or appear in chronological models (Baker et al., 2014; Moseley et al., 2015) also referred to as 'crypto-hiatuses' (Stoll et al., 2015). Drips characterised by $100 \%$ diffuse flow would be stable with little hydrological or biological seasonality. The likelihood for microhiatuses or drying is low for stalagmites fed by diffuse flow, but the seasonal signal is probably muted, unless at a site where the seasonal signal is controlled by a forcing other than hydrological variability (see Section 2.4.). The optimal hydrology for imparting seasonality onto a stalagmite is a drip fed by moderately diffuse flow that is 
responsive to monthly-scale shifts in rainfall, but that does not have a substantial fracture component to transmit event-scale (and possibly undersaturated) water.

\subsection{Non-deposition and seasonal bias in samples}

Although growth hiatuses lasting longer than a few years are often (but not always) apparent within stalagmites as horizons of detrital material followed by competitive growth of carbonate crystals (Broughton, 1983), brief growth hiatuses occurring seasonally are often undetectable (though occasionally they have a petrographic manifestation). Thus, the existence of these microhiatuses is often inferred by applying monitoring data to isolate intervals through the year where environmental conditions suggest temporary nondeposition could exist. Because drip rate is one of the fundamental controls on stalagmite growth (Genty et al., 2001), the use of drip loggers to detect seasonal drying of the stalagmite feeder drip is important for understanding whether a stalagmite record excludes a certain season's climate information.

Additionally, careful examination of sample petrography can reveal important insights into the nature of the climate signal retained by a stalagmite. Petrographic microscopy helps in identifying growth interruptions caused by lack of water, and dissolution features caused by undersaturated dripwater. An excellent example of this approach exists for Holocene stalagmites from northern Spain (Railsback et al., 2011; Railsback et al., 2017); the analysis reveals horizons of dissolution (termed Type ' $E$ ' surfaces), interpreted as reflecting occasional undersaturation of the feeder drip. Other examples of careful petrographic analysis informing seasonality studies are provided from Drotsky's Cave, Botswana, where the alternating wet 
and dry seasons are manifested by alternating calcite and aragonite (respectively) couplets

416 (Railsback et al., 1994) and from Grotta di Carburangeli, Italy, where columnar fabrics were interpreted as reflected pronounced seasonal variability in drip rates (Frisia, 2015).

Cave air carbon dioxide concentrations $\left(p \mathrm{CO}_{2}\right)$ have shown to be inversely linked to stalagmite growth rate (Banner et al., 2007; Sherwin and Baldini, 2011). For example, in a study of three caves across Texas, it was observed that farmed calcite growth rate was inversely correlated with cave air $p \mathrm{CO}_{2}$ (Banner et al., 2007). Negligible calcite growth and even microhiatuses occurred during the warmest summer months, when cave air $p \mathrm{CO}_{2}$ increased due to low cave ventilation rates (Banner et al., 2007). Elevated cave air $p \mathrm{CO}_{2}$ discourages the dripwater's thermodynamic tendency to degas $\mathrm{CO}_{2}$, thereby slowing the carbonate precipitation rate. In most caves where the entrance is located above the rest of the cave, outside air with low $p \mathrm{CO}_{2}$ advects into the cave when the outside air density becomes greater than the cave air density (e.g., Spötl et al., 2005). This is usually driven by temperature gradients; colder, denser air moves down into a cave during winter, lowering the cave air $p \mathrm{CO}_{2}$ and encouraging stalagmite growth (James et al., 2015). However, cave air $p \mathrm{CO}_{2}$ does not act in isolation, but instead the critical growth determining variable is the differential between cave air $p \mathrm{CO}_{2}$ and dissolved $\mathrm{CO}_{2}$ in dripwater (Baldini et al., 2008). Carbonate deposition thus could increase in the high cave air $p \mathrm{CO}_{2}$ season if the dripwater had equilibrated with an atmosphere with even greater seasonal dissolved $\mathrm{CO}_{2}$ increases (e.g., stemming from seasonal soil bioproductivity increases) which exceed those of the cave atmosphere. These types of drips are generally quite responsive to rain events, so determining if a seasonal growth bias exists should incorporate both hydrology and cave atmospheric chemistry. Drips with stable drip rates, that are not responsive to storm events may have more constant dissolved $\mathrm{CO}_{2}$ and therefore 
seasonal deposition rates that are affected exclusively by cave air $p \mathrm{CO}_{2}$ dynamics. However, several recent publications suggest that dripwater equilibrates not only with soil air, but also with a reservoir of carbon dioxide within the unsaturated zone of aquifers (termed 'ground air') that may have very high $p \mathrm{CO}_{2}$ values ( 2 to $7 \%$ ), much higher than typical soils (0.1 to $\left.2 \%\right)$ (Baldini et al., 2018; Bergel et al., 2017; Markowska et al., 2019; Mattey et al., 2016; Noronha et al., 2015). Thus, it is possible that drip dissolved $\mathrm{CO}_{2}$ is often near-constant, having equilibrated with a ground air reservoir of near-constant $p \mathrm{CO}_{2}$, and that carbonate precipitation is anticorrelated with cave air $\mathrm{pCO}_{2}$ regardless of drip type, although this requires further research. The complexities of cave atmospheres are now reasonably well understood, but more long datasets describing the dissolved $\mathrm{CO}_{2}$ of cave drips are essential for determining the variability of cave percolation waters.

449 Although a temperate-zone (Peel et al., 2007) cave's tendency to ventilate during the winter is generally predicable from seasonality in external temperature (James et al., 2015), occasionally cave geometry provides a more dominant control. In New St. Michael's Cave in Gibraltar, ventilation is driven by seasonal changes in wind speed and direction (Mattey et al., 2016; Mattey et al., 2009). The cave experiences the lowest cave air $p \mathrm{CO}_{2}$ values in summer, and consequently growth (assuming constant drip rate) is biased towards summer (Baker et al., 2014). The cave's position high within the Rock of Gibraltar contributes to strong winds and unusual seasonal ventilation, illustrating how cave position or geometry can dominate seasonal ventilation patterns. Other examples include Bunker Cave in Germany, where an essentially horizontal plan with little altitude difference between entrances produces very little seasonal variability in $\mathrm{pCO}_{2}$ (e.g., Riechelmann et al., 2011; Riechelmann et al., 2019), 
and Císařská Cave (Czech Republic) where a U-shaped cave produces nonlinearities between air temperature, density, and ventilation (Faimon and Lang, 2013).

Because seasonal microhiatuses can lack either a petrological or a geochemical manifestation, cave monitoring is critical for assessing the likelihood of seasonal non-deposition (Shen et al., 2013). Stalagmite growth rate modelling, informed by cave monitoring data, can provide invaluable information regarding how seasonal growth variability affects geochemical climate proxy records integrating more than one year's worth of growth. For example, seasonal nondeposition during summer due to either high evapotranspiration-induced drip cessation or elevated cave air $p \mathrm{CO}_{2}$ might bias lower resolution records towards wintertime rainfall values (generally towards lower $\delta^{18}$ O values) (e.g., James et al., 2015) at sites where drip water is not well mixed. Stoll et al. (2012) used an inverse model to illustrate that rainfall seasonality shifts relative to the cave air $p \mathrm{CO}_{2}$ can greatly affect $\mathrm{PCP}$ and consequently stalagmite trace element concentrations. Baldini et al. (2008) used theoretical stalagmite growth rate equations and theory developed previously (Buhmann and Dreybrodt, 1985; Dreybrodt, 1980, 1988, 1999), coupled with monitoring information, to model stalagmite $\delta^{18} \mathrm{O}$ for various drips within Crag

475 Cave, Ireland. The results suggest that the amount of time integrated by the analyses, the nature of the drip, and the ventilation dynamics of the cave, all strongly modulate carbonate $477 \quad \delta^{18} \mathrm{O}$ signals.

These studies all highlight how characterising the surface and depositional environment is critical for interpreting the climate signal. Either seasonal microhiatuses or reduced growth may bias annual- (or coarser-) scale geochemical records towards particular seasons. Additionally, it is also important to consider how regional climate shifts may have affected a sample in the past, because modern processes may not have applied throughout the record. 
483 Understanding climate signal emplacement processes within stalagmite carbonate is 484 therefore fundamental for building robust climate records.

\subsection{A drip classification scheme to quantify seasonal responsiveness}

Existing drip classification schemes are not designed to characterise the likelihood that a sampled stalagmite retains a hydrologically induced seasonal signal. However, such knowledge is crucial if research goals include a component of seasonal climate reconstruction. Here, we introduce a new drip categorisation scheme that not only permits the identification of stalagmites most likely to retain a hydrology-modulated seasonal climate signal, but that also helps predict the general nature of the climate signal within any sample. This is important for both the accurate interpretation of stalagmite palaeoclimate records, but also for cave conservation (i.e., to maximise the usefulness of collected samples for the purpose of the research goals) and for the appropriate usage of research-related resources. A seasonalresolution stable isotope record of any length requires considerable resources, and we hope that this new drip classification scheme will help direct these resources to appropriate stalagmite samples.

The scheme's essence is the collection of (ideally) at least one year of hourly drip rate data for a drip feeding a stalagmite of interest. For every month, the minimum and maximum hourly drip rate values are extracted. When plotted, these data reveal the extent to which the drip is affected by seasonal activation of fracture permeability, and what proportion of the drip consists of diffuse 'baseflow' (and whether this varies through the year). Drip categorisation then involves evaluating the distribution of the datapoints, and is described with terminology broadly consistent with the Smart and Friedrich (1987) scheme. Because the 
classification scheme uses multiple data points per site, a very large number of possible combinations of descriptors are possible. For example, some drip sites (e.g., drip site YOK-LD within Yok Balum Cave, Belize; (Ridley et al., 2015a) are fed by a slow diffuse flow most of the year, where the minimum and maximum monthly drip rates are almost identical (Figure 3). However, during wetter months an overflow route is activated, and the maximum drip rate increases substantially, whereas the minimum remains the same; this would be characterised as a diffuse drip with a seasonally active overflow component. If this overflow component is saturated with respect to calcite or aragonite, some seasonal signal may be preserved, but if the overflow water is undersaturated a stalagmite fed by this drip type has less potential for seasonal climate reconstructions. Similarly, drip YOK-SK is characterised by almost entirely invariant diffuse recharge and would not record seasonal changes in recharge (Figure 3). At another cave site (Leamington Cave, Bermuda, (Walczak, 2016), drip BER-drip \#5 is fed by diffuse recharge during drier intervals of the year, but during wetter months more water is routed to the diffuse flow, increasing the base flow. Consequently, the drip does experience some seasonality without risk of undersaturation, and thus a stalagmite fed by it should retain hydrology-induced seasonality.

In this new drip classification plot, the drips that are expected to produce stalagmites that retain the clearest seasonal signal are those that plot with a slope approaching unity. In other words, those that are not fed by either an extremely diffuse drip or an extremely flashy drip, and that consequently respond to seasonal rainfall shifts without transient extreme rapid drip rate episodes caused by individual storm events (which may lead to dripwater undersaturation and signal loss). Consequently, the two drip sites plotted in Figure 3 that best display this type of behaviour (drips YOK-G and BER-drip \#5) have both yielded stalagmites retaining exceptional seasonal signals, stalagmites YOK-G (Ridley et al., 2015b) and BER-SWI- 
530

531

532

533

534

535

536

13 (Walczak, 2016). Other drip sites that have a slope approaching unity and have a pronounced difference between the highest and the lowest set of drip rates (Figure 3B) should also produce stalagmites with well-developed records of seasonality.

Importantly, this drip classification scheme equally helps to identify drips that are unlikely to produce good seasonality records. For example, stalagmites fed by drips that are invariant throughout the year would not record hydrologically-induced seasonality (although a seasonal signal might still be preserved based on non-hydrological factors - see Section 2.4). Stalagmites fed by drips that have one or more monthly values plotting at the origin (i.e., no drips for an entire month, Figure 3D) would contain seasonal microhiatuses and would consequently not record that interval's climate information. Drips where the diffuse flow component (i.e., the monthly minimum flow) remains constant but the fracture flow component (i.e., the monthly maximum flow) changes considerably (Figure 3C) may experience undersaturation and either non-deposition or even corrosion of the stalagmite.

This classification scheme comes with some caveats. First, as discussed in Section 2.4., it is possible that the seasonality signal is imparted onto the stalagmite independent of hydrology. If seasonal cave ventilation controls the seasonality signal, the application of the scheme would differ. For example, at a site with strong seasonal ventilation, a stalagmite deposited by a purely diffuse flow-fed drip would reflect a largely cave atmospheric seasonality signal (i.e., with no hydrological seasonality). This would reduce the complexity of the geochemical signal and obviate the need to deconvolve hydrological- and cave atmosphere-induced seasonality from any geochemical record produced. Second, some drips are so-called 'underflow' drip sites, which respond to recharge linearly up until a maximum drip rate and then become unresponsive to further drip rate increases. This is often caused by a constriction 
in the flow pathway leading to the water egress point into the cave. Despite the lack of

554 variability at high flow, the dripwater is still in dynamic equilibrium with recharge (unlike high residence time diffuse flow fed sites) and the stalagmite may reflect the dripwater isotopic variability. Similarly, some drips are affected by piston flow, whereby an increase in hydrologic head might push through a slug of older water, leading to an instantaneous response to recharge but of water with a signature more in keeping with 'old' water; careful monitoring can identify and mitigate these issues (see Section 3.4). Despite these caveats, this drip evaluation scheme will hopefully provide an efficient means for identifying actively growing stalagmite samples most likely to record a seasonal climate signal prior to collection of that sample.

\subsection{Dripwater oxygen isotope seasonality}

The extent that cave dripwater $\delta^{18} \mathrm{O}\left(\delta^{18} \mathrm{O} \mathrm{dw}\right)$ values reflect the $\delta^{18} \mathrm{O}$ of meteoric precipitation $\left(\delta^{18} \mathrm{O}_{\mathrm{p}}\right)$ is critical to climate studies and for understanding the palaeoseasonality signal in particular. Many publications have investigated the relationship between $\delta^{18} \mathrm{O}_{\mathrm{p}}$ and $\delta^{18} \mathrm{O}_{\mathrm{dw}}$ (Ayalon et al., 1998; Baker et al., 2019; Baldini et al., 2015; Bar-Matthews et al., 1996; Cruz Jr. et al., 2005; Duan et al., 2016; Feng et al., 2014; Harmon, 1979; Luo et al., 2014; Markowska et al., 2016; Mischel et al., 2015; Moquet et al., 2016; Moreno et al., 2014; Oster et al., 2012; et al., 2016; Tremaine et al., 2011; Verheyden et al., 2008; Wu et al., 2014; Yonge et al., 1985; Zeng et al., 2015). Depending on the drip site's hydrological characteristics (Arbel et al., 2010;

574 Baker and Brunsdon, 2003; Smart and Friedrich, 1987), $\delta^{18} \mathrm{O}_{\mathrm{dw}}$ values may reflect $\delta^{18} \mathrm{O}_{\mathrm{p}}$ on timescales ranging from the annual weighted mean (Baker et al., 2019; Cabellero et al., 1996; 
577 al., 1985; Frappier et al., 2007; Harmon, 1979).

578 Factors such as depth below surface, residence time and mixing of the water within the 579 unsaturated zone, soil depth and texture, and aquifer hydraulics can vary between drip sites. Important reservoirs for storage and mixing of effective rainfall are documented as the soil and epikarst zones (Cabellero et al., 1996; Chapman et al., 1992; Gazis and Feng, 2004; Perrin et al., 2003; Yonge et al., 1985). Rainwater infiltrating into the soil reservoir is variably lost to evapotranspiration but in karst regions preferential recharge through dolines and grikes may occasionally circumvent the soil and related evapotranspiration (e.g., Hess and White, 1989). Secondary evaporation from infiltrating water can be detected using dripwater $\delta^{18} \mathrm{O}$ and $\delta \mathrm{D}$ values potted relative to the local meteoric water line (Ayalon et al., 1998; Breitenbach et al., 2015). Bar-Matthews et al. (1996) observed a $1.5 \% \circ \delta^{18} \mathrm{O}_{\mathrm{dw}}$ enrichment relative to rainwater and attributed this primarily to seasonal evaporation in the soil and epikarst zones above their Israeli cave site. Evaporative enrichment of infiltrating rainwater is greater in arid and semiarid regions than in temperate regions where conditions of water excess occur through much of the year (Markowska et al., 2016; McDermott, 2004). Any excess, nonevapotranspired water is then transmitted to the epikarst, karst, and finally the cave. Dripwater residence times in the aquifer or epikarst are highly variable, ranging from minutes to years, depending on soil thickness, hydraulic properties (Gazis and Feng, 2004), and drip pathway (e.g., diffuse vs. conduit flow) (Baldini et al., 2006). Mixing of infiltrating rainwater with existing epikarst water can buffer the climate signal and reduce seasonal $\delta^{18} \mathrm{O}_{\mathrm{dw}}$ variability from muted to invariant (within analytical error, and assuming no cave atmosphere-induced seasonality) (Baker et al., 2019; Breitenbach et al., 2019; Onac et al., 
2008; Schwarz et al., 2009). At some cave sites, $\delta^{18} \mathrm{O}_{\mathrm{dw}}$ does not necessarily correlate with $600 \delta^{18} \mathrm{O}_{\mathrm{p}}$ shifts, most likely due to mixing within the aquifer (Moquet et al., 2016), underscoring that different hydrologies produce stalagmites retaining different environmental signals.

A recent global compilation of available dripwater monitoring data has further clarified the relationship between climate (e.g., mean annual temperature and annual precipitation) and $\delta^{18} \mathrm{O}_{\mathrm{dw}}$ (Baker et al., 2019). In cooler regions where mean annual temperature (MAT) $<10^{\circ} \mathrm{C}$, $\delta^{18} \mathrm{O}_{\mathrm{dw}}$ most closely reflects the amount-weighted $\delta^{18} \mathrm{O}_{p}$ (i.e., evaporation from the soil and epikarst does not exert much influence). In seasonal climates with MAT between $10^{\circ} \mathrm{C}$ and $16^{\circ} \mathrm{C}, \delta^{18} \mathrm{O}_{\mathrm{dw}}$ values generally reflect the recharge-weighted $\delta^{18} \mathrm{O}_{\mathrm{p}}$ (see Fig. 1 of (Baker et al., 2019). In regions where MAT $>16^{\circ} \mathrm{C}, \delta^{18} \mathrm{O}_{\mathrm{dw}}$ is generally higher relative to amount-weighted precipitation $\delta^{18} \mathrm{O}_{p}$ because fractionation processes related to evaporative effects on stored karst water are more substantial (Baker et al., 2019). Stalagmite $\delta^{18} \mathrm{O}$ records from regions experiencing high temperatures and/or aridity will probably not reflect rainfall $\delta^{18} \mathrm{O}$ (Baker et al., 2019).

\subsection{The uniqueness of each stalagmite record}

Recent publications have made a case for the importance of replication in stalagmite geochemical records (Wong and Breecker, 2015; Zeng et al., 2015), which is a worthwhile and useful goal. Producing the same geochemical record from multiple samples ensures that no analytical issues exist and can facilitate correlating records whose growth intervals overlap in regions and for time periods with high signal-to-noise ratios. Particularly in cases where evidence for a short-lived climate anomaly exists, replication from within the same sample 
and from other stalagmites is critical. However, stalagmite geochemistry is affected by a myriad of variables, and the precise combination of factors affecting any one sample are essentially unique. Thus, every stalagmite retains a different component of the environmental signal, and a lack of reproducibility does not necessarily indicate that a record is 'incorrect' or flawed. Even stalagmites that are affected by strong kinetic effects retain accurate environmental data; it is a matter of recognising this control, and basing any interpretations accordingly.

Unless two stalagmites are fed by a very similar drip type (often two samples growing near each other whose feeder drips share the same hydrological pathway), stalagmite records from the same cave may not match. This is a clear consequence of the diversity of possible drip pathways feeding individual stalagmites. For example, a stalagmite growing underneath a diffuse drip fed by an extremely low hydrologic permeability pathway that is unresponsive to large rain events would not contain the same record as a stalagmite growing underneath a drip with no diffuse component but that is instead fed by fracture flow. The former (diffuse flow-fed) stalagmite may retain long-term climate information but lack seasonal-scale information, whereas the latter (fracture flow-fed) stalagmite may retain some seasonal environmental information, but may also experience occasional undersaturation following large rain events, leading to microhiatuses and information loss. The fracture flow-fed stalagmite may have a more rapid overall growth rate, but may experience flow re-routing and stochastic drip variability due to solutional enlargement of the fracture pathway, potentially leading to a shorter overall growth interval due to the eventual diversion of water away from the stalagmite. Once cave- and site-specific ventilation factors are considered as well, it is apparent that no two stalagmites can yield precisely the same record; rather it is 
imperative to understand the environmental conditions recorded by each individual sample.

645 If the goal is to reconstruct seasonality, it is important to understand the nature of the seasonality signal for each potential sample, e.g., whether the sample is affected by hydrological seasonality or cave atmospheric seasonality. In the latter case, it is then favourable to select a stalagmite from a diffuse flow drip in order to simplify the extraction of the seasonal ventilation signal.

The considerable range of stalagmite records possible, even from the same site, is potentially advantageous. The individuality of stalagmite records may yield a powerful tool for the quantitative reconstruction of historically elusive environmental variables. For example, differences in oxygen isotope ratios between two samples from the same site could reflect in-cave temperature-induced kinetic fractionation effects, and modelling (Deininger and Scholz, 2019; Deininger et al., 2016; Dreybrodt, 1988; Dreybrodt and Deininger, 2014; Riechelmann et al., 2013) could theoretically yield the cave temperature, potentially even at a seasonal resolution. This perspective is consistent with the recent appreciation that speleothems deposited at isotopic equilibrium are extremely rare (Daëron et al., 2019; Mickler et al., 2006) and that kinetic effects are an integral part of the environmental signal retained by stalagmites (Millo et al., 2017; Sade and Halevy, 2017). The concept that kinetic effects are undesirable is a vestige of early studies attempting to extract absolute palaeotemperatures from stalagmite oxygen isotope ratios, in which case kinetic effects do indeed interfere with the extraction of the desired signal. However, because stalagmite $\delta^{18} \mathrm{O}$ values are no longer considered pure in-cave temperature proxies, kinetic effects no longer present a serious issue, provided that they are considered within any interpretations. In fact, 
tend to occur during drier periods accentuating the already elevated stalagmite $\delta^{18} \mathrm{O}$ and $\delta^{13} \mathrm{C}$ signature) they tend to help the climate signal stand out above background noise.

Stalagmite climate reconstructions are usually based around one record or an overlapping series of records; future research could use the differences between two records (considering in-cave kinetic effects) to reconstruct aspects of the environmental signal, including seasonal temperature shifts. Recent research utilising several stalagmites from along the same moisture trajectory across a wide region to reconstruct oxygen isotope systematics and temperature represent an exciting development in speleothem climate sciences (Deininger et al., 2017; Hu et al., 2008; McDermott et al., 2011; Wang et al., 2017), and similar methodologies could reveal in-cave fractionation processes that are ultimately relatable to temperature, potentially on a seasonal-scale. For example, changes in outside temperatureinduced ventilation may affect samples fed by different hydrologies differently (promoting more kinetic fractionation in the slower dripping sample), and comparing the isotope ratio records may reveal the range of external seasonal temperature variability. We suggest that the comparison of multiple coeval stalagmite geochemical records from within the same cave site is a crucial research frontier that is well worth investigating further.

\section{Analysis techniques}

Detection of seasonal variations in stalagmite geochemical parameters requires sampling or analysis at sufficiently high spatial resolution to mitigate signal averaging (Figure 4). Sampling frequency should approach monthly resolution to detect a seasonality signal and to avoid aliasing issues during intervals with slower growth. This necessitates careful consideration 
prior to analysis to ensure both sufficient resolution to detect seasonal-scale variability, and sufficient material for the analysis method. In addition to the pre-analysis considerations, we also recommend publishing complete micro-analytical data tables, in order to increase transparency. Below we discuss common microanalytical techniques capable of palaeoseasonality reconstruction and compare advantages and disadvantages of each.

\subsection{Sampling for palaeoseasonality}

Sub-sampling stalagmites for geochemical analysis requires careful planning and execution. We recommend a thorough reconnaissance of a sample's petrography using microscopy prior to geochemical analysis. The conversion of a sample into polished thin sections can provide critical information but is destructive. Reflected light microscopy provides and nondestructive alternative that can yield crucial information regarding crystal growth habit, the location of possible hiatuses, inclusions, and porosity.

The various methods available for the extraction of proxy data all require different sample amounts depending on analytical limits of detection and other factors (Fairchild et al., 2006). Methods are broadly categorizable as destructive and non-destructive, depending on the amount of material required. The former is further divisible into: i) macro-destructive (e.g., cuttings for fluid inclusion studies, low-concentration proxies like biomarkers or DNA) (e.g., Blyth et al., 2011; Vonhof et al., 2006; Wang et al., 2019a), ii) meso-destructive (e.g., conventional and micro-milling for U-series samples, stable isotopes, ICP-OES, ${ }^{14} \mathrm{C}$ ) (e.g., Lechleitner et al., 2016a; Ridley et al., 2015b; Spötl and Mattey, 2006), and iii) microdestructive (e.g., laser ablation or secondary ionization mass spectrometer (SIMS) analyses for traditional and non-traditional isotope systems, element concentrations or ratios) (Baldini 
713 Non-destructive methods include (but are not restricted to): i) simple desktop scanning and photography, ii) $\mu$ XRF line scanning and mapping (e.g., Breitenbach et al., 2019; Scroxton et al., 2018), iii) synchrotron analyses (e.g., Frisia et al., 2005; Vanghi et al., 2019; Wang et al., 2019b; Wynn et al., 2014), iv) phosphor mapping via beta-scanning (e.g., Cole et al., 2003), v) reflected light, and fluorescence, including confocal laser fluorescent microscopy (CLFM) (e.g., Orland et al., 2012) and other microscopy techniques (e.g. SEM, EMPA, RAMAN), or vi) X-ray Computed Tomography (CT) scanning (e.g., Walczak et al., 2015; Wortham et al., 2019). The choice of technique should consider suitability for answering the targeted research questions, and logistical considerations such as sample sectioning. Although the list above categorises techniques based on their destructiveness, it does not account for sample preparation; for example, SIMS analysis uses only a small amount of sample (i.e., essentially non-destructive), but requires sectioning of the stalagmite into centimetre-scale cubes, polishing and epoxymounting. Another major consideration is the length of the record required; it is possible (though labour-intensive) to produce seasonal-scale records extending hundreds or even thousands of years using micromilling, but this is not practical using SIMS, unless automated protocols allowing for unattended analysis can be developed (Orland et al., 2019).

Although macro-destructive sampling can inform interpretations based on higher resolution data, it cannot generally reconstruct seasonality on its own. Thus, here we discuss only selected meso-, micro-, and non-destructive techniques. The focus is first on 'conventional drilling' and 'micromilling' of powder samples, which probably are the most widely used techniques to obtain material for inorganic chemistry, followed by the highly versatile, fast, and cost-effective laser ablation sampling (LA-ICP-MS). SIMS requires substantial sample preparation, offers excellent resolution and is a good choice in situations requiring in-depth 
737 over the past decade, and it is now possible to obtain high-resolution (0.5-5 $\mu \mathrm{m})$ quantitative

738 trace element data non-destructively through fast scanning of large samples (Borsato et al., 739 2019). Below we describe the relevance and applicability of these techniques towards the reconstruction of palaeoseasonality.

\subsubsection{Conventional drilling}

Conventional drilling (or 'spot-sampling') (Fairchild et al., 2006) is the drilling of powders from discrete spots, that are normally separated by unsampled material, and is still amongst the most widely used methods to obtain carbonate powders from speleothems. This method is comparably fast and, with a sufficiently small drill bit (typical $\varnothing$ ca. 0.2-1 $\mathrm{mm}$ ), can achieve a spatial resolution of up to $0.3-0.5 \mathrm{~mm}$ along the growth axis, although more frequently the resolution is $\sim 1 \mathrm{~mm}$. Conventional drilling is ideally performed with instruments that allow computer-aided control of $x-y-z$ dimensions, such as Sherline ${ }^{\circledR}$ or Mercantek ${ }^{\circledR}$ instruments.

With typical stalagmite growth rates of 0.1 to $0.2 \mathrm{~mm}$ year ${ }^{-1}$, this technique is usually inadequate when targeting sub-annual resolution (Figure 5). If used on samples with growth rates approaching twice the sampling interval, aliasing may occur and unfavourably affect the recovery of high-frequency variability (Fairchild et al., 2006). Furthermore, this type of spot sampling usually does not integrate all the carbonate material, i.e. the time slices at the top and bottom of the hole are under-represented in the average for the drill-hole; this undersampling could miss short-lived climate excursions. Consequently, we cannot recommend conventional drilling for recovering a seasonal signal, although the technique is effective at quickly producing a lower-resolution record and is well suited for longer records 
of climate (e.g., those covering multiple glacial cycles), and for screening potential target stalagmites. Additionally, conventional drilling is possible on a large stalagmite slab, obviating the need for sectioning into multiple smaller slabs. A related technique which is preferred for sampling at seasonal scale is micromilling, discussed below.

\subsubsection{Micromilling}

Micromilling refers to continuous sample cutting along a trench parallel to a stalagmite's growth axis (Fairchild et al., 2006; Spötl and Mattey, 2006). Usually performed with computercontrolled milling devices (such as the ESI/New Wave micromill) this technique can achieve 20-micron spatial resolution (e.g., Myers et al., 2015), but is critically dependent on the textural characteristics of the sample. Dense columnar, fascicular, radiaxial, or radial fibrous calcites are the most suitable material, but needle-like aragonite can also be sampled, although gaps between needle-shaped crystals may lead to loss of sample and require painstaking cleaning procedures. The sample morphology throughout the stalagmite also warrants consideration. Planar, parallel, and laterally continuous laminae across the sample are ideal, but often stalagmite laminae appear curved in a slabbed sample. These are normally convex, but in some cases are concave (particularly in the case of a 'splash' cup), and with laminae that thin towards the edges. The greater such curvature, the narrower the micromilling trough required for sub-annual (seasonal-scale) sampling (Figure 5), because a wider trench would integrate material from other laminae. Similarly, the sample should allow taper out in the third dimension. X-ray and Neutron CT scans can help visualise the 3D internal 
structure of the sample (Walczak et al., 2015; Wortham et al., 2019), and the appropriate

782 milling depth.

783 The determination of the $x, y$, and $z$ dimensions of the sampling increment is the first step of 784 any sampling strategy (Figure 5). For seasonal resolution, this strategy will ideally permit a very small $y$-axis increment (the $y$-axis is parallel to the stalagmite growth axis). The other dimensions must then allow the collection of enough carbonate for analysis (typically 50-120 $\mu \mathrm{g}$ for carbon and oxygen stable isotopes). Depending on sample characteristics and desired resolution, dimensions of $y=10-100 \mu \mathrm{m}$ and $\mathrm{x}=10-300 * \mathrm{y} \mu \mathrm{m}$ (parallel to visible growth layers on the slab) are ideal (Figure 5). The sampling depth (z-axis) is best minimised because lamina behaviour into the sample is often unknown, unless CT scans of the sample exist. Larger sample masses are occasionally needed for non-traditional proxies.

A common issue in the speleothem sciences is the precise correlation between two datasets obtained via different means, for example a micromilled stable isotope dataset and a LAICPMS derived trace element dataset. Annual- to decadal-scale correlations are usually possible, but rarely are the records correlative on the seasonal- or even annual-scale. Comparisons are achievable using very careful measurements from a datum (often the stalagmite top), with or without the use of banding as 'landmarks' (e.g., (Johnson et al., 2006; Treble et al., 2005a)). A recent technological advance is the development of software, such the open-source GIS-based QGIS software (Linzmeier et al., 2018), which integrates microimaging and analysis into a single spatial reference frame. This approach is particularly useful for organising different analyses derived from differently sectioned portions of samples and has been successfully applied to stalagmite data (Orland et al., 2019). 
The problem of correlating different types of data is to some extent avoidable by sampling sufficient material with the micromill for both stable isotope and trace elemental analysis via ICP-MS. The sampled powder is divided into two aliquots, one for each analytical technique. The resultant trace element and stable isotope data permit zero-lag cross-correlations and highly robust interpretations of different environmental processes (e.g., Jamieson et al., 2016).

For example, if planned multi-proxy analyses require $0.8 \mathrm{mg}$ of carbonate powder (e.g., stable isotope ratios, ${ }^{14} \mathrm{C}$, and trace elements), and a $50 \mu \mathrm{m}$ spatial resolution is desired using a milling bit diameter of $0.8 \mathrm{~mm}$, a $0.05 \mathrm{~mm} \times 4.15 \mathrm{~mm} \times 1 \mathrm{~mm}$ trench would suffice (assuming calcite density of $2.7 \mathrm{~g} / \mathrm{cm}^{3}$ and no sample loss via incomplete recovery); sample loss and a particularly low-density sample would require a larger volume. An often-overlooked additional consideration involves the corners that are initially unsampled when milling trenches (red corner areas, Figure 5). Depending on the drill bit diameter and trench dimensions, the corners at each end of the trench would lead to unwanted integration of material from several sample increments and thus time slices. Use of a smaller milling bit diameter minimizes this effect. Additionally, a $50 \%$ reduction of this sampling effect is achieved if a trench is milled along the growth axis prior to the high-resolution milling, or if the milled trench is adjacent to a longitudinal cut (Figure 5). Material from the first trench can be used for reconnaissance studies. Another approach yielding similar results involves collecting the desired powder, and then moving the milling bit along the horizontal sampling track (i.e., parallel to the growth layer) for a distance corresponding to half the width of the milling bit. This powder is then discarded (or collected as auxiliary powder), and the milling bit returns to the original position, ready to produce the next aliquot of powder. Either of these sampling approaches effectively reduce spatial integration of sample (Kennett et al., 

a clear seasonal signal (Figure 6).

Other issues include growth layers that slope inward rather than geometrically perfect layers

830 (where the layering is perpendicular to section) and the use of tapered rather than cyclindrical drill bits, which would fail to sample some carbonate at depth during each run. A study comparing micromilling/IRMS and SIMS techniques on annually layered otoliths found that an offset existed between the two techniques (with SIMS yielding values $\sim 0.5 \%$ lower) and that the amplitude of annual oxygen isotope signal derived via micromilling was approximately half of the SIMS signal; both of these observations are potentially explained by deviations from an ideal sample geometry, and consequently greater integration of unwanted material arising from micromilling (Helser et al., 2018). Despite these differences, both techniques were able to detect annual isotope ratio cycles (Helser et al., 2018). A thorough reconnaissance of the sample using CT scanning or other means to characterise its geometry in advance of slabbing can minimise these issues.

Other minor issues include the possible conversion of aragonite to calcite during milling, which would result in a decrease in $\delta^{18} \mathrm{O}$ values of $0.02 \%$ for every $1 \%$ aragonite converted to calcite (Waite and Swart, 2015). This effect may have implications for modelling oxygen isotope variability or calculating deviations from equilibrium deposition. However, using a slower rotation rate of the milling bit $(500-800 \mathrm{rpm})$ will minimise, or even eliminate, this effect. A final recommendation is to run micromilled samples through the IRMS nonsequentially (i.e., out of stratigraphic order). Ideally the laboratory environment is static and will not affect results, but any unaccounted for diurnal changes (e.g., lab temperature) may affect the analyses in a cyclical way. Running samples non-sequentially both helps ensures 
that any cycles detected (e.g., a seasonal cycle) are not analytical artefacts and helps to identify issues, if they exist (e.g., a persistent cycle when samples are arranged in the order that they were run).

\subsubsection{LA-ICPMS}

Laser Ablation Inductively Coupled Plasma Mass Spectrometry (LA-ICPMS) is a beam method sampling technique. A polished speleothem slab is analysed by ablating small portions of material using a laser within a sample cell. The laser (typically an ArF excimer laser at a 193 $\mathrm{nm}$ wavelength) physically ablates the sample, aerosolising the material which is then carried into the ICP-MS system by a carrier gas (typically helium and/or argon, with helium yielding a greater signal intensity (Luo et al., 2018)) where trace element concentrations are measured and quantified against standards of known compositions. The specific mass spectrometer setup depends on the research question; for example, by using a quadrupole ICP-MS for elemental measurements using a reference isotope, or a multi-collector ICP-MS for isotope ratio analyses. Additional analytical set-ups are compatible with LA-ICPMS, including reaction cells, triple-quadrupoles, and split-stream analysis using two mass spectrometers in tandem (Frick et al., 2016; Kylander-Clark et al., 2013; Woodhead et al., 2016).

The advantages of LA-ICPMS for speleothem trace element analysis are numerous and include excellent spatial resolution (down to $\sim 3$ microns (Müller and Fietzke, 2016), using a rectangular aperture with long axis oriented along laminae) whilst preserving low detection limits (Figure 6). Although historically LA-ICPMS instruments used round 'spots', some laser ablation instruments are now fitted with rectangular masks (apertures), resulting in rectangular spots optimised for speleothem analysis, where the ablation spot is oriented 
perpendicular to speleothem growth axis, along the x-axis (Müller et al., 2009). This permits the ablation of a surface area equivalent to large circular spot sizes, while retaining high spatial resolution in the growth direction (similar to the micromill sampling described in 4.1.2). The speed of analysis via this method is also exceptionally high, with typical scan speed of $10 \mu \mathrm{m} \mathrm{s}^{-1}$ (e.g., (Jamieson et al., 2015)). Two-volume laser cells are now available, minimising sample damage incurred via sectioning and ensuring consistent aerosol flow within the cell. The coupling of a laser ablation system with a large-capacity gas exchange device even allows analysis under atmospheric air (Tabersky et al., 2013) although with somewhat elevated limits of detection. This technique is particularly suitable for large stalagmites, or archaeological samples, because it minimises physical sample destruction by requiring less sectioning.

The presence of a localised impurity can produce a trace elemental concentration peak even in the absence of a laterally contiguous geochemical horizon with that geochemistry. LAICPMS can produce elemental maps that can verify the spatial continuity of geochemical laminae of interest, particularly when combined with a square aperture (Evans and Müller, 2013; Rittner and Müller, 2012; Treble et al., 2005b; Woodhead et al., 2007). This permits the resolution of spatial relationships with greater confidence, and can corroborate interpretations based on stacked and parallel line scans, thereby avoiding issues related to the overinterpretation of a small number of points. Other microanalytical techniques (e.g., SIMS, synchrotron, $\mu \mathrm{XRF}$, etc.) can also produce elemental maps, but LA-ICPMS techniques can provide greater spatial coverage more rapidly.

The most significant disadvantage to LA-ICPMS is related to difficulties with standardisation. The use of matrix matched standards (i.e., made of the same material as the sample) during 
laser ablation analysis is ideal, but the limited availability, variable degrees of standard

897 homogeneity, and accurate standardisation of carbonate materials are ongoing challenges.

898 Orland et al. (2014) and later Müller et al. (2015) provide promising tests for a carbonate standard, albeit for a limited range of elements. Many analyses are standardised with somewhat greater uncertainty than is ideal using glasses such as NIST 620 or 622 . These analyses are often regarded as semi-quantitative, with high levels of confidence regarding variability and data trends but uncertainty regarding absolute values. Another minor disadvantage is lack of precise knowledge regarding the position of individual analytical spots. The sheer number of analyses possible via this technique (often $>10,000$ ) and indistinct, continuous track means that the exact position of any one individual spot is often difficult to determine precisely, complicating the correlation with other climate proxies. This disadvantage is mitigatable by precise notetaking, syn-analytical microscopy recording, careful reflected light imaging, cross-correlation, application of QGIS or similar software, and judicious 'wiggle-matching' with other proxy records, as well as creating marker laser lines at certain intervals to further help to constrain spatial uncertainties.

\subsubsection{Secondary ionisation mass spectrometry}

Secondary ionisation mass spectrometry (SIMS) uses a primary beam of positive (often caesium) or negative (often oxygen) ions to impact a sample surface under a vacuum, 'sputtering' secondary ions into a mass spectrometer (Wiedenbeck et al., 2012). A positively charged primary beam (commonly $\mathrm{Cs}^{+}$) ionises negative secondary ions (e.g. $\mathrm{C}^{-}, \mathrm{O}^{-}$), and a negatively charged primary beam (commonly $\mathrm{O}^{-}$) ionises positive secondary ions (e.g., $\mathrm{Mg}^{2+}$, 
919

920

921

922

923

924

925

926

927

928

929

930

931

932

933

934

935

936

937

spectrometer, and counted by ion detectors (electron multiplier or Faraday cup). This analytical technique can yield both trace element analysis and stable isotope ratio data in speleothem carbonate at the micron scale, with very little damage to the sample, and with very high sensitivity (Figure 6).

The spatial resolution typically ranges between 1 to $10 \mu \mathrm{m}$ spot size and $1-2 \mu \mathrm{m}$ spot depth for trace elements, with stable isotope analyses historically restricted to $20-30 \mu \mathrm{m}$ resolution (Fairchild and Baker, 2012) but now capable of achieving $10 \mu \mathrm{m}$ resolution (Orland et al., 2019). This represents a very high-resolution method for stable isotope analysis within speleothem carbonate, and is therefore ideal for detecting palaeoseasonality (Fairchild et al., 2006). The analysis resolution for trace elements is second only to using synchrotron radiation, but with the added advantage of full quantification of concentration data and the ability to cover much greater areas of sample. Matrix matched materials, typically calcium carbonate, are used for standardisation to ensure consistent ionisation of chemical species and ablation rates (Fairchild and Treble, 2009).

Early studies of SIMS-derived trace element trends in speleothems helped to demonstrate that many stalagmites retained a seasonal signal (Baldini et al., 2002; Finch et al., 2001; Roberts et al., 1998), representing a considerable shift in resolving power compared to the former decadal- to centennial-scale of analysis previously possible. The presence of annual trace element cycles was quickly established as the norm rather than the exception for shallow cave sites, even in the absence of visible speleothem laminations (Fairchild et al., 2001). Divalent alkaline earth metals such as magnesium and barium were suggested as palaeohydrological proxies, phosphorus as indicative of bioproductivity, and strontium as reflecting calcite growth rate and/or PCP (Fairchild et al., 2001; Fairchild et al., 2000; Treble 
et al., 2003). However, need for better empirical transfer functions between speleothems and external climatic processes, and partitioning between drip waters and speleothem calcite, complicated interpretations (Fairchild et al., 2001). Subsequent process-based studies have revealed the complexity involved in interpreting trace elements at seasonal scales, highlighting the role they play in complexation with organic matter as colloids (Borsato et al., 2007), in speleothem diagenesis (Martin-Garcia et al., 2014), and the complex controls on transfer through vegetation/soil/epikarst (Hartland et al., 2009; Hartland et al., 2012), as well as controls on partitioning via internal cave microclimate and crystallographic structures 950 (Fairchild and Treble, 2009). The use of trace element cycles obtained via SIMS as chronological markers is exemplified through the work of Smith et al. (2009), where the ability of trace element cycles to provide relative age constraints at a finer spatial resolution than traditional U-series age models is unambiguously demonstrated.

A frontier for SIMS trace element measurements lies in the potential of combining these trace element records with stable isotope measurements undertaken at sub-annual scale. Prior to the advent of SIMS techniques for stable isotope analysis, there were very few combined trace element - stable isotope studies due to the incompatibility of analytical resolution between the two parameters (Orland et al., 2014). However, the analysis of stable isotopes by SIMS now achieves a spatial resolution capable of allowing direct comparability between both isotopic and trace element indicators of seasonality (Orland et al., 2014).

SIMS stable isotope studies have investigated the $\delta^{18} \mathrm{O}, \delta^{13} \mathrm{C}$ and $\delta^{34} \mathrm{~S}-\mathrm{SO}_{4}$ dynamics in stalagmite records (typical uncertainties $(2 \sigma): \delta^{18} \mathrm{O}=0.2 \%$ (Orland et al., 2019); $\delta^{13} \mathrm{C}=0.6$ 0.7\%o (Oerter et al., 2016; Sliwinski et al., 2015); $\delta^{34} S=1.6 \%$ o $(1 \sigma)$ at $70 \mathrm{ppm} S$ concentrations (Wynn et al., 2010)). Whereas each of these isotope ratios reflects changing surface 
environmental conditions over inter-annual timescales, only the $\delta^{18} \mathrm{O}$ measurements by SIMS can produce records of intra-annual seasonality. Analysis of $\delta^{13} \mathrm{C}$ in speleothem carbonate cannot be undertaken simultaneously with $\delta^{18} \mathrm{O}$, and any available records in the literature (e.g., (Pacton et al., 2013)) are not undertaken at seasonal resolution. The apparent lack of seasonal change in cave dripwater $\delta^{34} \mathrm{~S}^{-\mathrm{SO}_{4}}$ (Borsato et al., 2015) has also so far prevented SIMS speleothem sulphur isotope measurements at the seasonal scale (Wynn et al., 2010). Treble et al. (2005a) produced the first $\delta^{18} \mathrm{O}$ record unambiguously linking seasonal cycles in speleothem oxygen isotopes to rainfall dynamics, and corroborated these interpretations with trace element cycles and contemporary rainfall monitoring. Subsequent work at Soreq Cave, Israel, further developed the technique to detect seasonality and links with rainfall dynamics across a range of time periods (Orland et al., 2012; Orland et al., 2009; Orland et al., 2014). Coupled annual variability in fluorescence and $\delta^{18} \mathrm{O}$ provided a seasonal marker of annual variability in rainfall from before the climate instrumental record (Orland et al., 2012; Orland et al., 2009). Careful correlation between fluorescent banding, $\delta^{18} \mathrm{O}$ and trace element measurements, and surface environmental conditions demonstrated that the fluorescent banding represented seasonal organic colloid flux variability into the cave.

Despite the clear advantages of utilising SIMS stable isotope analyses of speleothem carbonate to reveal seasonal patterns of rainfall delivery and drivers of climatic change, the technique also comes with its analytical challenges, including the considerable impact of geometric imperfections (e.g., sample topography, porosity, inclusions, cracks, etc) (Kita et al., 2011; Pacton et al., 2013; Treble et al., 2005a). In most instances, the ability to control the precise location of SIMS analyses enable geometric imperfections to be avoided, provided good surface mapping can be used to identify optimal locations for analysis and post 
processing can be used to see any geometric imperfections in each analysis pit (Orland et al., 2009). This is in contrast to micromilling, where large swathes of sample are often bulked together regardless of sample porosity or imperfections. The need to use matrix matched standard materials presents similar problems of availability and homogeneity for the accuracy of data analysis as encountered with LA-ICPMS. However, recent improvements in this area, alongside improvements in sample preparation techniques have been substantial enough to enable accurate correction for instrumental drift (Valley and Kita, 2009). The impact of trace element content on carbonate $\delta^{18} \mathrm{O}$ and $\delta^{13} \mathrm{C}$ analyses also requires careful consideration (Sliwinski et al., 2017), but can be corrected following careful standardisation and is generally not a problem encountered through speleothem analysis where the trace element content is typically less than 1 weight \%. An emerging analytical frontier concerns the impact of water and/or organic content on SIMS carbonate $\delta^{18} \mathrm{O}$ and $\delta^{13} \mathrm{C}$, requiring careful pre-screening of sample material and simultaneous analysis of $\mathrm{OH}$ - and $\mathrm{CH}$ - respectively (Orland et al., 2012; Orland et al., 2015; Orland et al., 2019; Wycech et al., 2018).

Despite these issues, SIMS remains an appealing choice for palaeoseasonality reconstruction using stalagmites due to its sensitivity and resolution. SIMS has produced some of the highest resolution records of palaeoseasonality available and will continue to play an important role in linking stalagmite records to seasonal changes in environmental conditions, particularly across discrete, short-lived events. Although the technique is not suitable for building long records, the comparison of discrete timeslices permits seasonality to be contrasted for key intervals (Orland et al., 2012; Orland et al., 2015; Orland et al., 2019).

\subsubsection{Synchrotron}


1012 speleothem carbonate opened up new possibilities in terms of greater resolving power for geochemical analysis (Kuczumow et al., 2003; Kuczumow et al., 2001). Based on the emission of electromagnetic radiation from charged electrons accelerated in an orbit, synchrotron radiation generates secondary radiation from speleothem carbonate based on the characteristic fluorescent properties of chemical elements. The excellent spatial resolution of analysis (0.5-5 microns), low detection limits, low background, and the ability to quantitatively map trace element variability across a given area has enabled the study of speleothem geochemical structures at the sub-annual timescale and in two dimensions

(Figure 6). The use of XANES (X-Ray Absorption Near Edge structure) can define the oxidation state of the element under consideration, thereby adding further resolving power to determine environmental processes.

Applications range from using SR- $\mu$ XRF to determine long-term (100 year) secular changes in elemental signals (Frisia et al., 2005), high resolution event imaging across sub-annual to multi-annual timescales (Badertscher et al., 2014; Frisia et al., 2008; Vanghi et al., 2019; Wang et al., 2019b), and for investigating petrological controls on geochemical composition (Frisia et al., 2018; Ortega et al., 2005; Vanghi et al., 2019). However, it is at the seasonal scale of analysis where the resolving power of synchrotron radiation has really pushed the boundaries 1029 of speleothem science.

No conventional dating technique provides an absolute timeframe at the sub-annual scale of 1031 speleothem carbonate deposition. However, linking the seasonality of external environmental processes to speleothem petrology and geochemical characteristics can yield a monthly scale resolution of trace element content. SR- $\mu$ XRF was used to determine the 
coincidence of trace element distributions and physical calcite characteristics within annual stalagmite laminations (Borsato et al., 2007). Based on the annually laminated stalagmite ER78 from Ernesto Cave, Italy, a suite of trace elements $(\mathrm{P}, \mathrm{Cu}, \mathrm{Zn}, \mathrm{Br}, \mathrm{Y}$, and $\mathrm{Pb})$ were found to form an annual peak, coincident with a characteristic thin (0.5-4 $\mu \mathrm{m})$ brown UV-fluorescent layer in each annual couplet. The brown colouration of each UV-fluorescent layer is probably due to organic acids derived from high rates of water infiltration during each autumn (Frisia et al., 2000; Huang et al., 2001; Orland et al., 2014). The transport of trace elements is associated with colloidal organic molecules (Hartland et al., 2010; Hartland et al., 2012), and leads to the incorporation of this distinctive elemental suite on a seasonal basis associated with the autumnal rains (the 'autumnal pulse' as described in Section 2.4). SR- $\mu$ XRF permits the detection of variability inherent to each individual year, which then can be contrasted against the symmetrical mean annual profile. Any differences (e.g., double peaks or shoulder peaks) provide an indication that the rainfall distribution throughout that year deviated from the mean annual profile. Strontium was observed to vary inversely to colloidally transported elements (Borsato et al., 2007), possibly due to competition for binding to defect sites, thus limiting incorporation into the calcite lattice. SR- $\mu$ XRF revealed seasonal patterns of zinc, lead, phosphorus, and strontium within speleothem Obi84 from Obir Cave, Austria, whose concentration peaks also coincided with the dark coloured visible laminae. These were similarly interpreted as hydrological event markers associated with autumnal infiltration, but could also result from dry deposition of aerosols (Dredge et al., 2013).

SR- $\mu$ XRF 2D mapping within speleothem Obi84 over three annual cycles demonstrated the effects of several infiltration events each year, present as short-lived peaks in $\mathrm{Zn}$ concentration and which build in magnitude towards the main autumnal flush (Wynn et al., 2014) (Figure 6). Using these event peaks as markers of autumnal flushing permitted 
1058

1059

1060

1061

1062

1063

1064

1065

1066

1067

1068

1069

1070

1071

1072

1073

1074

1075

1076

1077

1078

1079

1080

attribution of annual sulphate cycles to summer high and winter low concentrations. At the

Obir Cave site, these seasonal shifts in speleothem sulphate content were attributed to temperature-driven cave ventilation and associated cave air $p \mathrm{CO}_{2}$ variability which controlled the dripwater $\mathrm{pH}$ and the sulphate:carbonate ratio. Wynn et al. (2018) later verified this proposed seasonal mechanism using controlled laboratory experiments, thereby permitting the extraction of seasonal temperature information based on the annual sulphate cycle's topology. SR- $\mu$ XRF can thus extract geochemical expressions of seasonality, and the technique is well-suited to investigating changing rainfall and temperature seasonality dynamics back through time.

\subsubsection{Data analysis}

Following the geochemical analyses and data processing, the information must be interpreted. For techniques producing tens to hundreds of data points, this is not particularly challenging. On the other hand, techniques such as LA-ICPMS can produce tens of thousands of data points for multiple elements, and can greatly increase the processing time on common spreadsheet programmes. To circumvent these issues, it is possible to simplify the data using a Principal Component Analysis (PCA), a multivariate statistical analysis technique which extracts modes of variation from large multivariate timeseries datasets that best describe overall variability of those datasets. The technique is ideal for large multivariate stalagmitederived LA-ICPMS datasets (Borsato et al., 2007; Jamieson et al., 2015; Orland et al., 2014). PCA has also been used to extract a seasonal signal from trace elemental concentrations even in the absence of visible laminae and applied towards the development of a chronology (Ban et al., 2018). 

et al., 2009; Orland et al., 2014; Orland et al., 2019) from monthly-resolved datasets is ideal for extracting seasonal information from an otherwise difficult to interpret dataset. For example, Ridley et al. (2015b) used the well-developed annual carbon isotope cycles with their Belizean stalagmite to extract seasonal amplitudes, which were then interpreted in terms of the strength of the seasonal ITCZ incursion into southern Belize. Orland et al.

1087 (2015) used the topology of oxygen isotope variability within individual growth bands in a 1088 Chinese stalagmite to clarify the origin the oxygen isotope variability. Spectral analysis of well-dated samples can also reduce data complexity (Myers et al., 2015). For example, Asmerom et al. (2020) used a wavelet analysis to reconstruct the strength of the wet season in Central America over the last two millennia, and to show that modern seasonality in rainfall was only emplaced in the $15^{\text {th }}$ Century. Extracting a meaningful metric from numerous more complex data using statistical techniques is one way of simplifying a complex geochemical dataset.

\section{Modelling techniques}

Many efforts at modelling both the hydrology feeding a stalagmite and the climate signal within exist. Proxy system models (PSMs) describe how geological or chemical archives are imprinted with climate signal (Evans et al., 2013). In terms of stalagmite-specific models, several exciting geochemical models now exist which can explore the emplacement of a geochemical signal in a stalagmite (Wong and Breecker, 2015), often based on established processes which govern stalagmite precipitation (e.g., (Buhmann and Dreybrodt, 1985)). Two recent examples (specifically of disequilibrium isotope fractionation processes proxy system 
models) are the IsoCave model, which can examine disequilibrium isotope effects in speleothems and related implications for speleothem isotope thermometry (Guo and Zhou, 2019), and the ISOLUTION model which similarly helps to better understand the effect of these disequilibrium isotope fractionation processes on stalagmite proxy records (Deininger and Scholz, 2019). The I-STAL model allows the simulation of PCP and how this affects dripwater Mg, Sr, and Ba (Stoll et al., 2012). A number of models looking specifically at drip hydrology now exist (e.g., KarstHydroModel (Baker and Bradley, 2010; Treble et al., 2003)), and these are extremely useful for understanding how the rainfall input signal is transformed before reaching the stalagmite. Rather than using hydrological or geochemical modelling, a recent publication introduced a Monte Carlo approach to model rainfall and temperature seasonality in a stalagmite from La Garma Cave, northern Spain, over the Holocene (Baldini et al., 2019). Here, we build on this work and compare both synthetic and real-world input data to the results of the second-generation model.

The model requires some widely available types of input data, including: i) a stalagmite-based $\delta^{18} \mathrm{O}$ record, ii) a record of regional mean annual temperature (MAT) of any resolution (e.g., borehole, marine sediments, stalagmite fluid inclusions) over the interval of interest, iii) monthly-scale modern instrumental records of rainfall and temperature above the site (or as close as possible to the site), and iv) cave air temperature and its relationship with above ground temperature. The relationship between meteoric precipitation $\delta^{18} \mathrm{O}$ and temperature at the site is useful but not required information because regional or global meteoric precipitation $\delta^{18} \mathrm{O}$ and temperature equations can provide a suitable alternative.

1125 Essentially, the model assumes that the MAT of the cave site is similar to the MAT of the regional temperature input record (ii above), and produces a sine function around this value 
of an amplitude reflecting modern temperature seasonality, but with random variability

1128 added to the absolute minimum and maximum temperatures (the amount of randomness is user-defined). A second sine function reflects the rainfall seasonality, and whereas the temperature wave's polarity is fixed (i.e., summers are always warmer than winters), the rainfall seasonality sine wave's polarity is allowed to flip randomly. The seasonal extreme values associated with either sine function are fixed to the same calendar months, linked to the timing of the modern minima and maxima.

These two sine waves produce synthetic monthly temperature and rainfall values, which are then converted to $\delta^{18} \mathrm{O}_{p}$ based ideally on local temperature-rainfall $\delta^{18} \mathrm{O}$ relationships, or in cases where this relationship is not known, to more global equations (e.g., (Schubert and Jahren, 2015)). It is assumed that the $\delta^{18} \mathrm{O}_{\mathrm{p}}$ is conveyed to the dripwater (see discussion regarding evapotranspiration, Section 4.3) and that this is converted to carbonate $\delta^{18} \mathrm{O}$ using the Tremaine equation (Tremaine et al., 2011) at ambient cave air temperature adjusted according to observed relationships between outside and inside air. This equation was chosen as most appropriate because its empirical nature accounts for in-cave disequilibrium fractionation processes more completely than other equations. The model therefore considers seasonal changes in rainfall but is independent of total annual rainfall. The annual amount-weighted mean modelled carbonate $\delta^{18} \mathrm{O}$ value is then compared with the actual measured carbonate $\delta^{18} \mathrm{O}$ value, and if it is within a certain user-defined value, it is logged as a successful simulation. If the difference between the modelled and actual carbonate $\delta^{18} \mathrm{O}$ is

1147 greater than this value (generally $\sim 0.1$ per mil), the simulation is logged as unsuccessful. 1,000 of these coupled temperature and rainfall simulations are conducted per time slice, all the 
successful and unsuccessful simulations are logged, and the mean monthly modelled rainfall and temperature values calculated from the successful simulations.

\subsection{Test Runs: Gradual shifts in rainfall polarity}

The model reproduces shifts in rainfall polarity in synthetic datasets well (Figure 7). In one experiment, the input $\delta^{18} \mathrm{O}$ dataset was created by using i) a temperature sine function that was set as invariant (i.e., it maintained its polarity and amplitude throughout the run), and ii) a rainfall sine function that shifted in polarity completely over 14 model years. The wettest month in the input rainfall record was April in Year 1, gradually changing polarity to November by Year 14. As such, model Year 7 was characterised by no seasonality (Figure 7). The model was run without a priori knowledge of these shifts other than the mean annually-resolved synthetic $\delta^{18} \mathrm{O}$ record, MAT, 'modern' seasonality range, and cave temperature (i.e., the simulations were run 'modeller blind'), but the output reproduced the shifting rainfall pattern very well. The gradual shift in rainfall polarity is detected, and the lack of seasonality in the input rainfall signal during Year 7 is reproduced. The input temperature data had a $15{ }^{\circ} \mathrm{C}$ annual temperature range, and two model simulations were conducted: one derived using an annual seasonal temperature range of $10 \pm 6{ }^{\circ} \mathrm{C}$, and a second using an annual seasonal temperature range of $15 \pm 6^{\circ} \mathrm{C}$. In the case of the lower annual temperature range, the model overestimates rainfall seasonality in order to compensate for the inappropriate annual temperature range, but still detects shifts in rainfall polarity (Figure 7). When the more appropriate temperature range is used, the simulation captures both the amplitude and polarity of the shifting rainfall input signal. However, this experiment highlights a limitation 
1171 of this modelling approach; $\delta^{18} \mathrm{O}$ data is explicable both in terms of rainfall and temperature 1172 seasonality shifts, and an unknown annual temperature range introduces uncertainties.

1173 A second experiment involved synthetic temperature and rainfall input records with both considerable inter-annual variability and noise introduced (Figure 8). Notably, one model year

1175 (Year 4) had the polarity of the rainfall signal completely reversed. Again, the model was able to extract the salient features of the input data very well. Reproduced were inter-annual variations in rainfall and temperature, and, importantly, the model detected the reversed seasonality of the rainfall signal in Year 4 (Figure 8).

\subsection{Application to a stalagmite $\delta^{18} \mathrm{O}$ dataset from a seasonally arid continental region}

1181 The first version of the model was run successfully across the Holocene using a $\delta^{18} \mathrm{O}$ dataset 1182 derived from the maritime climate of northern Spain (Baldini et al., 2019). Here, we apply the model to a dataset from Bir-Uja Cave in the Keklik-Too mountain ridge, Kyrgyzstan, a location characterised by extremely strong seasonal fluctuations in both temperature and rainfall. The cave $\left(40^{\circ} 29^{\prime} \mathrm{N}, 72^{\circ} 35^{\prime} \mathrm{E}\right)$ is $\sim 60 \mathrm{~m}$ long and is developed at an altitude of $\sim 1,325 \mathrm{~m}$ above sea level (Fohlmeister et al., 2017). The input data consisted of the $\delta^{18} \mathrm{O}$ dataset from stalagmite Keklik1 reported on in Fohlmeister et al. (2017), a 500-year long, centennial-resolution borehole temperature record from the Tian Shan mountains ( $461 \mathrm{~km}$ to the north of the cave site) (Huang et al., 2000), instrumental precipitation and temperature records since 1880 C.E. from Tashkent, Uzbekistan ( $300 \mathrm{~km}$ to the east) (Menne et al., 2012), and cave temperature (Fohlmeister et al., 2017). The $\delta^{18} \mathrm{O}$ input data were decadally-resolved, and the stalagmite was dated using a recently developed radiocarbon technique (Fohlmeister and 
Lechleitner, 2019; Fohlmeister et al., 2017; Lechleitner et al., 2016b). The Keklik1 record

1194 extends from 2011 C.E. back to 1150 C.E., but the borehole record only extends back to 1500

C.E., so the interval modelled only extends to 1500 C.E. On average, the site receives $\sim 450$

$\mathrm{mm}$ of precipitation per year (based on Global Network of Isotopes in Precipitation data from

Tashkent), with 80\% falling from November to April. Summers are very dry, with August (the

to $25.0{ }^{\circ} \mathrm{C}$ in July, with a MAT of $12.1{ }^{\circ} \mathrm{C}$. Stalagmite Keklik1 was located $\sim 40$ meters from the \%0\% during the warmer months (Fohlmeister et al., 2017).

Unlike the Spanish GAR-01 record which extended back to 13,500 years BP and was modelled using 100-year timeslices (Baldini et al., 2019), the Keklik1 $\delta^{18} \mathrm{O}$ record was modelled using annual timeslices. The timings of the minimum and maximum values of the modelled temperature sine function were fixed at January and July, respectively. These months were also designated as the minimum/maximum of the modelled rainfall sine wave, which fits present day observations, but the sine function's polarity was not prescribed in advance.

Baldini et al. (2019) noted that the modelled temperature curve for northern Iberia closely resembled a previously published temperature reconstruction for the region (Martin-Chivelet et al., 2011) with a temporal resolution that exceeded the information provided by the lowresolution input dataset. Although no annual-scale MAT record exists in the Kyrgyzstan region for the last 500 years, summer temperatures are well constrained by tree ring records. A 

comparison of the modelled July temperature derived from the Keklik1 $\delta^{18} \mathrm{O}$ record reveals a very good match with the NTREND AG2 temperature anomalies ( $300 \mathrm{~km}$ to the north of the cave site) (Anchukaitis et al., 2017; Cook et al., 2013) (Figure 9). The model's ability to reconstruct palaeotemperature may reflect the fact that the probability of a successful model run is maximised when modelled temperature approximates the actual temperature shift. Successful model runs with a different (and incorrect) temperature pattern are possible with certain modelled rainfall simulations, but the mean monthly temperature values (reflecting the mean of all successful runs) will be biased towards model simulations with the correct temperature shift. The apparently robust reconstruction of warm-season palaeotemperature is an unexpected and exciting model outcome, but one that requires further evaluation.

The rainfall reconstruction reproduces many of the same features highlighted by Fohlmeister et al. (2017). In particular, decreases in the winter rainfall contributions in the late 1500 s, the mid-1700s, and the early 1800 s are apparent in both records. Although to a certain extent this is expected because the $\delta^{18} \mathrm{O}$ record is integral to both reconstructions, it is interesting that the two reconstructions use two fundamentally different techniques (numerical versus geochemical modelling) to estimate the importance of winter rainfall to the overall annual water budget at the site, and arrive at broadly similar results. For example, a winter rainfall peak occurs in $1797 \mathrm{CE}$ in both records and transitions to drier winters by $1815 \mathrm{CE}$, with 22\% and $\sim 50 \%$ reductions in winter rainfall implied by the model and $\delta^{18} \mathrm{O}$ data, respectively. The model underestimating the reduction in rainfall probably arises because of the model's utilisation of smooth sine waves rather than more step-like functions; in other words, although it is possible for one month per year to have zero rainfall in the model, the adjacent two months must necessarily have some rainfall, whereas in reality, several dry months per 
summer could occur. The use of step functions would permit the incorporation of several dry months annually and would amplify apparent shifts in seasonal rainfall amounts. Modelled DJFM rainfall compares reasonably well with GHCN rainfall from Tashkent (Figure 9), particularly considering that the Tashkent meteorological station is $\sim 300 \mathrm{~km}$ away from and $\sim 1,000 \mathrm{~m}$ lower in altitude than the cave site.

\subsection{Limitations to the modelling technique and future work}

Several limitations to the presented modelling technique exist. First, the timing of the rainfall minima and maxima versus temperature signal could affect the model's efficacy; for example, if the rainiest month occurs three months after (or before) the warmest month, the use of the sine function means that all outcomes are possible. This is because the maxima/minima in one parameter's sine function occur at the nodes of the other sine wave, effectively making both sine waves independent of each other. At many sites, temperature and rainfall are intrinsically linked and their seasonal cycle broadly synchronous, but the above may be an issue at some locations. Additionally, the model would require a differently shaped rainfallfunction to model rainfall at locations with two distinct rainy intervals every year, such as low latitude sites affected by the ITCZ twice each year.

The current version of the model does not incorporate evapotranspiration, and this is an obvious oversimplification. This may have repercussions for sites like Kyrgyzstan that experience a pronounced hot and dry season with negative effective infiltration. Similarly, variable kinetic fractionation almost certainly occurred within the cave (Fohlmeister et al., 2017) but is not considered within the model. Future versions of the model will incorporate 
both evapotranspiration and kinetic effects, but the model currently likely overcomes this

1262 limitation simply by reducing rainfall amount for months with high evapotranspiration rates.

Potentially, coupling the new model discussed here with a dripwater isotope evolution model

(e.g., ISOLUTION (Deininger and Scholz, 2019)) could produce very robust results. The model also cannot identify intervals characterized by changes in moisture pathway or fractionation amount; rather, it highlights intervals that are not explicable in terms of changes in temperature or rainfall amount seasonality (intervals where the model cannot converge on any solutions), and thus points to the involvement of other processes.

The model is allowed to randomly vary MAT above or below the low-resolution temperature input record, but only within user-defined bounds. Too great a range of permissible MAT values would allow essentially any outcome. For example, if there were no limits to minimum winter temperature, a low $\delta^{18} \mathrm{O}$ value could be modelled as either a very cold winter with a subdued rainfall seasonality or as a mild winter but with substantial winter rain. Limiting the temperature seasonality to reasonable bounds (for example, based modern interannual MAT variability) permits assessing whether any given month is warmer or colder than the lowresolution temperature input, but may underestimate the total amount of cooling and warming. In extreme cases, this may manifest itself as a failure to converge upon any successful model, thus highlighting timeslices that require closer inspection and potentially an alternative explanation.

As discussed in Section 5.2, the utilisation of step functions to describe rainfall seasonality may facilitate the modelling of climate for sites where several months receive similar amounts of rainfall. Future studies should investigate the ramifications of function choice on output. Additionally, theoretically arriving at a mathematical solution utilising the relevant equations 
and input data is possible, obviating the need for $\mathrm{MC}$ simulations, and future research will investigate this possibility. Finally, future models could incorporate options for geochemical modelling of drip and carbonate chemistry.

\section{Regional seasonality}

In this section we analyse global meteoric precipitation and temperature data to highlight regions experiencing pronounced seasonal variability in temperature, precipitation amount, and precipitation $\delta^{18} \mathrm{O}$ (Figures 10 and 11), helping to facilitate the identification of cave sites sensitive to seasonality. This also highlights locations that are at the margins of such regions, where seasonality may have affected the record in the past, despite the lack of a modern influence.

\subsection{Identification of seasonally sensitive regions}

WorldClim Version 2 data were obtained at a 2.5 minute ( $4.5 \mathrm{~km}$ at the equator) spatial resolution (Fick and Hijmans, 2017). Inland continental regions within the mid- to highlatitudes of the Northern Hemisphere (e.g., central and northern Canada, eastern Russia, northeast China, and Mongolia) are characterised by the greatest mean annual temperature range (Figure 10a). A greater annual temperature range is characteristic of continental climates due to the reduced oceanic influence, with ocean water's high heat capacity and moderating influence on air temperature. The lowest mean annual temperature ranges occur in the low latitudes (where insolation remains high year-round) and maritime regions of the 
world (where oceans moderate temperature variability) (Figure 10a). The pattern of global

1306 temperature seasonality (herein calculated as the maximum temperature of the warmest month minus the minimum temperature of the coldest month averaged over the period 1970 $1308-2000$ based on WorldClim Version 2 data) is consistent with the geographic pattern of cave air ventilation reported in (James et al., 2015), a study concerning the role of outside temperature seasonality in the seasonal ventilation of caves.

Seasonality in precipitation amount (Figure 10b) is greatest in the low latitudes due to the annual migration of the Intertropical Convergence Zone (ITCZ) and monsoonal systems that cause distinct wet and dry seasons, along the western coast of North America, southern South America, and Europe where seasonal westerlies preferentially bring enhanced winter precipitation, and bordering the Mediterranean where a 'Mediterranean climate' characterised by wet-winters and dry-summer dominates (Figure 10b). The lowest precipitation amount seasonality occurs in arid and semi-arid regions of the world and the non-coastal mid- to high-latitudes of the northern and southern hemispheres.

Global seasonality in amount-weighted $\delta^{18} \mathrm{O}_{p}$ (Figure 11) approximates the pattern of temperature seasonality (Figure 10a), with the greatest annual range in $\delta^{18} \mathrm{O}_{\mathrm{p}}$ observed at Northern Hemisphere continental interior and high latitude sites (e.g., northeast Asia, central Canada, northern Greenland). In addition, high altitude sites (e.g., the Andes in western South America, the Caucasus Mountains at the intersection of Europe and Asia) also exhibit higher annual WM $\delta^{18} \mathrm{O}_{p}$ ranges due to the altitude effect. The lowest $\delta^{18} \mathrm{O}_{p}$ seasonality occurs within maritime (e.g., NW Europe, SW and SE Australia) and arid/semi-arid regions (e.g., East Africa, eastern Brazil, South Africa). Many stalagmite records are from temperate regions where 
Huang et al., 2001; Johnson et al., 2006; Orland et al., 2014). Global cave dripwater $\delta^{18}$ O data reveal that caves from regions with this MAT range have dripwater chemistry that reflects recharge-weighted $\delta^{18} \mathrm{O}_{p}$ (Baker et al., 2019). The seasonal distribution of $\delta^{18} \mathrm{O}_{p}$ is therefore a critical control in the case of many different stalagmite samples.

In other cases, very pronounced seasonality inherent in stalagmite geochemical records are not due to seasonality in $\delta^{18} \mathrm{O}_{\mathrm{p}}$, but instead to seasonality in rainfall amount (Ridley et al., 2015b) and associated shifts in bioproductivity (Baldini et al., 2005) or PCP (Fairchild and Hartland, 2010; Fairchild et al., 2006). Seasonality in temperature can also induce cave ventilation in temperate zone caves during the winter (providing the cave geometry is appropriate), promoting carbonate deposition within the cave and biasing annual- to decadalscale records towards the winter season rainfall (James et al., 2015). The maps provided herein can help identify regions containing speleothems retaining the desired seasonal signal, and determine what the most likely control is on any seasonal signal found within a stalagmite. Furthermore, the maps help highlight cave sites that are located on the peripheries of climatologically seasonal zones at present, where past seasonality shifts could have influenced a record. Examples include the Sahel and southern Belize (Figure 12), both currently at the very northern extent of the ITCZ, where a small ITCZ shift to the south would produce both severe drying and a substantial decrease in rainfall seasonality. This perspective was underscored by recent results from Central America that used monthly-scale rainfall proxy data over the last two millennia to suggest that the region has only been affected by the ITCZ since 1400 C.E., and that the ITCZ influence may wane in the near future (Asmerom et al., 2020) (Figure 12). 


\subsection{Complexities despite strong seasonality: northeast India as an example}

1352 The seasonality maps presented here highlight regions most likely to contain stalagmites

1353

1354

1355

1356

1357

1358

1359

1360

1361

1362

1363

1364

1365

1366

1367

1368

1369

1370

1371

1372

1373 which retain seasonal signals in temperature, rainfall amount, or $\delta^{18} \mathrm{O}_{\mathrm{p}}$. However, they also illustrate that not all seasonal variations in $\delta^{18} \mathrm{O}_{\mathrm{p}}$ are explicable in regional temperature or rainfall amount terms. In many cases, complex moisture source variability overprints temperature-induced seasonality, hampering the use of models such as the one presented in Section 5. Here, we discuss the Indian Summer Monsoon (ISM) as an example of such a situation, and focus specifically on Mawmluh Cave in Meghalaya, northeast India, one of the most seasonal locations on Earth in terms of rainfall amount (Fig. 10). In Meghalaya, hydroclimate is characterised by extreme seasonality, as the plateau constitutes the first topographic barrier for moisture-laden air masses travelling inland from the Bay of Bengal (Murata et al., 2007; Prokop and Walanus, 2003). At present, the ISM brings $80 \%$ of the annual rainfall to the cave site, inducing extreme amounts of rainfall (up to 12 meters per year (Breitenbach et al., 2015). The seasonal precipitation cycle is reflected in rainfall $\delta^{18} \mathrm{O}$ composition (Berkelhammer et al., 2012; Breitenbach et al., 2010). Rainfall $\delta^{18} \mathrm{O}$ becomes progressively lighter during the ISM, but this effect is only partially driven by increasing precipitation intensity and the amount effect because the period of maximum precipitation (June-August) precedes maximum ${ }^{18} \mathrm{O}$ depletion (August-October) (Breitenbach et al., 2010)). Instead, the ${ }^{18} \mathrm{O}$-depletion results predominantly from the moisture source shifting from a proximal location (the Bay of Bengal) in the early and late ISM to a more distal location (the open Indian Ocean) during the peak ISM (longer transport times resulting in more Rayleigh distillation). Rainfall and dripwater $\delta^{18} \mathrm{O}$ at Mawmluh Cave are thus highly seasonal, but the relationship between temperature, rainfall amount, and rainfall $\delta^{18} \mathrm{O}$ is not straightforward 
1374 (Breitenbach et al., 2010; Breitenbach et al., 2015). Additional complexity arises from the

1375 filtering and buffering capacity of the karst aquifer through which rainwater percolates en 1376 route to a stalagmite. Although a clear seasonal dripwater $\delta^{18} \mathrm{O}$ cycle exists, with its lowest 1377 value approximating ISM rainfall $\delta^{18} \mathrm{O}$, its annual amplitude is compressed, reflecting buffering 1378 in the karst (Breitenbach et al., 2015). This further complicates the interpretation of $\delta^{18} \mathrm{O}$ 1379 records from these stalagmites, and information from independent proxies that are sensitive to processes dominating during the winter season is required to disentangle such processes. Combining summer-sensitive $\delta^{18} \mathrm{O}$ with winter-sensitive $\mathrm{Mg} / \mathrm{Ca}$ (reflecting $\mathrm{PCP}$ ) permitted disentangling ISM strength and the degree of dry season dryness in a stalagmite from Mawmluh Cave (Myers et al., 2015; Ronay et al., 2019). Such a multi-proxy approach, supported by local monitoring and karst process modelling, allows robust interpretations of complex processes than temperature or rainfall amount alone.

\section{Future directions and recommendations}

In this review, we introduce and discuss several concepts that we hope will facilitate the

1390 development and interpretation of robust seasonal-resolution resolution climate records from stalagmites, will improve the extraction and interpretation of seasonal information from stalagmites, and promote future discussion, including: A) that replication of records should not always be an expectation without a priori knowledge that the drip type and environmental conditions responsible for the deposition of the stalagmites are comparable (e.g., some stalagmites retain seasonal information, whereas others do not), B) that every stalagmite-based geochemical record is different and records a unique component of the 
environmental signal of varying complexity (i.e., each stalagmite retains an accurate history

1398 of its environment; the question is whether or not this history can be deconvolved), and C) that the application of at least one year's worth of hourly-resolved drip rate monitoring combined with a new drip classification scheme presented here may help identify stalagmites retaining a seasonal signal. Furthermore, we have (D) developed global seasonality maps of temperature (as was done previously by (James et al., 2015)), meteoric precipitation amount, and meteoric precipitation $\delta^{18} \mathrm{O}$ ratios which allow the identification of regions sensitive to different types of seasonality recordable by stalagmites. The maps facilitate predicting what type of seasonality potentially affects modern stalagmite samples from that region. They also assist in palaeoclimate interpretations by identifying locations proximal to regions with pronounced seasonality, where past migration of key atmospheric circulation systems could have altered the geochemical record retained by a stalagmite. On a similar note, we (E) present a model that interprets annual- to centennial-scale stalagmite $\delta^{18} \mathrm{O}$ records in terms of seasonal temperature and meteoric precipitation seasonality shifts. Although we stress that this model only highlights one possible interpretation (that the data were modulated primarily by regional long-term mean annual temperature variability combined with seasonality shifts in rainfall and temperature), often this interpretation is the most parsimonious. The modelling technique also helps identify time intervals when altered seasonality cannot account for the observed isotope shifts, suggesting that another variable needs consideration. We (F) discuss four major controls on the seasonality signal within stalagmites: i) Earth atmospheric, ii) Meteoric precipitation, iii) biological (e.g., soil processes), and iv) cave atmospheric, and (G) discuss a case study from India that serves as an example of a stalagmite whose seasonal signal is not derived from rainfall amount or regional 

seasonal shifts in Earth atmospheric processes).

1422 Stalagmites are remarkable archives of information regarding climate (on both seasonal and 1423 longer timescales), surface and cave environmental conditions, dry deposition, moisture 1424 source pathway, marine aerosols contributions, and hydrological routing. Replication of proxy records present strong support for palaeoclimatic interpretations, and should remain a goal of any stalagmite science research programme, but unless the climate signal-to-noise ratio of a region is unusually high, replication is only possible when comparing stalagmites deposited under similar conditions. A thorough understanding of the environmental processes affecting both entire caves (e.g., ventilation) as well as individual stalagmites (e.g., drip rate) facilitates replication efforts. The geochemical record from even adjacent stalagmites will reflect numerous processes, some of which are common to the two samples but many which are not, and only through a thorough understanding of the processes affecting each sample are robust (and replicable) climate interpretations achievable. However, unless analytical issues exist, non-replication does not imply that one record is incorrect; rather it generally implies that the two records simply record different environmental parameters.

Cave monitoring prior to the collection of a stalagmite will increase the likelihood of obtaining a record of the desired sensitivity to seasonal climate shifts, or other desired forcing. We recommend monitoring the drip feeding the stalagmite for at least one year using an automated drip logger and plotting the results in a diagram similar to Figure 3 to evaluate a 1440 stalagmite's likelihood of retaining hydrological seasonality. We recommend monitoring multiple sites within the cave and selecting the most appropriate stalagmite for collection 1442 based on the monitoring results. It is worth bearing in mind that unless the seasonality signal 
in a stalagmite is conveyed via seasonal cave ventilation, stalagmites fed by diffuse flow drips

1444 with long residence times may not retain seasonal information. Other drips that are seasonally either dry or undersaturated with respect to carbonate will lead to the formation of microhiatuses in the stalagmites and signal loss for that particular season. Monitoring a stalagmite's drip rate and drip chemistry for as long as possible represents one of the simplest but most effective means of understanding the potential climate signal contained within a sample prior to collection. This also has implications for cave conservation and protection efforts, because clearly formulated research goals and drip monitoring prior to stalagmite sample collection can greatly reduce the number of samples removed from a cave for research purposes.

If sample growth rate permits, we suggest that the extraction of the palaeoseasonality signal over long timescales is best achieved via micromilling, leaving no gap between adjacent samples, or LA-ICPMS. The major disadvantages of micromilling is that it is resource intensive, and that many samples may not have growth rates high enough to permit the required resolution; the major disadvantage of LA-ICPMS is that the trace element signature of a stalagmite is often dominated by site-specific factors such as temperature, sea spray, volcanic aerosols, fire, variable throughput of colloidal material, or rainfall, and consequently aligning the data with other records is sometimes complex. Micromilled carbonate powders that are divided into two or more aliquots that are subsequently analysed for stable isotope ratios, trace elements, and other geochemical proxies can provide very robust interpretations (e.g., Jamieson et al., 2016). This eliminates issues of cross-correlation and enables a powerful multiproxy approach, where each stable isotope ratio value is linked directly and unambiguously to numerous elemental concentration values. The technique can yield 
important information regarding palaeoseasonality but is considerably more resource

1467 intensive than running multiple LA-ICPMS tracks parallel to each other and the micromilled stable isotope track. An alternative is to produce a long decadal-scale isotope ratio traverse complemented by higher resolution transects or maps across key intervals of interest using LA-ICPMS, SIMS, synchrotron, or $\mu$ XRF to corroborate interpretations based on the longer transects. In the future, proxy mapping at micron-scale resolution using these techniques will help reduce uncertainties related to geometric ambiguities such as those associated with crystal boundaries and improve the robustness of interpretations.

\section{Conclusions}

1476 The reconstruction of palaeoseasonality using stalagmites is an exciting research direction

1477 that has yet to mature into its full potential. Numerous records of palaeoseasonality exist, but 1478 few direct reconstructions extend before the last two millennia. Ideally, future studies 1479 concluding that a decadal- to annual-scale isotope ratio record is affected by seasonality changes should support this by either using short windows of sub-annual data or by 1481 modelling.

Any climate proxy record is affected by inherent complexities in climate signal transfer to the stalagmite and by selective sampling of the stalagmite for analysis. A high-resolution (submaximises the likelihood of extracting a signal approximating the climate input signal. For long records annual- to decadal-scale resolution is ideal, and shorter records could benefit from an even higher resolution if resources permit. Large shifts in isotope ratios could reflect 
changes in seasonality, potentially associated with the migration of key atmospheric

1489 circulation systems over the cave site. New models incorporating seasonality can provide information regarding whether observed geochemical shifts are interpretable in terms of altered seasonality, and these represent an exciting and inexpensive new research tool. A seasonal-scale sampling strategy over short intervals of interest can verify these model interpretations, and LA-ICPMS or line-scan $\mu$ XRF represent potentially the most efficient methods to achieve this; other alternatives include monthly-scale micromilling, synchrotron analysis (SR- $\mu \mathrm{XRF}$ ), and SIMS.

The robust interpretation of stalagmite geochemical records in terms of seasonality represents a key challenge for the next decade. Achieving this is complicated by multiple incave and exogenic environmental forcings with dynamic seasonality, including: rainfall, temperature, humidity, bioproductivity, cave air $p \mathrm{CO}_{2}$, drip rate, source moisture region and $\delta^{18} \mathrm{O}$, and moisture mass trajectory from the source region. Even apparently straightforward $\delta^{18} \mathrm{O}$ records from regions with high signal-to-noise ratios typically interpretable as either varying total annual rainfall or summer rainfall may instead reflect another parameter instead (e.g., a change in moisture source or rainfall seasonality), as is the case with the Indian Summer Monsoon. Most records would benefit from a rigorous multi-proxy approach utilising not only multiple geochemical proxy datasets, but also site monitoring and new modelling approaches. Similarly, focussing research efforts at the same well-understood cave sites both maximises the quality of interpretations and contributes to the conservation of caves and stalagmite samples. The application of multiple stalagmites from the same site but with different drip rates and affected by different amounts of disequilibrium fractionation may provide the key to reconstructing formerly elusive climate variables, such as temperature. 
Instead of representing an irresolvable issue, we suggest that disequilibrium fractionation

1512 may present opportunities to quantify temperature, potentially even at seasonal resolutions.

1513

1514

1515

1516

1517

1518

1519

1520

1521

1522

Similarly, multi-proxy data could yield seasonal information even in the absence of seasonal sampling resolution; if two or more independent proxies reflect different seasonal data, combining the proxies could yield palaeoseasonality.

Over the past few decades stalagmites have provided some of the most iconic records in palaeoclimatology. In the future, stalagmites will continue to not only provide long records of exceptional quality, but they will also provide rare glimpses into palaeoseasonality at unprecedented temporal resolution. Recent microanalytical advances have facilitated the construction of exquisitely resolved stalagmite-based climate records; we are now at a stage where the interpretation of these records is catching up with their remarkable technical aspects. Extracting quantitative and accurate seasonal climate information from these geochemical records is a key challenge over the next decade, and, if this is achieved, stalagmites will truly be considered in a class of their own as climate archives.

\section{Acknowledgements}

We thank SISAL and PAGES for access to the SISAL database v1b. Portions of this research were funded by European Research Council Grant \#240167. Tim Horscroft is thanked for his support in facilitating the preparation of the manuscript. lan Orland and an anonymous reviewer are thanked for detailed constructive reviews that greatly improved the manuscript. Alex Iveson is thanked for useful comments regarding LA-ICPMS. 
1534 Allison, V.C., 1923. The growth of stalagmites and stalactites. Journal of Geology 31, 106-125.

1535 Allison, V.C., 1926. The antiquity of the deposit in Jacob's cavern. American Museum of Natural 1536 History, Anthropological Papers 19, 204-225.

1537 Anchukaitis, K.J., Wilson, R., Briffa, K.R., Buntgen, U., Cook, E.R., D'Arrigo, R., Davi, N., Esper, J., 1538 Frank, D., Gunnarson, B.E., Hegerl, G., Helama, S., Klesse, S., Krusic, P.J., Linderholm, H.W., Myglan, 1539 V., Osborn, T.J., Zhang, P., Rydval, M., Schneider, L., Schurer, A., Wiles, G., Zorita, E., 2017. Last 1540 millennium Northern Hemisphere summer temperatures from tree rings: Part II, spatially resolved 1541 reconstructions. Quaternary Sci. Rev. 163, 1-22.

1542 Arbel, Y., Greenbaum, N., Lange, J., Inbar, M., 2010. Infiltration processes and flow rates in 1543 developed karst vadose zone using tracers in cave drips. Earth Surface Processes and Landforms 35, $1544 \quad 1682-1693$.

Arbel, Y., Greenbaum, N., Lange, J., Shtober-Zisu, N., Grodek, T., Wittenberg, L., Inbar, M., 2008. Hydrologic classification of cave drips in a Mediterranean climate, based on hydrograph separation and flow mechanisms. Israel Journal of Earth Sciences 57, 291-310.

1548 Asmerom, Y., Baldini, J.U.L., Prufer, K.M., Polyak, V.J., Ridley, H.E., Aquino, V.V., Baldini, L.M., 1549 Breitenbach, S.F.M., Macpherson, C.G., Kennett, D.J., 2020. Intertropical convergence zone 1550 variability in the Neotropics during the Common Era. Science Advances 6, eaax3644.

Atkinson, T.C., 1977. Diffuse flow and conduit flow in limestone terrain in the Mendip Hills, Somerset 1552 (Great Britain). Journal of Hydrology 35, 93-110.

Atkinson, T.C., Hess, J.W., Harmon, R.S., 1985. Stable isotope variations in recharge to a karstic aquifer, Yorkshire dales, England. Annales de la Société Géologique de Belgique 108, 225. 
Atsawawaranunt, K., Comas-Bru, L., Mozhdehi, S.A., Deininger, M., Harrison, S.P., Baker, A., Boyd, M., Kaushal, N., Ahmad, S.M., Brahim, Y.A., Arienzo, M., Bajo, P., Braun, K., Burstyn, Y., Chawchai, S., Duan, W.H., Hatvani, I.G., Hu, J., Kern, Z., Labuhn, I., Lachniet, M., Lechleitner, F.A., Lorrey, A., PerezMejias, C., Pickering, R., Scroxton, N., Members, S.W.G., 2018. The SISAL database: a global resource to document oxygen and carbon isotope records from speleothems. Earth System Science Data 10, $1687-1713$.

Ayalon, A., Bar-Matthews, M., Sass, E., 1998. Rainfall-recharge relationships within a karstic terrain in the Eastern Mediterranean semi-arid region, Israel: $\delta 180$ and $\delta D$ characteristics Journal of Hydrology 207, 18-31.

Badertscher, S., Borsato, A., Frisia, S., Cheng, H., Edwards, R.L., Tuysuz, O., Fleitmann, D., 2014. Speleothems as sensitive recorders of volcanic eruptions - the Bronze Age Minoan eruption recorded in a stalagmite from Turkey. Earth Planet. Sci. Lett. 392, 58-66.

Baker, A., Barnes, W.L., Smart, P.L., 1997. Variations in the discharge and organic matter content of stalagmite drip waters in Lower Cave, Bristol. Hydrol Process 11, 1541-1555.

Baker, A., Bradley, C., 2010. Modern stalagmite $\delta 180$ : Instrumental calibration and forward modelling. Global and Planetary Change 71, 201-206.

Baker, A., Brunsdon, C., 2003. Non-linearities in drip water hydrology: an example from Stump Cross Caverns, Yorkshire. J Hydrol 277, 151-163.

Baker, A., Hartmann, A., Duan, W., Hankin, S., Comas-Bru, L., Cuthbert, M.O., Treble, P.C., Banner, J., Genty, D., Baldini, L.M., Bartolomé, M., Moreno, A., Pérez-Mejías, C., Werner, M., 2019. Global analysis reveals climatic controls on the oxygen isotope composition of cave drip water. Nature Communications 10, 2984. 
Baker, A., Smart, P.L., Edwards, R.L., Richards, D.A., 1993. Annual growth banding in a cave stalagmite. Nature $364,518-520$

Baker, A.J., Mattey, D.P., Baldini, J.U.L., 2014. Reconstructing modern stalagmite growth from cave monitoring, local meteorology, and experimental measurements of dripwater films. Earth and Planetary Science Letters 392, 239-249.

Baldini, J.U.L., Bertram, R.A., Ridley, H.E., 2018. Ground air: A first approximation of the Earth's second largest reservoir of carbon dioxide gas. Sci. Total Environ. 616-617, 1007-1013.

Baldini, J.U.L., McDermott, F., Baker, A., Baldini, L.M., Mattey, D.P., Railsback, L.B., 2005. Biomass effects on stalagmite growth and isotope ratios: A 20th century analogue from Wiltshire, England. Earth Planet. Sci. Lett. 240, 486-494.

Baldini, J.U.L., McDermott, F., Baldini, L.M., Ottley, C.J., Linge, K.L., Clipson, N., Jarvis, K.E., 2012. Identifying short-term and seasonal trends in cave drip water trace element concentrations based on a daily-scale automatically collected drip water dataset. Chem. Geol. 330, 1-16.

Baldini, J.U.L., McDermott, F., Fairchild, I.J., 2002. Structure of the 8200 -year cold event revealed by a speleothem trace element record. Science 296, 2203-2206.

Baldini, J.U.L., McDermott, F., Fairchild, I.J., 2006. Spatial variability in cave drip water hydrochemistry: Implications for stalagmite paleoclimate records. Chem. Geol. 235, 390-404.

Baldini, J.U.L., McDermott, F., Hoffmann, D.L., Richards, D.A., Clipson, N., 2008. Very high-frequency and seasonal cave atmosphere $P_{\mathrm{CO} 2}$ variability: Implications for stalagmite growth and oxygen isotope-based paleoclimate records. Earth Planet. Sci. Lett. 272, 118-129.

Baldini, L.M., Baldini, J.U.L., McDermott, F., Arias, P., Cueto, M., Fairchild, I.J., Hoffmann, D.L., Mattey, D.P., Müller, W., Nita, D.C., Ontañón, R., Garciá-Moncó, C., Richards, D.A., 2019. North 
Iberian temperature and rainfall seasonality over the Younger Dryas and Holocene. Quaternary Science Reviews 226, 105998.

Baldini, L.M., McDermott, F., Baldini, J.U.L., Arias, P., Cueto, M., Fairchild, I.J., Hoffmann, D.L., Mattey, D.P., Müller, W., Nita, D.C., Ontañón, R., Garciá-Moncó, C., Richards, D.A., 2015. Regional temperature, atmospheric circulation, and sea-ice variability within the Younger Dryas Event constrained using a speleothem from northern Iberia. Earth Planet. Sci. Lett. 419, 101-110.

Ban, F.M., Baker, A., Marjo, C.E., Duan, W.H., Li, X.L., Han, J.X., Coleborn, K., Akter, R., Tan, M., Nagra, G., 2018. An optimized chronology for a stalagmite using seasonal trace element cycles from Shihua Cave, Beijing, North China. Scientific Reports 8, 4551.

Banner, J.L., Guilfoyle, A., James, E.W., Stern, L.A., Musgrove, M., 2007. Seasonal variations in modern speleothem calcite growth in Central Texas, USA. J Sediment Res 77, 615-622.

Bar-Matthews, M., Ayalon, A., Matthews, A., Sass, E., Halicz, L., 1996. Carbon and oxygen isotope study of the active water-carbonate system in a karstic Mediterranean cave: Implications for paleoclimate research in semiarid regions. Geochim. Cosmochim. Acta 60, 337-347.

Bergel, S.J., Carlson, P.E., Larson, T.E., Wood, C.T., Johnson, K.R., Banner, J., Breecker, D.O., 2017. Constraining the subsoil carbon source to cave-air $\mathrm{CO}_{2}$ and speleothem calcite in central Texas. 217, 112-127.

Berkelhammer, M., Sinha, A., Stott, L., Cheng, H., Pausata, F.S.R., Yoshimura, K., 2012. An abrupt shift in the Indian Monsoon 4000 years ago. Geophysical Monograph Series 198, 75-87.

Blyth, A.J., Baker, A., Thomas, L.E., Van Calsteren, P., 2011. A 2000-year lipid biomarker record preserved in a stalagmite from north-west Scotland. J. of Quaternary Sci. 26, 326-334. 
Borsato, A., Frisia, S., Fairchild, I.J., Somogyi, A., Susini, J., 2007. Trace element distribution in annual stalagmite laminae mapped by micrometer-resolution X-ray fluorescence: implications for incorporation of environmentally significant species. Geochim. Cosmochim. Acta 71, 1494-1512.

Borsato, A., Frisia, S., Hellstrom, J., Treble, P., Johnson, K., Howard, D., Greig, A., 2019. Fast highresolution synchrotron micro-XRF mapping of annuallylaminated stalagmites, European Geoscience Union General Assembly. EGU, Vienna.

Borsato, A., Frisia, S., Wynn, P.M., Fairchild, I.J., Miorandi, R., 2015. Sulphate concentration in cave dripwater and speleothems: long-term trends and overview of its significance as proxy for environmental processes and climate changes. Quaternary Sci. Rev. 127, 48-60.

Breecker, D.O., Payne, A.E., Quade, J., Banner, J.L., Ball, C.E., Meyer, K.W., Cowan, B.D., 2012. The sources and sinks of $\mathrm{CO} 2$ in caves under mixed woodland and grassland vegetation. Geochim. Cosmochim. Acta 96, 230-246.

Breitenbach, S.F.M., Adkins, J.F., Meyer, H., Marwan, N., Kumar, K.K., Haug, G.H., 2010. Strong influence of water vapor source dynamics on stable isotopes in precipitation observed in Southern Meghalaya, NE India. Earth and Planetary Science Letters 292, 212-220.

Breitenbach, S.F.M., Bernasconi, S.M., 2011. Carbon and oxygen isotope analysis of small carbonate samples (20 to 100 mu g) with a GasBench II preparation device. Rapid Commun. Mass Spectrom. $25,1910-1914$.

Breitenbach, S.F.M., Lechleitner, F.A., Meyer, H., Diengdoh, G., Mattey, D., Marwan, N., 2015. Cave ventilation and rainfall signals in dripwater in a monsoonal setting - a monitoring study from NE India. Chemical Geology 402, 111-124.

Breitenbach, S.F.M., Plessen, B., Waltgenbach, S., Tjallingii, R., Leonhardt, J., Jochum, K.P., Meyer, H., Goswami, B., Marwan, N., Scholz, D., 2019. Holocene interaction of maritime and continental climate 
in Central Europe: New speleothem evidence from Central Germany. Global and Planet. Change 176, 144-161.

Broecker, W.S., 1960. Radiocarbon measurements and annual rings in cave formations. Nature 185, 93-94.

Broughton, P.L., 1983. Environmental Implications of competitive growth fabrics in stalactitic carbonate. International Journal of Speleology. 13, 31-41.

Buhmann, D., Dreybrodt, W., 1985. The kinetics of calcite dissolution and precipitation in

Cabellero, E., Jimenez de Cisneros, C., Reyes, E., 1996. A stable isotope study of cave seepage waters. Applied Geochemistry 11, 583-587.

Carlson, P.E., Miller, N.R., Banner, J.L., Breecker, D.O., Casteel, R.C., 2018. The potential of nearentrance stalagmites as high-resolution terrestrial paleoclimate proxies: Application of isotope and trace-element geochemistry to seasonally-resolved chronology. Geochimica et Cosmochimica Acta $235,55-75$.

Chapman, J.B., Ingraham, N.L., Hess, J.W., 1992. Isotopic investigation of infiltration and unsaturated zone flow processes at Carlsbad Caverns. Journal of Hydrology 133, 343-363.

Chen, C.-J., Li, T.-Y., 2018. Geochemical characteristics of cave drip water respond to ENSO based on a 6-year monitoring work in Yangkou Cave, Southwest China. Journal of Hydrology 561, 896-907.

Cheng, H., Lawrence Edwards, R., Shen, C.-C., Polyak, V.J., Asmerom, Y., Woodhead, J., Hellstrom, J., 230Th and 234U half-life values, and U-Th isotopic measurements by multi-collector inductively 
Cole, J.M., Nienstedt, J., Spataro, G., Rasbury, E.T., Lanzirotti, A., Celestian, A.J., Nilsson, M., Hanson, G.N., 2003. Phosphor imaging as a tool for in situ mapping of ppm levels of uranium and thorium in rocks and minerals. Chem. Geol. 193, 127-136.

Comas-Bru, L., Harrison, S.P., 2019. SISAL: Bringing Added Value to Speleothem Research. Quaternary 2, 7.

Comas-Bru, L., Harrison, S.P., Werner, M., Rehfeld, K., Scroxton, N., Veiga-Pires, C., Ahmad, S.M., Brahim, Y.A., Mozhdehi, S.A., Arienzo, M., Atsawawaranunt, K., Baker, A., Braun, K., Breitenbach, S., Burstyn, Y., Chawchai, S., Columbu, A., Deininger, M., Demeny, A., Dixon, B., Hatvani, I.G., Hu, J., Kaushal, N., Kern, Z., Labuhn, I., Lachniet, M.S., Lechleitner, F.A., Lorrey, A., Markowska, M., Nehme, C., Novello, V.F., Oster, J., Perez-Mejias, C., Pickering, R., Sekhon, N., Wang, X.F., Warken, S., Atkinson, T., Ayalon, A., Baldini, J., Bar-Matthews, M., Bernal, J.P., Boch, R., Borsato, A., Boyd, M., Brierley, C., Cai, Y.J., Carolin, S., Cheng, H., Constantin, S., Couchoud, I., Cruz, F., Denniston, R., Dragusin, V., Duan, W.H., Ersek, V., Finne, M., Fleitmann, D., Fohlmeister, J., Frappier, A., Genty, D., Holzkamper, S., Hopley, P., Johnston, V., Kathayat, G., Keenan-Jones, D., Koltai, G., Li, T.Y., Lone, M.A., Luetscher, M., Mattey, D., Moreno, A., Moseley, G., Psomiadis, D., Ruan, J.Y., Scholz, D., Sha, L.J., Smith, A.C., Strikis, N., Treble, P., Unal-Imer, E., Vaks, A., Vansteenberge, S., Voarintsoa, N.R.G., Wong, C., Wortham, B., Wurtzel, J., Zhang, H., Grp, S.W., 2019. Evaluating model outputs using integrated global speleothem records of climate change since the last glacial. Clim Past 15, 15571579.

Cook, E.R., Krusic, P.J., Anchukaitis, K.J., Buckley, B.M., Nakatsuka, T., Sano, M., Asia2K, P., 2013. Tree-ring reconstructed summer temperature anomalies for temperate East Asia since $800 \mathrm{CE}$. Clim. Dynam. 41, 2957-2972.

Cowan, B.D., Osborne, M.C., Banner, J.L., 2013. Temporal variability of cave air PCO2 in Central Texas. J Cave Karst Stud 75, 38-50. 
Cruz Jr., F.W., Karmann, I., Vianna, J., O., Burns, S.J., Ferrari, J.A., Vuille, M., Sial, A.N., Moreira, M.Z., 2005. Stable isotope study of cave percolation waters in subtropical Brazil: Implications for paleoclimate inferences from speleothems. Chemical Geology 220, 245-262.

Czuppon, G., Demény, A., Leél-Össy, S., Óvari, M., Stieber, J., Kiss, K., Kármán, K., Surányi, G., Haszpra, L., 2018. Cave monitoring in the Béke and Baradla caves (Northeastern Hungary): implications for the conditions for the formation cave carbonates. International Journal of Speleology, 13-28.

Daëron, M., Drysdale, R.N., Peral, M., Huyghe, D., Blamart, D., Coplen, T.B., Lartaud, F., Zanchetta, G., 2019. Most Earth-surface calcites precipitate out of isotopic equilibrium. Nat Commun 10.

Deininger, M., McDermott, F., Mudelsee, M., Werner, M., Frank, N., Mangini, A., 2017. Coherency of late Holocene European speleothem delta 0-18 records linked to North Atlantic Ocean circulation. Clim. Dynam. 49, 595-618.

Deininger, M., Scholz, D., 2019. ISOLUTION 1.0: an ISOtope evoLUTION model describing the stable oxygen (delta 0-18) and carbon (delta C-13) isotope values of speleothems. International Journal of Speleology 48, 21-32.

Deininger, M., Werner, M., McDermott, F., 2016. North Atlantic Oscillation controls on oxygen and hydrogen isotope gradients in winter precipitation across Europe; implications for palaeoclimate studies. Clim Past 12, 2127-2143.

Dredge, J., Fairchild, I.J., Harrison, R.M., Fernandez-Cortes, A., Sanchez-Moral, S., Jurado, V., Gunn, J., Smith, A., Spotl, C., Mattey, D., Wynn, P.M., Grassineau, N., 2013. Cave aerosols: distribution and contribution to speleothem geochemistry. Quaternary Sci. Rev. 63, 23-41.

Dreybrodt, W., 1980. Deposition of calcite from thin films of natural calcareous solutions and the growth of speleothems. Chem. Geol. 29, 89-105. 
Dreybrodt, W., 1988. Processes in karst systems - physics, chemistry and geology. Springer, Berlin, New York.

Dreybrodt, W., 1999. Chemical kinetics, speleothem growth and climate. Boreas 28, 347-356.

Dreybrodt, W., Deininger, M., 2014. The impact of evaporation to the isotope composition of DIC in calcite precipitating water films in equilibrium and kinetic fractionation models. Geochim. Cosmochim. Acta 125, 433-439.

Duan, F.C., Wu, J.Y., Wang, Y.J., Edwards, R.L., Cheng, H., Kong, X.G., Zhang, W.H., 2015. A 3000-yr

1719 annually laminated stalagmite record of the Last Glacial Maximum from Hulu Cave, China. Quaternary Res. 83, 360-369.

1721 Duan, W., Ruan, J., Luo, W., Li, T., Tian, L., Zeng, G., Zhang, D., Bai, Y., Li, J., Tao, T., Zhang, P., Baker, A., Tan, M., 2016. The transfer of seasonal isotopic variability between precipitation and drip water at eight caves in the monsoon regions of China. Geochim. Cosmochim. Acta 183, 250-266. precise measurement of time over the past 500,000 years. Earth Planet. Sci. Lett. 81, 175-192. temperature scale. Bulletin of the Geological Society of America 62, 417-427.

Evans, D., Müller, W., 2013. LA-ICPMS elemental imaging of complex discontinuous carbonates: An example using large benthic foraminifera. J. Anal. At. Spectrom. 28, 1039-1044. system modeling in high resolution paleoclimatology. Quaternary Science Reviews 76, 16-28. 
1734

1735

1736

1737

1738

1739

1740

1741

1742

1743

1744

1745

1746

1747

1748

1749

1750

1751

1752

1753

1754

Faimon, J., Lang, M., 2013. Variances in airflows during different ventilation modes in a dynamic Ushaped cave. Int J Speleol 42, 115-122.

Fairchild, I.J., Baker, A., 2012. Speleothem Science: From Processes to Past Environments. WileyBlackwell, Chichester, UK.

Fairchild, I.J., Baker, A., Borsato, A., Frisia, S., Hinton, R.W., McDermott, F., Tooth, A.F., 2001. Annual to sub-annual resolution of multiple trace-element trends in speleothems. J. Geol. Soc. London 158, 831-841.

Fairchild, I.J., Borsato, A., Tooth, A.F., Frisia, S., Hawkesworth, C.J., Huang, Y., McDermott, F., Spiro, B., 2000. Controls on trace element (Sr-Mg) compositions of carbonate cave waters: implications for speleothem climatic records. Chem. Geol. 166, 255-269.

Fairchild, I.J., Hartland, A., 2010. Trace element variations in stalagmites: controls by climate and by karst system processes. EMU Notes in Mineralogy 10, 259-287.

Fairchild, I.J., Smith, C.L., Baker, A., Fuller, L., Spotl, C., Mattey, D., McDermott, F., Eimp, 2006.

Modification and preservation of environmental signals in speleothems. Earth Sci. Rev. 75, 105-153.

Fairchild, I.J., Treble, P.C., 2009. Trace elements in speleothems as recorders of environmental change. Quaternary Sci. Rev. 28, 449-468.

Feng, W., Casteel, R.C., Banner, J.L., Heinze-Fry, A., 2014. Oxygen isotope variations in rainfall, dripwater and speleothem calcite from a well-ventilated cave in Texas, USA: Assessing a new speleothem temperature proxy. Geochim. Cosmochim. Acta 127, 233-250.

Feng, X., Porporato, A., Rodriguez-Iturbe, I., 2013. Changes in rainfall seasonality in the tropics. Nature Climate Change 3, 811-815. 
Fick, S.E., Hijmans, R.J., 2017. WorldClim 2: new 1-km spatial resolution climate surfaces for global land areas. Int J Climatol 37, 4302-4315.

Finch, A.A., Shaw, P.A., Weedon, G.P., Holmgren, K., 2001. Trace element variation in speleothem aragonite: potential for palaeoenvironmental reconstruction. Earth and Planetary Science Letters $186,255-267$.

Fohlmeister, J., Lechleitner, F.A., 2019. STAlagmite dating by radiocarbon (star): A software tool for reliable and fast age depth modelling. Quat Geochronol 51, 120-129.

Fohlmeister, J., Plessen, B., Dudashvili, A.S., Tjallingii, R., Wolff, C., Gafurov, A., Cheng, H., 2017. Winter precipitation changes during the Medieval Climate Anomaly and the Little Ice Age in arid Central Asia. Quaternary Sci. Rev. 178, 24-36.

Frappier, A.B., Sahagian, D., Carpenter, S.J., González, L.A., Frappier, B.R., 2007. Stalagmite stable isotope record of recent tropical cyclone events. Geology 35.

Frick, D.A., Schuessler, J.A., von Blanckenburg, F., 2016. Development of routines for simultaneous in situ chemical composition and stable Si isotope ratio analysis by femtosecond laser ablation inductively coupled plasma mass spectrometry. Analytica Chimica Acta 938, 33-43.

Frisia, S., 2015. Microstratigraphic logging of calcite fabrics in speleothems as tool for palaeoclimate studies. Int J Speleol 44, 1-16.

Frisia, S., Borsato, A., Fairchild, I.J., McDermott, F., 2000. Calcite fabrics, growth mechanisms, and environments of formation in speleothems from the Italian Alps and southwestern Ireland. J Sediment Res 70, 1183-1196.

Frisia, S., Borsato, A., Fairchild, I.J., Susini, J., 2005. Variations in atmospheric sulphate recorded in stalagmites by synchrotron micro-XU and XANES analyses. Earth Planet. Sci. Lett. 235, 729-740. 
Frisia, S., Borsato, A., Hellstrom, J., 2018. High spatial resolution investigation of nucleation, growth and early diagenesis in speleothems as exemplar for sedimentary carbonates. Earth Sci. Rev. 178, 6891.

Frisia, S., Borsato, A., Susini, J., 2008. Synchrotron radiation applications to past volcanism archived in speleothems: An overview. J. Volcanol. Geotherm. Res. 177, 96-100.

Gascoyne, M., Schwarcz, H.P., Ford, D.C., 1980. A palaeotemperature record for the mid-Wisconsin in Vancouver Island. Nature 285, 474-476.

Gazis, C., Feng, X.H., 2004. A stable isotope study of soil water: evidence for mixing and preferential flow paths. Geoderma 119, 97-111.

Genty, D., 2008. Palaeoclimate research in Villars Cave (Dordogne, SW France). Int J Speleol 37, 173191.

Genty, D., Baker, A., Vokal, B., 2001. Intra- and inter-annual growth rate of modern stalagmites. Chemical Geology 176, 191-212.

Genty, D., Deflandre, G., 1998. Drip flow variations under a stalactite of the Père Noël cave (Belgium). Evidence of seasonal variations and air pressure constraints. J Hydrol 211, 208-232.

Guo, W., Zhou, C., 2019. Patterns and controls of disequilibrium isotope effects in speleothems: Insights from an isotope-enabled diffusion-reaction model and implications for quantitative thermometry. Geochimica et Cosmochimica Acta 267, 196-226.

Harmon, R.S., 1979. An isotopic study of groundwater seepage in the Central Kentucky karst. Water Resources Research 15, 476. 
Hartland, A., Fairchild, I.J., Lead, J.R., 2009. Colloids in karstic percolation waters: Implications for the interpretation of trace element variations in speleothems. Geochim. Cosmochim. Acta 73, A498A498.

Hartland, A., Fairchild, I.J., Lead, J.R., Baker, A., 2010. Fluorescent properties of organic carbon in cave dripwaters: Effects of filtration, temperature and pH. Sci. Total Environ. 408, 5940-5950.

Hartland, A., Fairchild, I.J., Lead, J.R., Borsato, A., Baker, A., Frisia, S., Baalousha, M., 2012. From soil to cave: Transport of trace metals by natural organic matter in karst dripwaters. Chem. Geol. 304, 68-82.

Hartland, A., Fairchild, I.J., Lead, J.R., Zhang, H., Baalousha, M., 2011. Size, speciation and lability of NOM-metal complexes in hyperalkaline cave dripwater. Geochim. Cosmochim. Acta 75, 7533-7551.

Hellstrom, J., 2003. Rapid and accurate U/Th dating using parallel ion-counting multi-collector ICPMS. J. Anal. At. Spectrom. 18, 1346-1351.

Helser, T.E., Kastelle, C.R., McKay, J.L., Orland, I.J., Kodzon, R., Valley, J.W., 2018. Evaluation of micromilling/conventional isotope ratio mass spectrometry and secondary ion mass spectrometry of $\delta 180$ values in fish otoliths for sclerochronology. Rapid Commun Mass Spectrom 32, 1781-1790.

Hendy, C.H., Wilson, A.T., 1968. Paleoclimatic data from speleothems. Nature 216, 48-51.

Hess, J.W., White, W.B., 1989. Water Budget and Physical Hydrology, in: B., W.W., White, E.L. (Eds.), Karst Hydrology: Concepts from the Mammoth Cave Area. Springer-Verlag, Boston, pp. 105-126.

Hoffmann, D.L., Prytulak, J., Richards, D.A., Elliott, T.R., Coath, C.D., Smart, P.L., Scholz, D., 2007. Procedures for accurate $\mathrm{U}$ and Th isotope measurements by high precision MC-ICPMS. Int. J. Mass Spectrom. Ion Processes 264, 97-109. 
Hsiang, S.M., Burke, M., Miguel, E., 2013. Quantifying the Influence of Climate on Human Conflict. Science 341,1235367

Hu, C., Henderson, G.M., Huang, J., Xie, S., Sun, Y., Johnson, K.R., 2008. Quantification of Holocene Asian monsoon rainfall from spatially separated cave records. Earth Planet. Sci. Lett. 266, 221-232.

Huang, S.P., Pollack, H.N., Shen, P.Y., 2000. Temperature trends ever the past five centuries reconstructed from borehole temperatures. Nature 403, 756-758.

Huang, Y., Fairchild, I.J., 2001. Partitioning of $\mathrm{Sr}^{2+}$ and $\mathrm{Mg}^{2+}$ into calcite under karst-analogue experimental conditions. Geochim. Cosmochim. Acta 65, 47-62.

Huang, Y., Fairchild, I.J., Borsato, A., Frisia, S., Cassidy, N.J., McDermott, F., Hawkesworth, C.J., 2001. Seasonal variations in Sr, Mg and P in modern speleothems (Grotta di Ernesto, Italy). Chem. Geol. $175,429-448$.

IAEA, 2001. GNIP Maps and Animations. , Vienna.

IAEA/WMO, 2001. Global Network of Isotopes in Precipitation. The GNIP Database.

James, E., Banner, J., Hardt, B., 2015. A global model for cave ventilation and seasonal bias in speleothem paleoclimate records.

Jamieson, R.A., Baldini, J.U.L., Brett, M.J., Taylor, J., Ridley, H.E., Ottley, C.J., Prufer, K.M., Wassenburg, J.A., Scholz, D., Breitenbach, S.F.M., 2016. Intra- and inter-annual uranium concentration variability in a Belizean stalagmite controlled by prior aragonite precipitation: A new tool for reconstructing hydro-climate using aragonitic speleothems. Geochim. Cosmochim. Acta 190, 332-346. 
Jamieson, R.A., Baldini, J.U.L., Frappier, A.B., Müller, W., 2015. Volcanic ash fall events identified using principle component analysis of a high-resolution speleothem trace element dataset. Earth and Planetary Science Letters 426, 36-45.

Johnson, K.R., Hu, C., Belshaw, N.S., Henderson, G.M., 2006. Seasonal trace-element and stableisotope variations in a Chinese speleothem: The potential for high-resolution paleomonsoon reconstruction. Earth and Planetary Science Letters 244, 394-407.

Kaufman, A., Bar-Matthews, M., Ayalon, A., Carmi, I., 2003. The vadose flow above Soreq Cave, Israel: a tritium study of the cave waters. Journal of Hydrology 273, 155-163.

Kennett, D.J., Breitenbach, S.F.M., Aquino, V.V., Asmerom, Y., Awe, J., Baldini, J.U.L., Bartlein, P., Culleton, B.J., Ebert, C., Jazwa, C., Macri, M.J., Marwan, N., Polyak, V., Prufer, K.M., Ridley, H.E., Sodemann, H., Winterhalder, B., Haug, G.H., 2012. Development and Disintegration of Maya Political Systems in Response to Climate Change. Science 338, 788-791.

Khiewtam, R.S., Ramakrishnan, P.S., 1993. Litter and fine root dynamics of a relict sacred grove forest at Cherrapunji in north-eastern India. Forest Ecology and Management 60, 327-344.

Kita, N.T., Huberty, J.M., Kozdon, R., Beard, B.L., Valley, J.W., 2011. High-precision SIMS oxygen, sulfur and iron stable isotope analyses of geological materials: accuracy, surface topography and crystal orientation. Surf. Interface Anal. 43, 427-431.

Köppen, W., 1918. Classification of climates according to temperature, precipitation and course of the year. Petermanns Mitt 64, 193-203.

Kuczumow, A., Genty, D., Chevallier, P., Nowak, J., Ro, C.U., 2003. Annual resolution analysis of a SW-France stalagmite by X-ray synchrotron microprobe analysis. Spectrochim Acta B 58, 851-865. 
Kuczumow, A., Vekemans, B., Schalm, O., Gysels, K., Ro, C.U., Van Grieken, R., 2001. Analysis of speleothems by electron and X-ray microprobes. J. Anal. At. Spectrom. 16, 90-95.

Kylander-Clark, A.R.C., Hacker, B.R., Cottle, J.M., 2013. Laser-ablation split-stream ICP petrochronology. Chemical Geology 345, 99-112.

Lachniet, M.S., 2009. Climatic and environmental controls on speleothem oxygen-isotope values. Quaternary Science Reviews 28, 412-432.

Lauritzen, S., 1995. High Resolution Paleotemperature Proxy Record for the Last Interglaciation Based on Norwegian Speleothems. Quaternary Res. 43, 133-146.

Lauritzen, S., Lundberg, J., 1999. Calibration of the speleothem delta function: an absolute temperature record for the Holocene in northern Norway. Holocene 9, 659-669.

Lechleitner, F.A., Baldini, J.U.L., Breitenbach, S.F.M., Fohlmeister, J., McIntyre, C., Goswami, B., Jamieson, R.A., van der Voort, T.S., Prufer, K., Marwan, N., Culleton, B.J., Kennett, D.J., Asmerom, Y., Polyak, V., Eglinton, T.I., 2016a. Hydrological and climatological controls on radiocarbon concentrations in a tropical stalagmite. Geochim. Cosmochim. Acta 194, 233-252.

Lechleitner, F.A., Fohlmeister, J., McIntyre, C., Baldini, L.M., Jamieson, R.A., Hercman, H., Gąsiorowski, M., Pawlak, J., Stefaniak, K., Socha, P., Eglinton, T.I., Baldini, J.U.L., 2016b. A novel approach for construction of radiocarbon-based chronologies for speleothems. Quat Geochronol 35, $54-66$.

Li, F., Vanwezer, N., Boivin, N., Gao, X., Ott, F., Petraglia, M., Roberts, P., 2019. Heading north: Late Pleistocene environments and human dispersals in central and eastern Asia. Plos One 14, e0216433.

Linzmeier, B.J., Kitajima, K., Denny, A.C., Cammack, J.N., 2018. Making maps on a micrometer scale. Eos 99. 

between the East Asian monsoon and North Atlantic climate during the 8,200 year event. Nat. Geosci. 6, 117-120.

Luetscher, M., Boch, R., Sodemann, H., Spotl, C., Cheng, H., Edwards, R.L., Frisia, S., Hof, F., Müller, W., 2015. North Atlantic storm track changes during the Last Glacial Maximum recorded by Alpine speleothems. Nat Commun 6, 6344.

Luo, T., Hu, Z., Zhang, W., Günther, D., Liu, Y., Zong, K., Hu, S., 2018. Reassessment of the influence 1888 of carrier gases He and Ar on signal intensities in $193 \mathrm{~nm}$ excimer LA-ICP-MS analysis. Journal of Analytical Atomic Spectrometry 33, 1655-1663.

Luo, W., Wang, S., Zeng, G., Zhu, X., Liu, W., 2014. Daily response of drip water isotopes to precipitation in Liangfeng Cave, Guizhou Province, SW China. Quaternary International 349, 153-158.

Markowska, M., Baker, A., Andersen, M.S., Jex, C.N., Cuthbert, M.O., Rau, G.C., Graham, P.W.,

Evaporation and hydrological controls on delta 0-18 drip water composition and implications for speleothem paleoclimate reconstructions. Quaternary Sci. Rev. 131, 285-301. 2015. Unsaturated zone hydrology and cave drip discharge water response: Implications for speleothem paleoclimate record variability. J Hydrol 529, 662-675. 14C bomb-pulse in young speleothems using a soil carbon continuum model. Geochim. Cosmochim. 
1902

1903

1904

1905

1906

1907

1908

1909

1910

1911

1912

1913

1914

1915

1916

1917

1918

1919

1920

1921

1922

Martin-Chivelet, J., Munoz-Garcia, M.B., Edwards, R.L., Turrero, M.J., Ortega, A.I., 2011. Land surface temperature changes in Northern Iberia since 4000 yr BP, based on delta C-13 of speleothems.

Global and Planet. Change 77, 1-12.

Martin-Garcia, R., Alonso-Zarza, A.M., Martin-Perez, A., Schroder-Ritzrau, A., Ludwig, T., 2014.

Relationships between colour and diagenesis in the aragonite-calcite speleothems in Basajaun Etxea cave, Spain. Sediment Geol 312, 63-75.

Mattey, D., Collister, C., 2008. Controls on water drop volume at speleothem drip sites: An experimental study. J Hydrol 358, 259-267.

Mattey, D., Lowry, D., Duffet, J., Fisher, R., Hodge, E., Frisia, S., 2008. A 53 year seasonally resolved oxygen and carbon isotope record from a modem Gibraltar speleothem: Reconstructed drip water and relationship to local precipitation. Earth Planet. Sci. Lett. 269, 80-95.

Mattey, D.P., Atkinson, T.C., Barker, J.A., Fisher, R., Latin, J.P., Durell, R., Ainsworth, M., 2016. Carbon dioxide, ground air and carbon cycling in Gibraltar karst. Geochim. Cosmochim. Acta 184, 88-113.

Mattey, D.P., Fairchild, I.J., Atkinson, T.C., 2009. Seasonal microclimate control on calcite fabrics, stable isotopes and trace elements in modern speleothem from St. Michaels Cave, Gibraltar. Geochim. Cosmochim. Acta 73, A849-A849.

Mattey, D.P., Fairchild, I.J., Atkinson, T.C., Latin, J.-P., Ainsworth, M., Durell, R., 2010. Seasonal microclimate control of calcite fabrics, stable isotopes and trace elements in modern speleothem from St Michaels cave, Gibraltar in: Pedley, H.M., Rogerson, M. (Eds.), Tufas and Speleothems: Unravelling the Microbial and Physical Controls. Geological Society of London Special Publication, London, pp. 323-344. 
1923

1924

1925

1926

1927

1928

1929

1930

1931

1932

1933

1934

1935

1936

1937

1938

1939

1940

1941

1942

Maupin, C.R., Partin, J.W., Shen, C.C., Quinn, T.M., Lin, K., Taylor, F.W., Banner, J.L., Thirumalai, K., Sinclair, D.J., 2014. Persistent decadal-scale rainfall variability in the tropical South Pacific

Convergence Zone through the past six centuries. Clim Past 10, 1319-1332.

McDermott, F., 2004. Palaeo-climate reconstruction from stable isotope variations in speleothems: a review. Quaternary Sci. Rev. 23, 901-918.

McDermott, F., Atkinson, T.C., Fairchild, I.J., Baldini, L.M., Mattey, D.P., 2011. A first evaluation of the spatial gradients in delta 0-18 recorded by European Holocene speleothems. Global and Planet. Change 79, 275-287.

McMillan, E.A., Fairchild, I.J., Frisia, S., Borsato, A., McDermott, F., 2005. Annual trace element cycles in calcite-aragonite speleothems: evidence of drought in the western Mediterranean 1200-1100 yr BP. J. of Quaternary Sci. 20, 423-433.

Menne, M.J., Durre, I., Vose, R.S., Gleason, B.E., Houston, T.G., 2012. An Overview of the Global Historical Climatology Network-Daily Database. J Atmos Ocean Tech 29, 897-910.

Mickler, P.J., Stern, L.A., Banner, J.L., 2006. Large kinetic isotope effects in modern speleothems. Geol. Soc. Am. Bull. 118, 65-81.

Millo, C., Strikis, N.M., Vonhof, H.B., Deininger, M., da Cruz, F.W., Wang, X.F., Cheng, H., Edwards, R.L., 2017. Last glacial and Holocene stable isotope record of fossil dripwater from subtropical Brazil based on analysis of fluid inclusions in stalagmites. Chem. Geol. 468, 84-96.

Mischel, S.A., Scholz, D., Spötl, C., 2015. $\delta 180$ values of cave drip water: a promising proxy for the reconstruction of the North Atlantic Oscillation? Climate Dynamics 45, 3035-3050. 

variability by vadose water mixing. Geophys Res Lett 41, 7907-7915.

Moquet, J.S., Cruz, F.W., Novello, V.F., Strikis, N.M., Deininger, M., Karmann, I., Santos, R.V., Millo,

Calibration of speleothem delta 0-18 records against hydroclimate instrumental records in Central

Morellón, M., Valero-Garcés, B., Vegas-Villarrúbia, T., González-Sampériz, P., Romero, O., DelgadoHellstrom, J., Edwards, R.L., Cheng, H., 2017. New speleothem data from Molinos and Ejulve caves reveal Holocene hydrological variability in northeast Iberia. Quaternary Research 88, 223-233. López-Moreno, J.I., Cacho, I., 2014. Climate controls on rainfall isotopes and their effects on cave 1959 drip water and speleothem growth: the case of Molinos cave (Teruel, NE Spain). Climate Dynamics 1960 43, 221-241.

1962 interstadial/stadial climate change recorded in two stalagmites from the north European Alps.

1963 Quaternary Science Reviews 127, 229-239.

1964 Müller, W., Fietzke, J., 2016. The role of LA-ICP-MS in palaeoclimate research. Elements 12, 329-334. 
Müller, W., Shelley, M., Miller, P., Broude, S., 2009. Initial performance metrics of a new customdesigned ArF excimer LA-ICPMS system coupled to a two-volume laser-ablation cell. J. Anal. At. Spectrom. 24, 209-214.

Müller, W., Valley, J.W., Warter, V., Kodzon, R., Evans, D., Orland, I.J., 2015. Natural hightemperature metamorphic calcite as compositionally homogenous microanalytical standard?, Goldschmidt 2015, Prague.

Murata, F., Terao, T., Hayashi, T., Asada, H., Matsumoto, J., 2007. Relationship between atmospheric conditions at Dhaka, Bangladesh, and rainfall at Cherrapunjee, India. Natural Hazards 44, 399-410.

Myers, C.G., Oster, J.L., Sharp, W.D., Bennartz, R., Kelley, N.P., Covey, A.K., Breitenbach, S.F.M., 2015. Northeast Indian stalagmite records Pacific decadal climate change: Implications for moisture transport and drought in India. Geophysical Research Letters 42, 4124-4132.

Nagra, G., Treble, P.C., Andersen, M.S., Bajo, P., Hellstrom, J., Baker, A., 2017. Dating stalagmites in mediterranean climates using annual trace element cycles. Sci. Rep. 7, 621.

Noronha, A.L., Johnson, K.R., Southon, J.R., Hu, C., Ruan, J., McCabe-Glynn, S., 2015. Radiocarbon evidence for decomposition of aged organic matter in the vadose zone as the main source of speleothem carbon. Quaternary Sci. Rev. 127, 37-47.

O'Neil, J.R., Clayton, R.M., Mayeda, T., 1969. Oxygen isotope fractionation in divalent metal carbonates. J. Chem. Phys. 30, 5547-5558.

Oerter, E.J., Sharp, W.D., Oster, J.L., Ebeling, A., Valley, J.W., Kodzon, R., Orland, I.J., Hellstrom, J., Woodhead, J.D., Hergt, J.M., Chadwick, O.A., Amundson, R., 2016. Pedothem carbonates reveal anomalous North American atmospheric circulation 70,000-55,000 years ago. Proc Natl Acad Sci U S A $113,919-924$. 
Onac, B.P., Pace-Graczyk, K., Atudirei, V., 2008. Stable isotope study of precipitation and cave drip water in Florida (USA): implications for speleothem-based paleoclimate studies. Isot. Environ. Health Stud. $44,149-161$

Orland, I.J., Bar-Matthews, M., Ayalon, A., Matthews, A., Kozdon, R., Ushikubo, T., Valley, J.W., 2012. Seasonal resolution of Eastern Mediterranean climate change since 34 ka from a Soreq Cave speleothem. Geochimica Et Cosmochimica Acta 89, 240-255.

Orland, I.J., Bar-Matthews, M., Kita, N.T., Ayalon, A., Matthews, A., Valley, J.W., 2008. Seasonal climate change as revealed by ion microprobe analysis of delta 0-18 in Soreq Cave (Israel) speleothems. Geochimica Et Cosmochimica Acta 72, A709-A709.

Orland, I.J., Bar-Matthews, M., Kita, N.T., Ayalon, A., Matthews, A., Valley, J.W., 2009. Climate deterioration in the Eastern Mediterranean as revealed by ion microprobe analysis of a speleothem that grew from 2.2 to 0.9 ka in Soreq Cave, Israel. Quaternary Res. 71, 27-35.

Orland, I.J., Burstyn, Y., Bar-Matthews, M., Kozdon, R., Ayalon, A., Matthews, A., Valley, J.W., 2014. Seasonal climate signals (1990-2008) in a modern Soreq Cave stalagmite as revealed by highresolution geochemical analysis. Chem. Geol. 363, 322-333.

Orland, I.J., Edwards, R.L., Cheng, H., Kozdon, R., Cross, M., Valley, J.W., 2015. Direct measurements of deglacial monsoon strength in a Chinese stalagmite. Geology 43, 555-558.

Orland, I.J., He, F., Bar-Matthews, M., Chen, G., Ayalon, A., Kutzbach, J.E., 2019. Resolving seasonal rainfall changes in the Middle East during the last interglacial period. Proc Natl Acad Sci U S A 116, 24985-24990.

Orr, P.C., 1952. Excavations in Moaning Cave. Santa Barbara Museum of Natural History Bulletin 1, 119. 
Ortega, R., Maire, R., Deves, G., Quinif, Y., 2005. High-resolution mapping of uranium and other trace elements in recrystallized aragonite-calcite speleothems from caves in the Pyrenees (France):

2011 Implications for U-series dating. Earth Planet. Sci. Lett. 237, 911-023.

Oster, J.L., Montañez, I.P., Kelley, N.P., 2012. Response of a modern cave system to large seasonal precipitation variability. Geochim. Cosmochim. Acta 91, 92-108.

Pacton, M., Breitenbach, S.F.M., Lechleitner, F.A., Vaks, A., Rollion-Bard, C., Gutareva, O.S., Osintcev, 2015 A.V., Vasconcelos, C., 2013. The role of microorganisms in the formation of a stalactite in Botovskaya Cave, Siberia - paleoenvironmental implications. Biogeosciences 10, 6115-6130.

2017

Parton, A., Farrant, A.R., Leng, M.J., Telfer, M.W., Groucutt, H.S., Petraglia, M.D., Parker, A.G., 2015.

2018 Alluvial fan records from southeast Arabia reveal multiple windows for human dispersal. Geol. 43, 295-298.

2020 Peel, M.C., Finlayson, B.L., MCMahon, T.A., 2007. Updated world map of the Köppen-Geiger climate classification. Hydrology and Earth System Sciences 11, 1633-1644.

2022

Perrin, J., Jeannin, P.-Y., Zwahlen, F., 2003. Epikarst storage in a karst aquifer: a conceptual model

2023 based on isotopic data, Milandre test site, Switzerland. Journal of Hydrology 279, 106-124.

2024 Prokop, P., Walanus, A., 2003. Trends and periodicity in the longest instrumental rainfall series for the area of most extreme rainfall in the world, northeast India. Geographia Polonica 76, 25-35. and oxygen isotope variation in modern calcite precipitation in a subtropical cave, Southwest China. Journal of Asian Earth Sciences 119, 167-178. 
2029

2030

2031

2032

2033

2034

2035

2036

2037

2038

2039

2040

2041

2042

2043

2044

2045

2046

2047

Railsback, L.B., Brook, G.A., Chen, J., Kalin, R., Fleisher, C., 1994. Environmental controls on the petrology of a late Holocene speleothem from Botswana with annual layers of aragonite and calcite. J Sediment Res A64, 147-155.

Railsback, L.B., Liang, F.Y., Romani, J.R.V., Grandal-d'Anglade, A., Rodriguez, M.V., Fidalgo, L.S., Mosquera, D.F., Cheng, H., Edwards, R.L., 2011. Petrographic and isotopic evidence for Holocene long-term climate change and shorter-term environmental shifts from a stalagmite from the Serra do Courel of northwestern Spain, and implications for climatic history across Europe and the Mediterranean. Palaeogeography Palaeoc. 305, 172-184.

Railsback, L.B., Liang, F.Y., Vidal-Romani, J.R., Garrett, K.B., Sellers, R.C., Vaqueiro-Rodriguez, M., Grandal-d'Anglade, A., Cheng, H., Edwards, R.L., 2017. Radiometric, isotopic, and petrographic evidence of changing interglacials over the past 550,000 years from six stalagmites from the Serra do Courel in the Cordillera Cantabrica of northwestern Spain. Palaeogeography Palaeoc. 466, 137-152.

Ramakrishnan, P.S., Subhash, C.R., 1988. Vegetation, biomass and productivity of seral grasslands of Cherrapunji in north-east India. Vegetatio 74, 47-53.

Ridley, H., Baldini, J., Prufer, K., Walczak, I., Breitenbach, S., 2015a. High-resolution monitoring of Yok Balum Cave, Belize: An investigation of seasonal ventilation regimes and the atmospheric and dripflow response to a local earthquake. Journal of Cave and Karst Studies 77, 183-199.

Ridley, H.E., Asmerom, Y., Baldini, J.U.L., Breitenbach, S.F.M., Aquino, V.V., Prufer, K.M., Culleton, B.J., Polyak, V., Lechleitner, F.A., Kennett, D.J., Zhang, M., Marwan, N., Macpherson, C.G., Baldini, L.M., Xiao, T., Peterkin, J.L., Awe, J., Haug, G.H., 2015b. Aerosol forcing of the position of the intertropical convergence zone since AD1550. Nat. Geosci. 8, 195-200.

Riechelmann, D.F.C., Deininger, M., Scholz, D., Riechelmann, S., Schroder-Ritzrau, A., Spotl, C., Richter, D.K., Mangini, A., Immenhauser, A., 2013. Disequilibrium carbon and oxygen isotope 
2064

2065

2066

2067

2068

2069

2070

2071

fractionation in recent cave calcite: Comparison of cave precipitates and model data. Geochim. Cosmochim. Acta 103, 232-244.

Riechelmann, D.F.C., Schroder-Ritzrau, A., Scholz, D., Fohlmeister, J., Spotl, C., Richter, D.K., Mangini, A., 2011. Monitoring Bunker Cave (NW Germany): A prerequisite to interpret geochemical proxy data of speleothems from this site. J Hydrol 409, 682-695.

Riechelmann, S., Breitenbach, S.F.M., Schroder-Ritzrau, A., Mangini, A., Immenhauser, A., 2019. Ventilation and Cave Air PCO2 in the Bunker-Emst Cave System (NW Germany): Implications for Speleothem Proxy Data. J Cave Karst Stud 81, 98-112.

Riechelmann, S., Schröder-Ritzrau, A., Spötl, C., Riechelmann, D.F.C., Richter, D.K., Mangini, A., Frank, N., Breitenbach, S.F.M., Immenhauser, A., 2017. Sensitivity of Bunker Cave to climatic forcings highlighted through multi-annual monitoring of rain-, soil-, and dripwaters. Chemical Geology 449, 194-205.

Rittner, M., Müller, W., 2012. 2D mapping of LA-ICPMS trace element distributions using R. Computers \& Geosciences 42, 152-161.

Roberts, M.S., Smart, P.L., Baker, A., 1998. Annual trace element variations in a Holocene speleothem. Earth Planet. Sci. Lett. 154, 237-246.

Ronay, E.R., Breitenbach, S.F.M., Oster, J.L., 2019. Sensitivity of speleothem records in the Indian Summer Monsoon region to dry season infiltration. Sci Rep 9, 5091.

Sade, Z., Halevy, I., 2017. New constraints on kinetic isotope effects during CO2(aq) hydration and hydroxylation: Revisiting theoretical and experimental data. Geochim. Cosmochim. Acta 214, 246265. 
2073

2074

2075

2076

2077

2078

2079

2080

2081

2082

2083

2084

2085

2086

2087

2088

2089

2090

2091

2092

2093

2094

Santer, B.D., Po-Chedley, S., Zelinka, M.D., Cvijanovic, I., Bonfils, C., Durack, P.J., Fu, Q., Kiehl, J., Mears, C., Painter, J., Pallotta, G., Solomon, S., Wentz, F.J., Zou, C.-Z., 2018. Human influence on the seasonal cycle of tropospheric temperature. Science 361, eaas8806.

Schubert, B.A., Jahren, A.H., 2015. Seasonal temperature and precipitation recorded in the intraannual oxygen isotope pattern of meteoric water and tree-ring cellulose. Quaternary Science Reviews 125, 1-14.

Schwarz, K., Barth, J.A.C., Postigo-Rebollo, C., Grathwohl, P., 2009. Mixing and transport of water in a karst catchment: a case study from precipitation via seepage to the spring. Hydrology and Earth System Sciences 13, 285-292.

Scroxton, N., Burns, S.J., Dawson, P., Rhodes, J.M., Brent, K., McGee, D., Heijnis, H., Gadd, P., Hantoro, W., Gagan, M., 2018. Rapid measurement of strontium in speleothems using core-scanning micro X-ray fluorescence. Chemical Geology 487, 12-22.

Shen, C.C., Lin, K., Duan, W., Jiang, X., Partin, J.W., Edwards, R.L., Cheng, H., Tan, M., 2013. Testing the annual nature of speleothem banding. Sci Rep 3, 2633.

Sherwin, C.M., Baldini, J.U.L., 2011. Cave air and hydrological controls on prior calcite precipitation and stalagmite growth rates: Implications for palaeoclimate reconstructions using speleothems. Geochim. Cosmochim. Acta 75, 3915-3929.

Shopov, Y.Y., Ford, D.C., Schwarcz, H.P., 1994. Luminescent microbanding in speleothems - highresolution chronology and paleoclimate. Geol. 22, 407-410.

Sliwinski, M.G., Kitajima, K., Kodzon, R., Spicuzza, M., Denny, A., Valley, J.W., 2017. In situ $\delta 13 C$ and $\delta 180$ microanalysis by SIMS: A method for characterizing the carbonate components of natural and engineered CO2-reservoirs. International Journal of Greenhouse Gas Control 57, 116-133. 
Sliwinski, M.G., Kodzon, R., Kitajima, K., Denny, A., Spicuzza, M., Valley, J.W., 2015. In-Situ, MicronScale $\delta 13 C \& \delta 180$ Analyses (by SIMS) of Chemo-Isotopically Zoned Carbonate Cements of Diagenetic Origin-A Case Study on the Implications for the Thermal and Burial History of the Eau Claire Fm., Illinois Basin (USA). AAPG Annual Convention and Exhibition.

Smart, P.L., Friedrich, H., 1987. Water movement and storage in the unsaturated zone of a maturely karstified aquifer, Mendip Hills, England, The conference on environmental problems in karst terrains and their solution. National Water Well Association, Bowling Green, Kentucky, pp. 57-87.

Smith, C.L., Fairchild, I.J., Spotl, C., Frisia, S., Borsato, A., Moreton, S.G., Wynn, P.M., 2009.

Chronology building using objective identification of annual signals in trace element profiles of stalagmites. Quat Geochronol 4, 11-21.

Spengler, R.N., 2019. Fruit from the Sands: The Silk Road Origins of the Foods We Eat, 1 ed. University of California Press, Oakland, California.

Spötl, C., Fairchild, I.J., Tooth, A.F., 2005. Cave air control on dripwater geochemistry, Obir Caves (Austria): implications for speleothem deposition in dynamically ventilated caves. Geochim. Cosmochim. Acta 69, 2451-2468.

Spötl, C., Mattey, D., 2006. Stable isotope microsampling of speleothems for palaeoenvironmental studies: A comparison of microdrill, micromill and laser ablation techniques. Chem. Geol. 235, 48-58.

Stoll, H., Mendez-Vicente, A., Gonzalez-Lemos, S., Moreno, A., Cacho, I., Cheng, H., Edwards, R.L., 2015. Interpretation of orbital scale variability in mid-latitude speleothem $\delta 180$ : Significance of growth rate controlled kinetic fractionation effects. Quaternary Science Reviews 127, 215-228.

Stoll, H.M., Müller, W., Prieto, M., 2012. I-STAL, a model for interpretation of Mg/Ca, Sr/Ca and $\mathrm{Ba} / \mathrm{Ca}$ variations in speleothems and its forward and inverse application on seasonal to millennial scales. Geochemistry Geophysics Geosystems 13, 09004. 
Surić, M., Lončarić, R., Lončar, N., Buzjak, N., Bajo, P., Drysdale, R.N., 2017. Isotopic characterization of cave environments at varying altitudes on the eastern Adriatic coast (Croatia) - Implications for future speleothem-based studies. Journal of Hydrology 545, 367-380.

Tabersky, D., Nishiguchi, K., Utani, K., Ohata, M., Dietiker, R., Fricker, M.B., de Maddalena, I.M., Koch, J., Gunther, D., 2013. Aerosol entrainment and a large-capacity gas exchange device (Q-GED) for laser ablation inductively coupled plasma mass spectrometry in atmospheric pressure air. J. Anal. At. Spectrom. 28, 831-842.

Tadros, C.V., Treble, P.C., Baker, A., Fairchild, I., Hankin, S., Roach, R., Markowska, M., McDonald, J., 2016. ENSO-cave drip water hydrochemical relationship: a 7-year dataset from south-eastern Australia. Hydrology and Earth System Sciences 20, 4625-4640.

Tan, M., Baker, A., Genty, D., Smith, C., Esper, J., Cai, B.G., 2006. Applications of stalagmite laminae to paleoclimate reconstructions: Comparison with dendrochronology/climatology. Quaternary Sci. Rev. 25, 2103-2117.

Taylor, W., Shnaider, S., Abdykanova, A., Fages, A., Welker, F., Irmer, F., Seguin-Orlando, A., Khan, N., Douka, K., Kolobova, K., Orlando, L., Krivoshapkin, A., Boivin, N., 2018. Early pastoral economies along the Ancient Silk Road: Biomolecular evidence from the Alay Valley, Kyrgyzstan. Plos One 13, e0205646.

Thompson, G.M., Lumsden, D.N., Walker, R.L., Carter, J.A., 1975. Uranium series dating of stalagmites from Blanchard Springs Caverns, U.S.A. Geochim. Cosmochim. Acta 39, 1211-1218.

Treble, P., Shelley, J.M.G., Chappell, J., 2003. Comparison of high resolution sub-annual records of trace elements in a modern (1911-1992) speleothem with instrumental climate data from southwest Australia. Earth Planet. Sci. Lett. 216, 141-153. 

of seasonal $\delta^{18} \mathrm{O}$ variations and analysis of isotopic trends in a modem speleothem from southwest Australia. Earth Planet. Sci. Lett. 233, 17-32. trace element mapping and scanning electron microscopy of annual layers. Geochim. Cosmochim. Acta 69, 4855-4863. Wang, Y.J., 2007. High resolution Secondary Ionisation Mass Spectrometry (SIMS) delta O-18 analyses of Hulu Cave speleothem at the time of Heinrich Event 1. Chem. Geol. 238, 197-212. calibration of $\delta^{18} \mathrm{O}$ and $\delta^{13} \mathrm{C}$ paleoclimate proxies in a continuously-monitored natural cave system.

2154 Geochim. Cosmochim. Acta 75, 4929-4950. course: secondary ion mass spectrometry in the earth sciences, pp. 19-63.

Vanghi, V., Borsato, A., Frisia, S., Howard, D., Gloy, G., Hellstrom, J., Bajo, P., 2019. High-resolution synchrotron X-ray fluorescence investigation of calcite coralloid speleothems: Elemental incorporation and their potential as environmental archives. Sedimentology 66, 2661-2685.

2160 Verheyden, S., Genty, D., Deflandre, G., Quinif, Y., Keppens, E., 2008. Monitoring climatological, 2161 hydrological and geochemical parameters in the Pere Noel cave (Belgium): implication for the 2162 interpretation of speleothem isotopic and geochemical time-series. Int J Speleol 37, 221-234. 
Vonhof, H.B., van Breukelen, M.R., Postma, O., Rowe, P.J., Atkinson, T.C., Kroon, D., 2006. A

continuous-flow crushing device for on-line delta $\mathrm{H}-2$ analysis of fluid inclusion water in

2165 speleothems. Rapid Commun. Mass Spectrom. 20, 2553-2558.

2166

Waite, A.J., Swart, P.K., 2015. The inversion of aragonite to calcite during the sampling of skeletal

2167 archives: Implications for proxy interpretation. Rapid Commun Mass Spectrom 29, 955-964.

Walczak, I.W., 2016. Holocene climate variability revealed using geochemistry and Computed Tomography scanning of stalagmites from the North Atlantic Basin, Earth Sciences. Durham University, Durham, p. 199.

Walczak, I.W., Baldini, J.U.L., Baldini, L.M., McDermott, F., Marsden, S., Standish, C.D., Richards, D.A.,

Andreo, B., Slater, J., 2015. Reconstructing high-resolution climate using CT scanning of unsectioned

2173 stalagmites: A case study identifying the mid-Holocene onset of the Mediterranean climate in southern Iberia. Quaternary Sci. Rev. 127, 117-128.

S., 2019a. Speleothem biomarker evidence for a negative terrestrial feedback on climate during Holocene warm periods. Earth Planet. Sci. Lett. 525, 115754. A., 2019b. Hydroclimatic variability in Southeast Asia over the past two millennia. Earth Planet. Sci. Lett. 525, 115737. 

$2345-2348$.

Webb, M., Dredge, J., Barker, P.A., Müller, W., Jex, C., Desmarchelier, J., Hellstrom, J., Wynn, P.M., 2014. Quaternary climatic instability in south-east Australia from a multi-proxy speleothem record. J. of Quaternary Sci. 29, 589-596.

2190

Welte, C., Wacker, L., Hattendorf, B., Christl, M., FohImeister, J., Breitenbach, S.F.M., Robinson, L.F., at High Spatial Resolution. Anal. Chem. 88, 8570-8576. GGR Biennial Critical Review: Analytical Developments Since 2010. Geostandards and Geoanalytical Research 36, 337-398.

Wong, C.I., Banner, J.L., Musgrove, M., 2011. Seasonal dripwater Mg/Ca and Sr/Ca variations driven by cave ventilation: Implications for and modeling of speleothem paleoclimate records. Geochimica et Cosmochimica Acta 75, 3514-3529.

Wong, C.I., Breecker, D.O., 2015. Advancements in the use of speleothems as climate archives. Quaternary Science Reviews 127, 1-18. 
Woodhead, J.D., Horstwood, M.S.A., Cottle, J.M., 2016. Advances in isotope ratio determination by

2207

LA-ICP-MS. Elements 12, 317-322.

2208

Wortham, B.E., Montanez, I.P., Rowland, D.J., Lerche, M., Browning, A., 2019. Mapping Fluid-Filled

2209 Inclusions in Stalagmites Using Coupled X-Ray and Neutron Computed Tomography: Potential as a

2210 Water Excess Proxy. Geochemistry Geophysics Geosystems 20, 2647-2656.

2211

Wu, X., Zhu, X., Pan, M., Zhang, M., 2014. Seasonal variability of oxygen and hydrogen stable

2212 isotopes in precipitation and cave drip water at Guilin, southwest China. Environmental Earth

2213 Sciences 72, 3183-3191.

2214

Wycech, J.B., Kelly, D.C., Kozdon, R., Orland, I.J., Spero, H.J., Valley, J.W., 2018. Comparison of $\delta 180$

2215 analyses on individual planktic foraminifer (Orbulina universa) shells by SIMS and gas-source mass

2216 spectrometry. Chemical Geology 483, 119-130.

2217

Wynn, P.M., Fairchild, I.J., Borsato, A., Spotl, C., Hartland, A., Baker, A., Frisia, S., Baldini, J.U.L., 2018.

2218

Sulphate partitioning into calcite: Experimental verification of $\mathrm{pH}$ control and application to

2219 seasonality in speleothems. Geochim. Cosmochim. Acta 226, 69-83.

2220

Wynn, P.M., Fairchild, I.J., Frisia, S., Spotl, C., Baker, A., Borsato, A., EIMF, 2010. High-resolution

2221 sulphur isotope analysis of speleothem carbonate by secondary ionisation mass spectrometry.

2222 Chem. Geol. 271, 101-107.

2223

Wynn, P.M., Fairchild, I.J., Spotl, C., Hartland, A., Mattey, D., Fayard, B., Cotte, M., 2014. Synchrotron X-ray distinction of seasonal hydrological and temperature patterns in speleothem carbonate. Environ Chem 11, 28-36. Chemical Geology 58, 97-105. 
Zeng, G., Luo, W., Wang, S., Du, X., 2015. Hydrogeochemical and climatic interpretations of isotopic signals from precipitation to drip waters in Liangfeng Cave, Guizhou Province, China. Environmental Earth Sciences 74, 1509-1519.

\section{Figure Captions:}

Figure 1: Top Panel: Resolution of speleothem isotope records over time, compiled from the SISALv1b database. Individual record resolution (small black circles) and mean resolution of all available (black bars) and Holocene (blue bars) records published in a given year. Bottom panel: Total number of stalagmite records identified (grey bars), total number of stalagmite records in SISALv1b (black bars), and total number of Holocene records in SISALv1b (blue bars).

Figure 2: Illustration of different drip responses from Yok Balum Cave, Belize, over approximately two months as captured by a series of automated drip loggers. Two clear rain events and the subsequent drip responses are indicated by the vertical dashed red lines.

Rainfall amount is recorded directly over the cave site using a tipping bucket rain gauge. Techniques are discussed in more detail in (Ridley et al., 2015a).

Figure 3: A new drip categorisation scheme designed to emphasise cave drip seasonality. The scheme does not use classification boundaries as such, but instead uses the data distribution to understand the hydrology. The scheme uses descriptors that map onto established drip terminology (see Panels B-D and main text for examples). A) Minimum and maximum hourly drip rates extracted for every month of record for numerous cave drips globally. The dashed line represents the 1:1 line, and all data points must necessarily plot 
over this (i.e., the minimum drip rate cannot exceed the maximum drip rate for any given

2251

2252

2253

2254

2255

2256

2257

2258

2259

2260

2261

2262

2263

2264

2265

2266

2267

2268

2269

2270

2271

2272

month). The closer a point plots to the dashed line, the lower the difference between

monthly maximum and minimum values for that point; if a point sits on the line the

minimum and maximum values for that month are identical. Panels B-D illustrate some common drip types (using synthetic data) and their pattern when plotted on this diagram.

Panels B-D are schematic and are not based on actual collected datasets; the symbols used are arbitrary and are not linked to the symbols used in Panel A.

Figure 4: The simulated effects of sampling resolution on the climate signal extracted from a stalagmite. The stalagmite data are from stalagmite YOK-G (Yok Balum Cave, Belize), which was originally sampled with a micromill at a 100 micron $(0.1 \mathrm{~mm})$ step size (Ridley et al., 2015b). The chronology for the stalagmite is precise at the seasonal scale. The rainfall data (bottom panel) are from the Punta Gorda meteorological station ( $30 \mathrm{~km}$ to the southeast of the cave site).

Figure 5: Schematic of a sampling scheme for achieving 50 micron spatial resolution. Plan view of a stalagmite surface with $1 \mathrm{~mm}$ conventional holes on the right and trenches cut for low and high resolution. The red trench was milled with a $0.8 \mathrm{~mm}$ diameter drill and the (blueshaded) higher resolution trench was cut laterally, with each sample integrating $50 \mu \mathrm{m}$. The red corners highlight the area that is incorporated into subsequent steps, which in this case includes material from the current and the previous sample. In this example each highresolution sample (e.g., yellow shaded area) integrates a minimal amount of powder of an older sample (because the milling direction is upward).

Figure 6: Several examples of output generated by different geochemical-based techniques for extracting seasonal climate. A) Variability in sulphate in speleothem calcite (Obi84, Obir 
cave, Austria) as determined by SR- $\mu$ XRF (Wynn et al., 2014). The clear annual sulphur maxima are evident as brighter green colours. B) lon microprobe-resolved strontium and phosphorous cycles apparent in stalagmite CC3 from Crag Cave, southwestern Ireland (Baldini et al., 2002). The well-developed cycles illustrate stronger seasonality at the time of deposition ( $8.336 \mathrm{ka}$ BP) than currently present. C) Annual UV-luminescent banding in a stalagmite from Shihua Cave, Beijing, China (adapted from Tan et al. (2006)). D) well-develop carbon isotope ratio cycles in stalagmite YOK-G from Yok Balum Cave, Belize, constructed using data obtained via micromilling at a 100-micron spatial resolution and analyses of powders on an IRMS (Ridley et al., 2015b) (see also Figure 4). E) Mg cycles apparent in stalagmite BER-SWI-13 from Leamington Cave, Bermuda, resolved using LA-ICPMS-derived Mg data (Walczak, 2016). All panels show three to four cycles, interpreted as annual.

Figure 7: A synthetic rainfall input signal (orange circles) with an annual temperature range of $15{ }^{\circ} \mathrm{C}$ compared with two mean model outputs, one derived using an annual temperature range of $10 \pm 6{ }^{\circ} \mathrm{C}$ (grey line), and another derived using an annual temperature range of $15 \pm$ $6{ }^{\circ} \mathrm{C}$ (blue line). At the beginning of the simulated rainfall input signal record (year $=0$ ), April is the wettest month and November the driest month, but this shifts in polarity slowly through the record, moving through a brief phase with no seasonality in rainfall (year $=7$ ), and then transitioning into a phase where April is the driest month (from year $=8$ ). The vertical gridlines highlight the month of April during every model year. The simulated rainfall input signal amplitude and polarity is reproduced by the model very satisfactorily, provided that the model temperature range is realistic, as it is in Model 2. Note that the polarity of the simulated rainfall input signal is still reproduced by Model 1 , but modelled rainfall seasonal amplitude is too large in order to compensate for the low amplitude of the modelled temperature range. 
Figure 8: Temperature (top panel) and rainfall (bottom panel) modelling results (black dashed lines) against 'noisy' synthetic input datasets (solid coloured lines) for seven model years. The grey rectangle highlights one model year (Year 4) where the input rainfall signal polarity was reversed; the model detects this shift. The modelling results presented are the mean values of all successful model runs for each timeslice.

Figure 9: Mean modelled monthly temperature and rainfall data against Global Historical

Climate Network (GHCN) and tree ring data. A) Stalagmite Keklik1 oxygen isotope ratio data from Bir-Uja Cave, Kyrgyzstan (input data) (Fohlmeister et al., 2017). B) Centennial-scale borehole temperature data from the Tian Shan region (Huang et al., 2000) from 1500 to 2000 C.E. (input data, shifted upwards for clarity) (blue diamonds), modelled July temperature (black curve) (output), and NTREND summer temperature reconstruction for Asia Grid 2 (AG2) (red curve) (Cook et al., 2013). C) Modelled January rainfall (black curve) (output) and GHCN January rainfall for Tashkent (orange curve), both in $\%$ of total annual rainfall. The grey rectangles highlight the years 1797 and 1815 C.E. discussed in the text.

Figure 10: Global seasonality in annual temperature $\left({ }^{\circ} \mathrm{C}\right)$ and annual precipitation $\left.(\mathrm{mm}) . \mathrm{A}\right)$

The annual temperature range was calculated as the maximum temperature of the warmest month minus the minimum temperature of the coldest month averaged over the period 1970-2000. B) Precipitation seasonality was calculated as the precipitation amount of the wettest month minus the precipitation amount of the driest month averaged over the period 1970-2000. WorldClim Version 2 data (https://www.worldclim.org/) were obtained at a 2.5 minute ( $\sim 4.5 \mathrm{~km}$ at the equator) spatial resolution (Fick and Hijmans, 2017). The data span the period 1970-2000 and thus may reflect anthropogenically-influenced temperature seasonality as discussed in Santer et al. (2018). Therefore, although the general 
spatial pattern of temperature (and potentially precipitation) seasonality may persist into

2320 the past, the magnitude of seasonality shifts may deviate from that presented here, particularly when extending records into the preindustrial era.

2322 Figure 11: Global seasonality in amount-weighted precipitation $\delta^{18} \mathrm{O}$ (\%० VWMOW). The amount-weighted mean (WM) monthly precipitation $\delta^{18} \mathrm{O}$ data (IAEA/WMO, 2001) were used to determine the annual range in precipitation isotopes globally (calculated as the maximum monthly WM $\delta^{18} \mathrm{O}$ minus minimum monthly $\mathrm{WM} \delta^{18} \mathrm{O}$ at 267 stations (yellow symbols) with a complete 12-month dataset over the period 1961-1999. GNIP station data were interpolated onto a $2.5^{\circ} \times 2.5^{\circ}$ global grid ( $\left.278 \mathrm{~km} \mathrm{X} 278 \mathrm{~km}\right)$ (IAEA, 2001).

Figure 12: A Hovmöller plot of the annual cycle of total-column precipitable water vapour 2329 for Central America, based on daily ERA5 re-analysis data across the region from -110 to 2330 $80 \mathrm{~W}$ and 0 to $35 \mathrm{~N}$ for the period $1979-2018$. Also indicated are the latitudes of three key cave sites that have yielded stalagmites which have produced oxygen isotope records of rainfall. 
Figures:

2335

2336

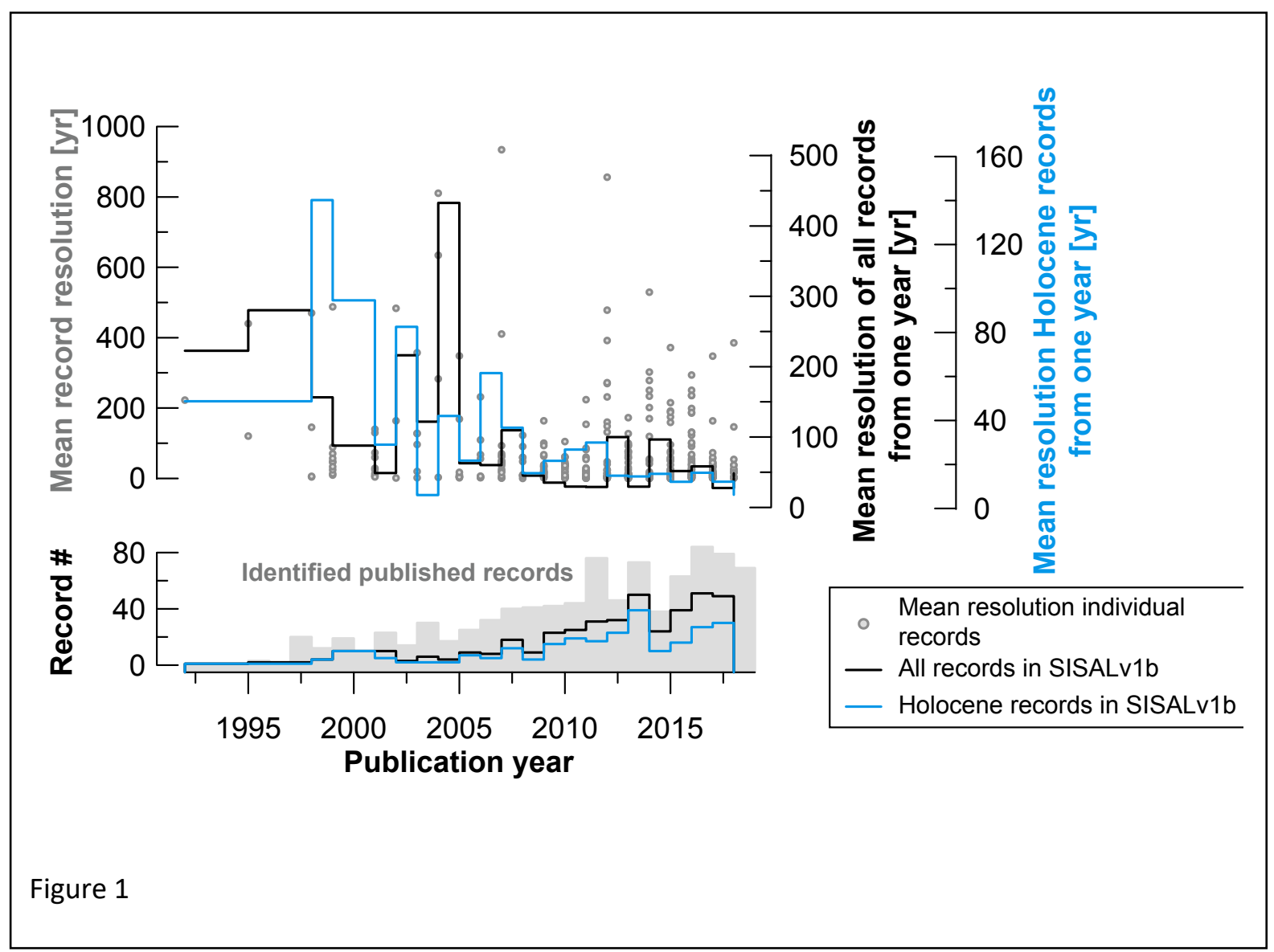




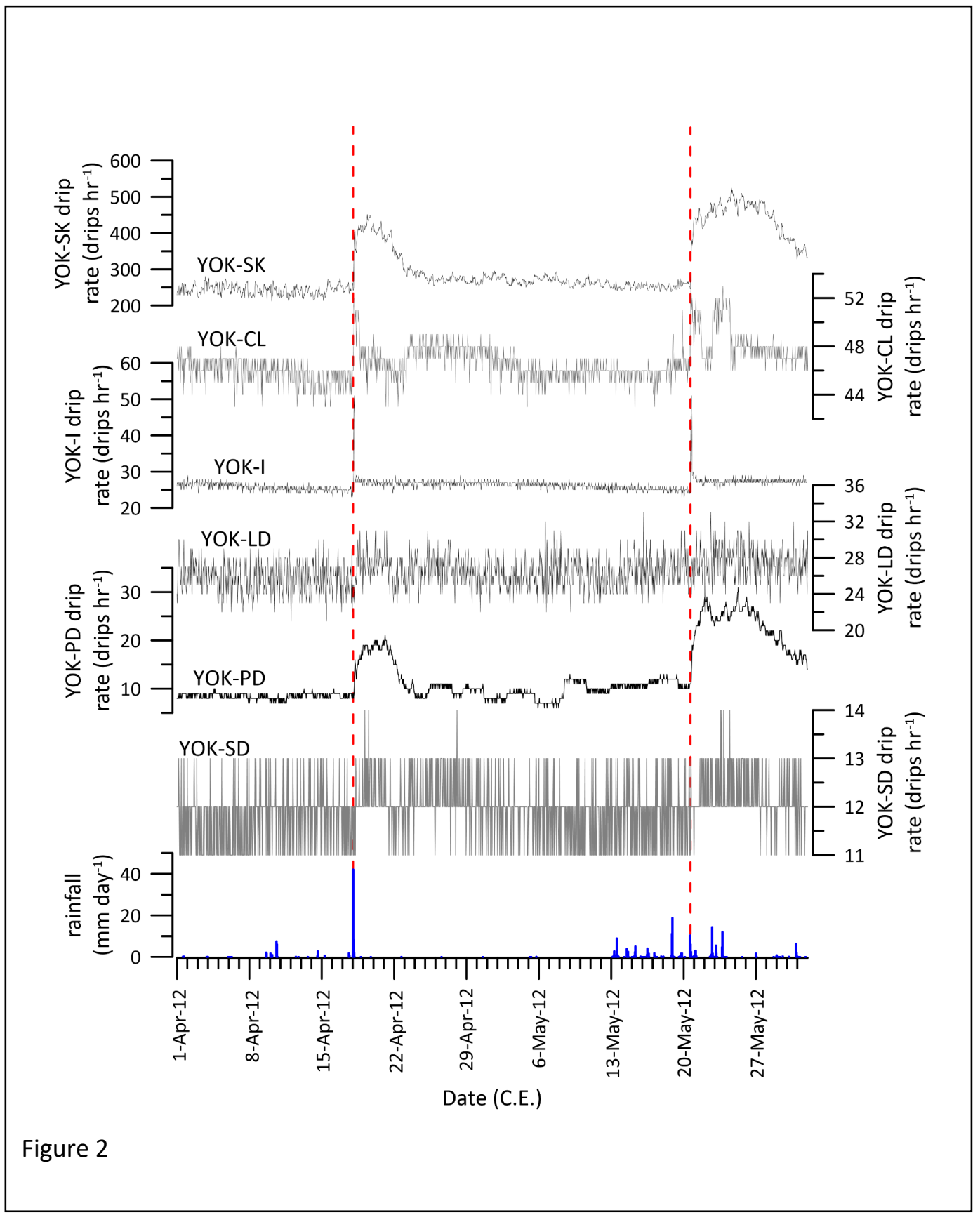




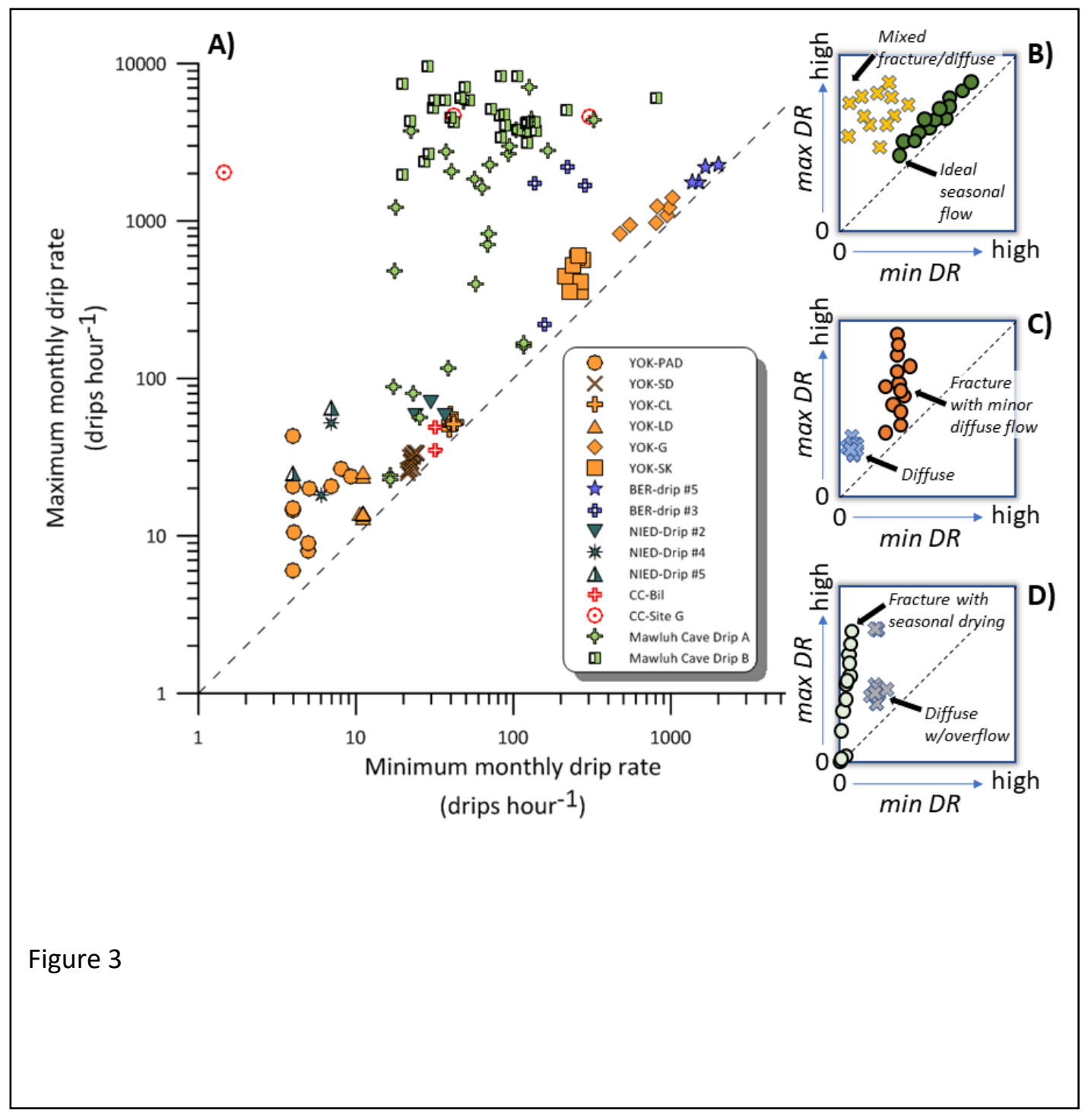

2342 


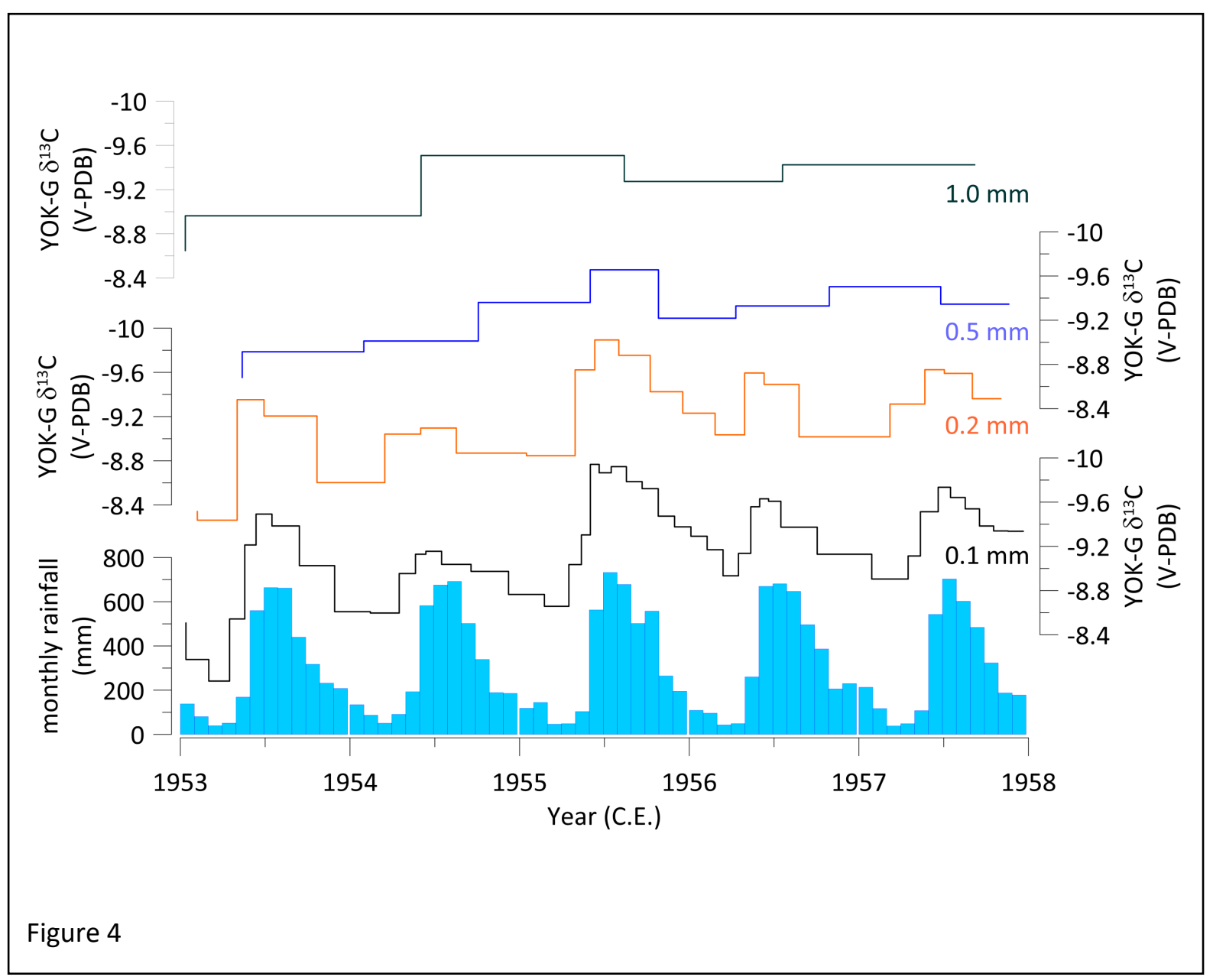

2345

2346

2347

2348

2349

2350 


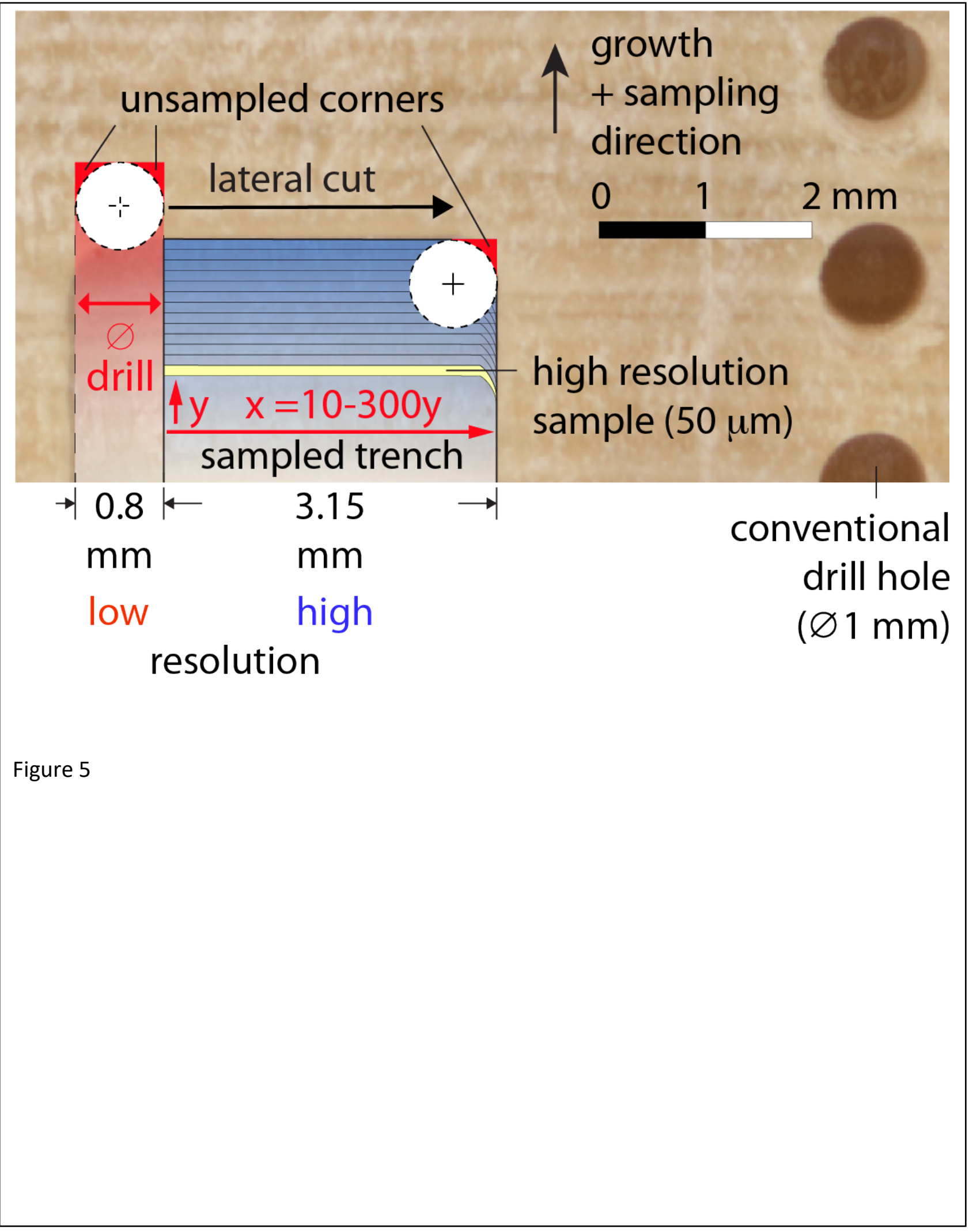




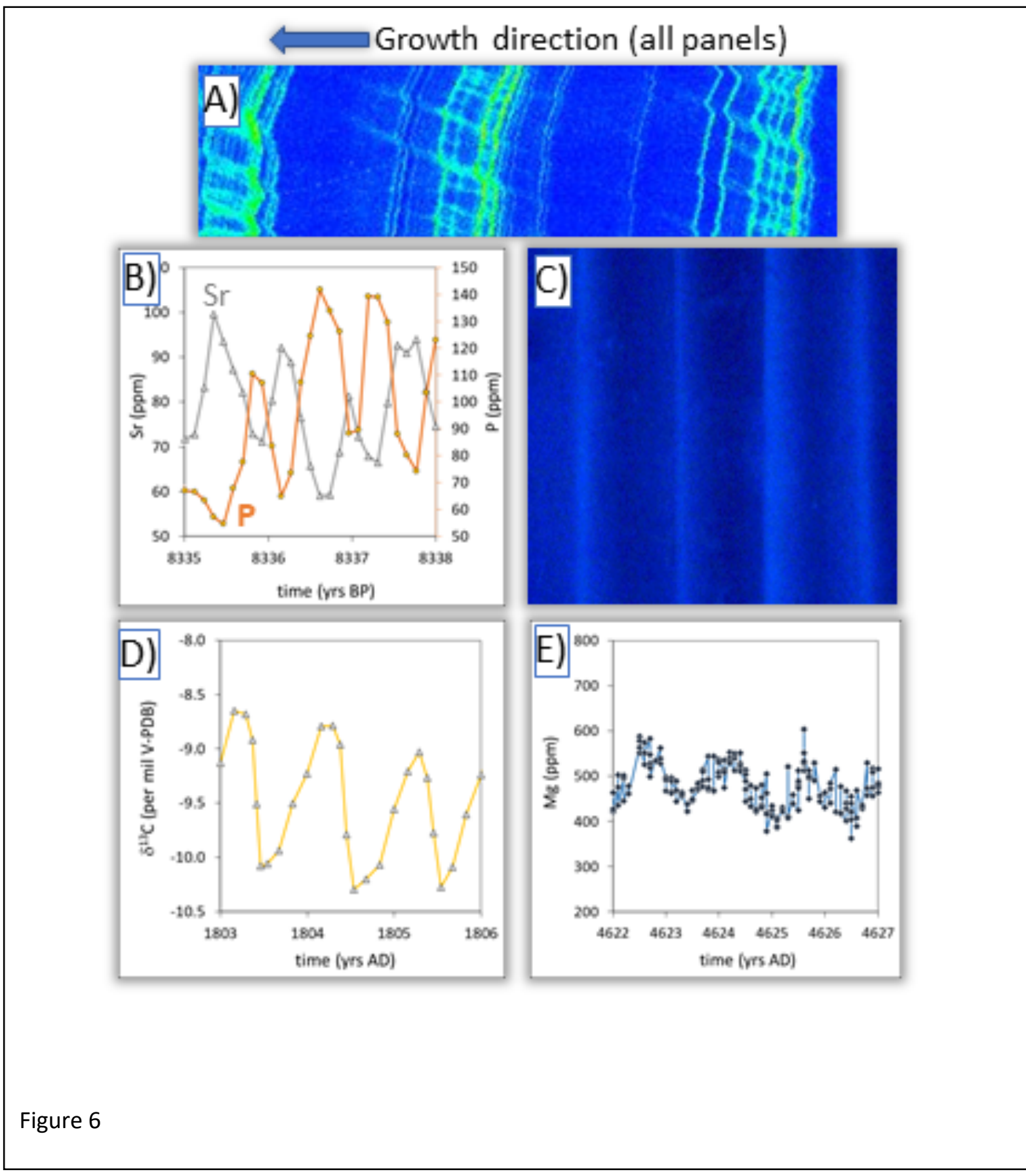




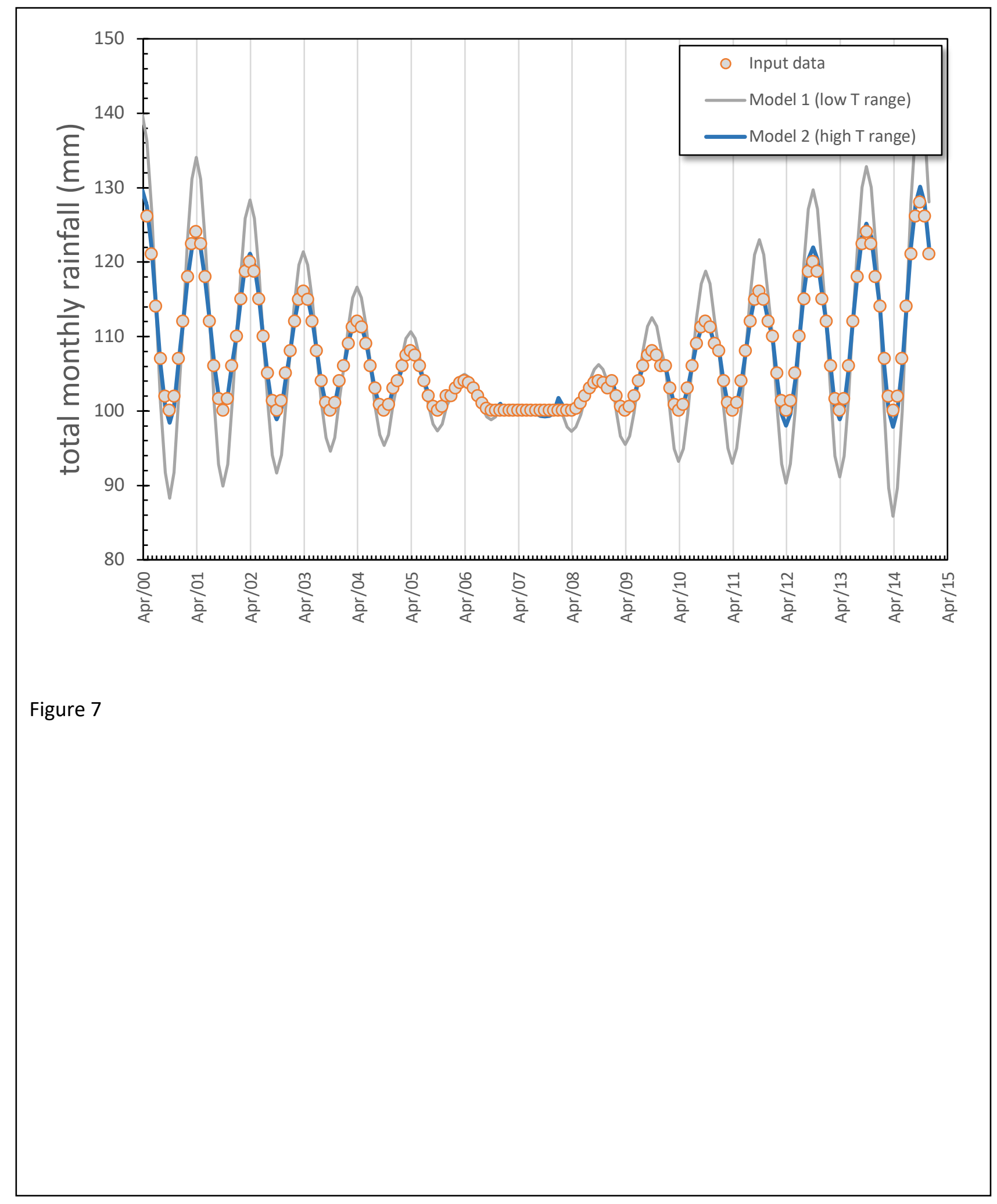




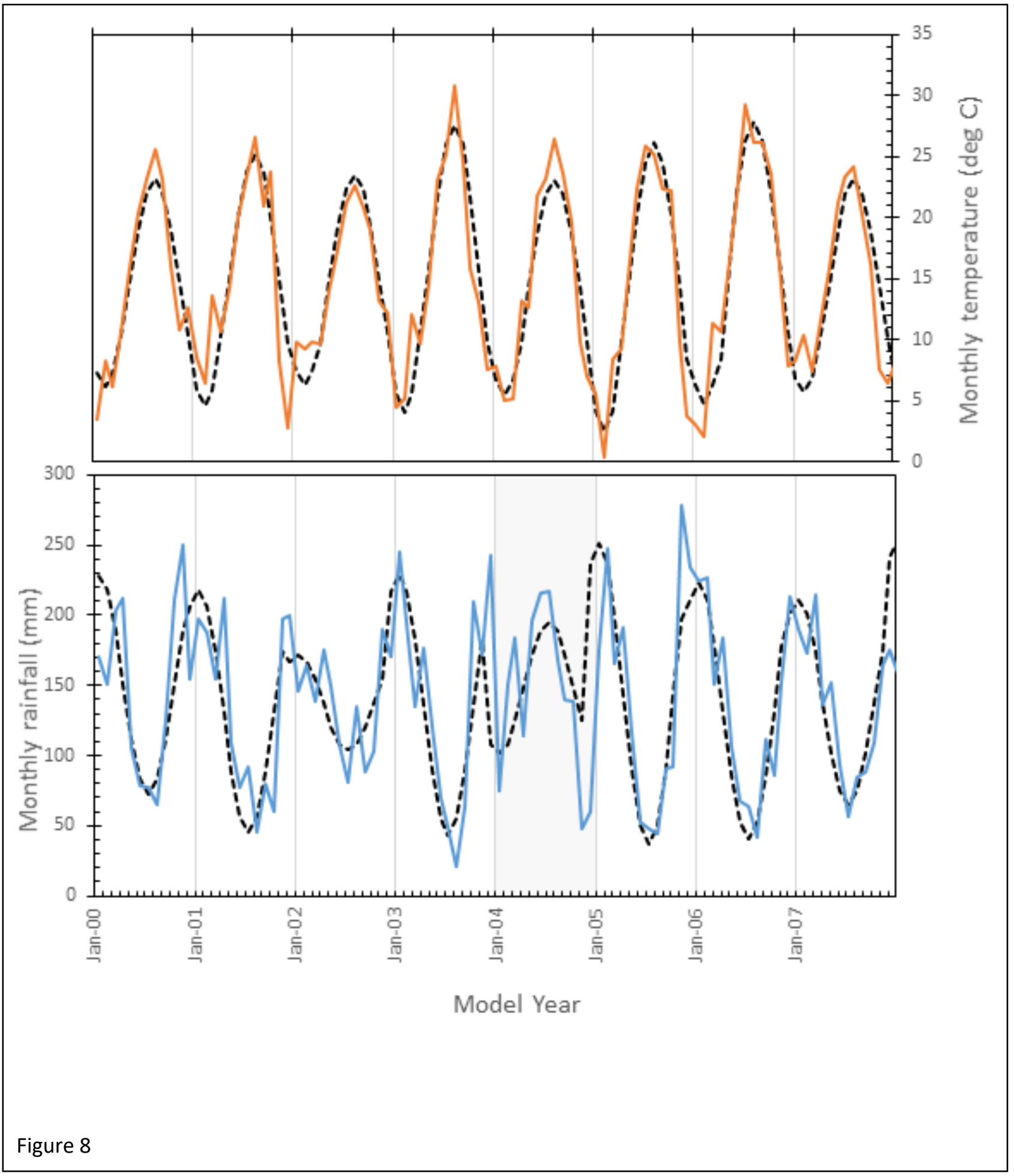

2359

2360

2361

2362 


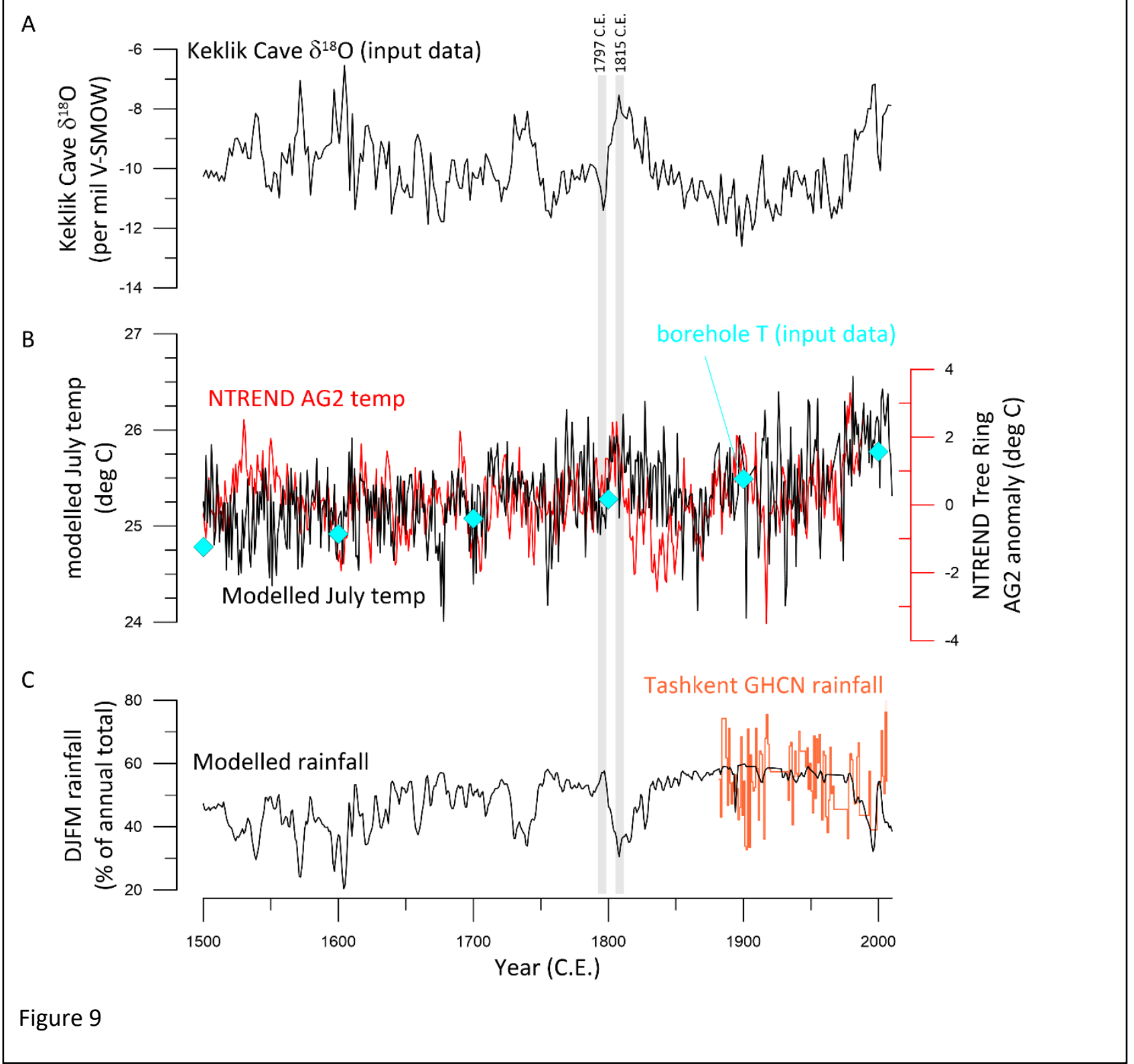




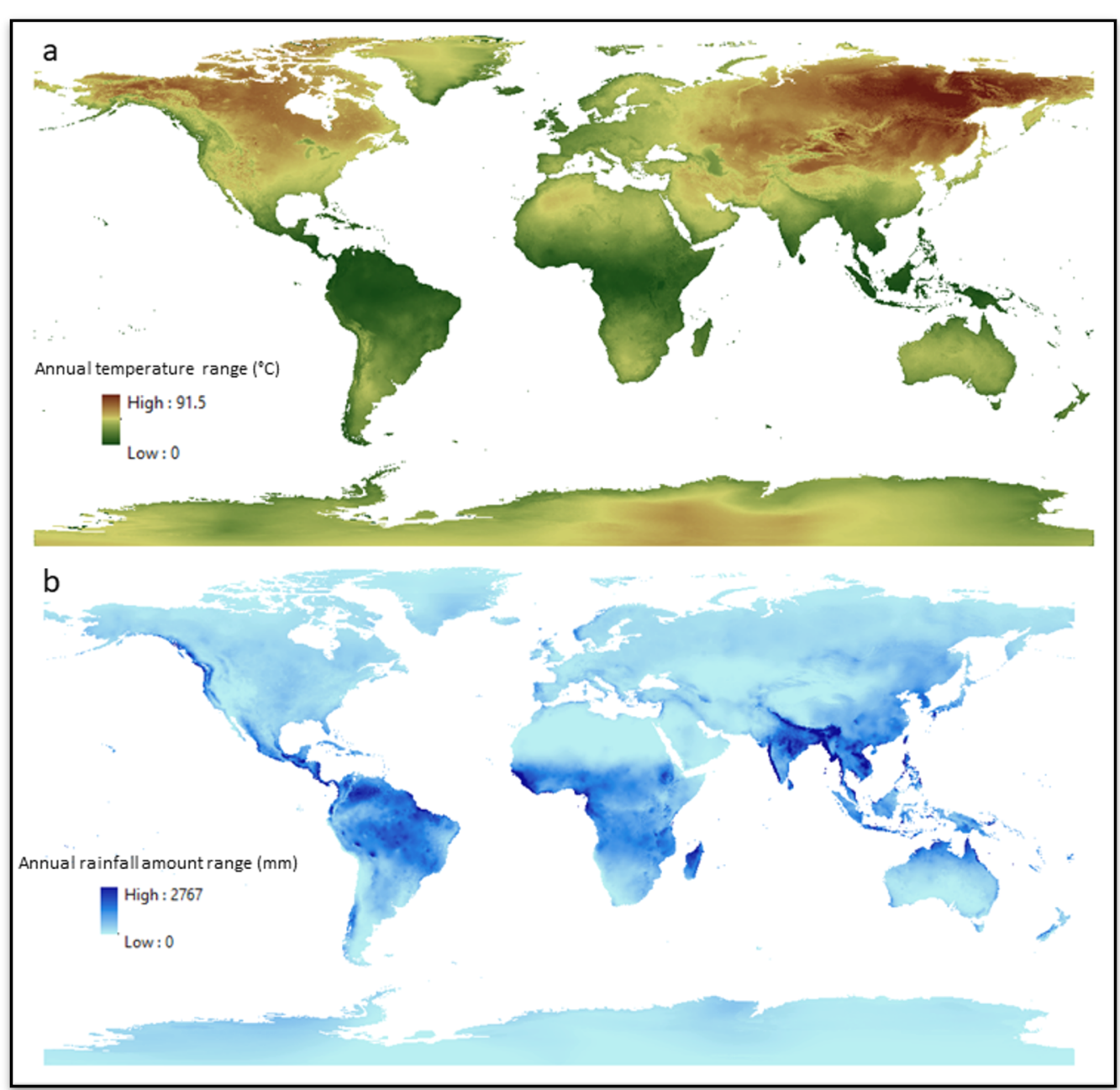

Figure 10

2366 


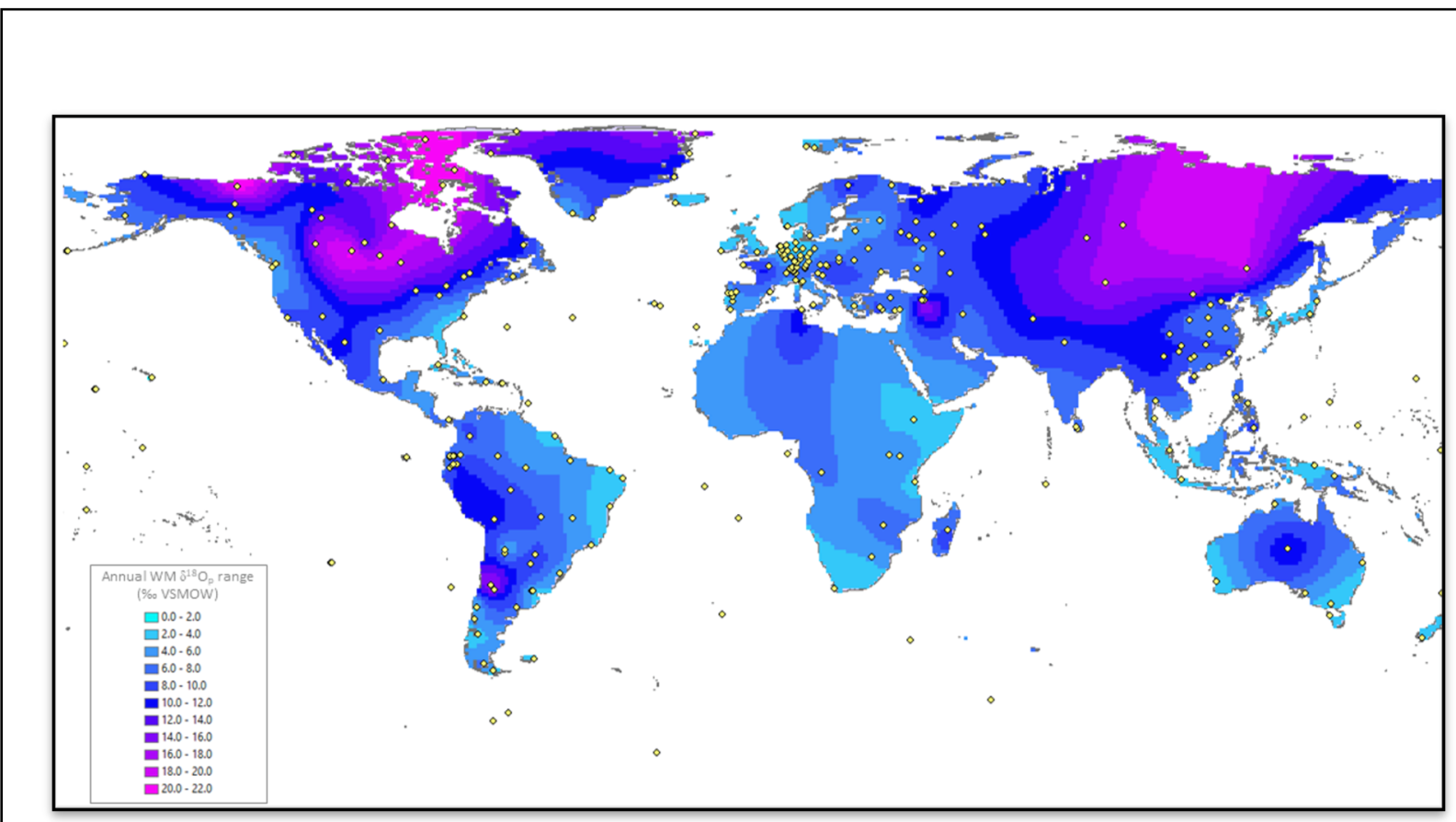

Figure 11 


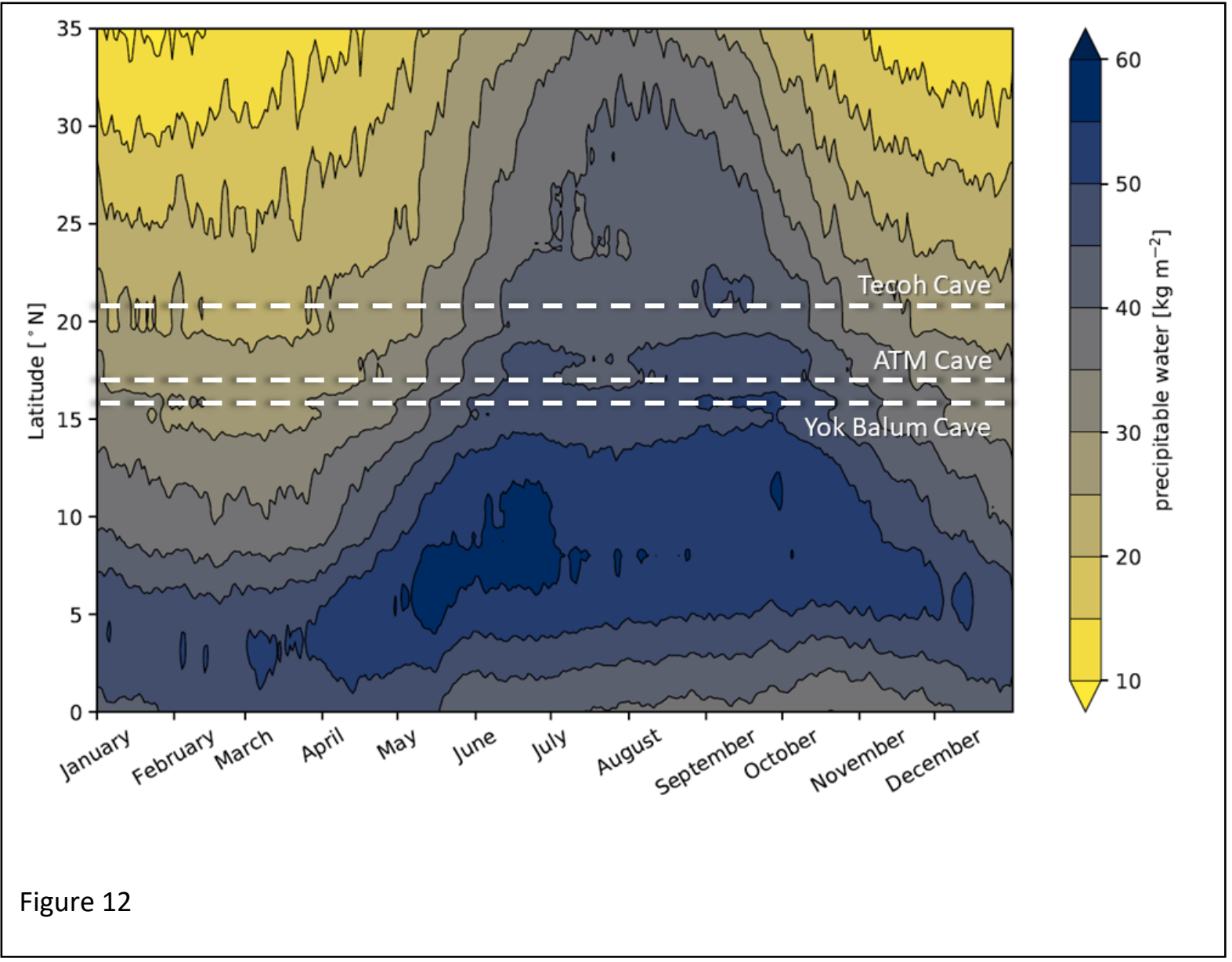

